\title{
Potentially active faults in dam foundations
}

\author{
J. L. SHERARD, ${ }^{*}$ L. S. CLUFF $\dagger$ and C. R. ALLEN $\ddagger$
}

The Paper contains information on existing dams founded on active faults, a summary of pertinent lessons learned from study of historic fault breaks and fault mechanisms, recommended practice for evaluation of active faults, and opinions concerning design of dams on active faults. While a dam site with an active fault should be avoided if possible, if a reservoir is vitally needed and a better site is not available, it is reasonable practice to construct a conservatively designed embankment dam. Concrete dams on active faults, or near some major active faults, are not advisable. For evaluation of fault activity, geological studies usually must be carried a considerable distance from the dam site, a departure from recent past practice. Experience of the last few years with many fault studies indicates that thorough geological investigations with modern techniques will usually provide sufficient evidence to allow a judgement on the activity or inactivity of a fault.
Cet Article présente des renseignements pertinents aux barrages construits sur des failles actives, un resumé historique des leçons tirées de la rupture de failles et de leurs mécanismes de rupture, des conseils pratiques pour l'évaluation de l'activité des failles, et des commentaires sur la conception de barrages situés sur des failles actives. Bien que la conception d'un barrage sur une faille active devrait être évitée, la construction d'un barrage en terre conçu d'une façon très sécuritaire est raisonable s'il est absolument nécessaire d'avoir un réservoir à cet endroit et qu'il n'y a pas d'alternative. Il est déconseillé de prévoir des barrages en béton sur des failles actives ou près d'importantes failles actives. Pour l'évaluation de l'activité d'une faille, il faut entreprendre des études géologiques généralement à une très grande distance du site, ce qui est contraire à une pratique encore récente. L'expérience de ces dernières années, avec l'étude de nombreuses failles, montre que des études géologiques détaillées, utilisant des techniques modernes, fourniront normallement suffisament d'évidences pour l'évaluation de l'activité ou de l'inactivité d'une faille.

\section{INTRODUCTION}

In earthquake regions faults are frequently found to exist in dam foundations. Evaluation of the likelihood that displacement could occur along the fault during the lifetime of the dam, and the selection of the design details to ensure safety against such possible fault displacement, are difficult problems for which there is little guidance in the literature.

In 1963, one of the Authors (with co-authors) summarized ideas about the influence of active faults in dam foundations (Sherard et al., 1963). This Paper presents a more intensive examination of the subject. Emphasis is on the engineer's problem in evaluating what kind of study should be made of the fault and how the results of the study should influence the dam design. While written primarily for the engineer, the Paper contains points of interest for the geologist regarding techniques employed in evaluation of potential fault activity not widely used in other geological studies.

Any dam site located near a potentially active fault may be subjected to strong earthquake shaking. The problems of designing the dam to withstand the accelerations imposed by strong earthquake shaking and of making the dam safe against fault movement in the foundation are related; however, this Paper is directed wholly to the potentially active foundation fault which might displace abruptly during an earthquake, rupturing the dam.

The terms 'fault break', 'fault movement', 'fault displacement', 'fault slippage' and 'faulting' are used synonymously to mean the shearing movement of ground on one side of the fault against the other. Usually this faulting occurs during a strong earthquake and, in fact, it is the energy release associated with the faulting which causes the earthquake. The

\footnotetext{
* Consulting Engineer, Berkeley, California.

† Vice President and Chief Engineering Geologist, Woodward Lungren and Associates, Oakland, California.

‡ Professor of Geology and Geophysics, Seismological Laboratory, California Institute of Technology, Pasadena, California.
} 

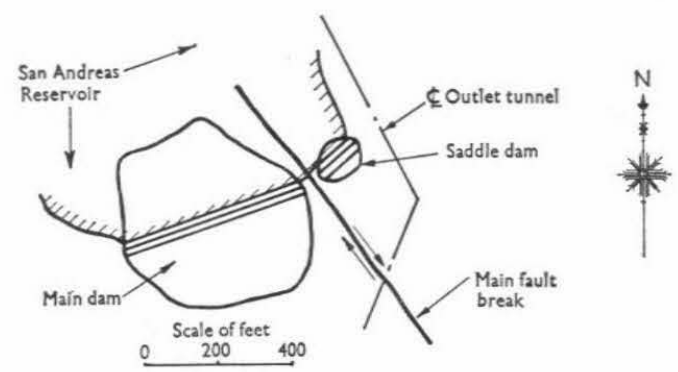

Fig. 1. San Andreas Dam-location of main fault break (after Lawson, 1908)

size of the earthquake at its source is described by the Richter magnitude $M$ in this Paper. For background information on this and other aspects of seismology and seismic geology the reader is referred to the classic work by Richter (1958).

In some areas of frequent strong earthquakes, faults in dam foundations are the rule rather than the exception for the two main reasons that very many faults exist, and that river channels often follow faults because the rocks in the fault zone are more crushed and broken and consequently more easily eroded. Of the hundreds of dams built in regions of high earthquake potential, there are few in locations where faults were not recognized or suspected to exist.

For the purposes of this study, an active fault (or a potentially active fault) is defined as one on which there is sufficient evidence of displacement within the recent geological past to make it reasonable to anticipate that future surface displacements could occur within the lifetime of a dam (about 100 years). It must be emphasized, however, that this definition implies the exercise of judgement by geologists, and that there will be honest differences of opinion among competent geologists specializing in this field as to the likelihood of displacements on a given fault.

According to the definition adopted by the US Atomic Energy Commission (1973) for nuclear power plant site studies, an active fault (now termed by the AEC a 'capable' fault) has one or more of the following characteristics:

(a) displacement at or near the ground surface at least once in 35000 years or movement of a recurring nature within the past 500000 years;

(b) instrumentally measured macro-seismicity determined with sufficient precision to demonstrate a direct relationship with the fault;

(c) a structural relationship with an active fault having the characteristics of $(a)$ or $(b)$ such that displacement on the one could be reasonably expected to be accompanied by displacement on the other.

This is a reasonable and conservative definition when applied also to dams; however, unfortunately the chronological histories of recent displacements on most faults cannot be as yet established with certainty, so that it finally becomes a matter of the geologist's judgement in interpreting the evidence as to how recently and how often the fault has moved in the past.

Dam design is largely an empirical activity. While increasingly useful methods of analytical treatment are available to guide design decisions, it is clear that one builds dams with confifidence primarily because many other dams of similar design details have been built and performed satisfactorily. With regard to movements of faults in dam foundations, there is essentially no experience record to guide us, so that related performance and judgement must be relied on. Because of this and of the many uncertainties and the judgement required in fault activity evaluation, it is clear that the main decisions concerned with designing safe dams at 
sites with potentially active faults must be based largely on judgement, guided by the accumulated experience and knowledge in the fields of geology, seismology, and the several engineering specialities that comprise dam engineering. In this Paper the Authors, who have collaborated for a number of years on several projects, attempt to summarize the main points involved and present opinions on some of the debatable aspects of the problem. No large changes are proposed in what might be considered current conservative practice for building dams in earthquake regions at sites with foundation faults. Information and opinions are given on lessons learned from study of historical active faulting, on methods of studying fault potential activity, and on interpreting the results of such studies.

\section{EXPERIENCE WITH FAULT BREAKS NEAR DAMS}

To the Authors' knowledge there have been essentially no failures or damage to dams caused by displacements of faults during earthquakes. There are of the order of 25000 dam structures of moderate size in existence in the world, and there are records of more than 500 which have failed or been seriously damaged in other ways. Hence, while fault displacements during earthquakes are spectactular events which could seriously damage a dam, they have been so rare that the coincidence of a large offset passing through a dam foundation has not yet taken place.

In addition to the fact that there have been no instances where faults have displaced in dam foundations during strong earthquakes, there have been only a few 'near misses'. The Authors know of only two examples.

\section{San Francisco earthquake}

The San Andreas Dam is a $27 \mathrm{~m}$ high earth dam, built more than 100 years ago a few miles south of San Francisco, California. It comprises a main embankment and a smaller saddle dam on the east abutment separated by a narrow ridge. During the 1906 San Francisco earthquake $(M=8 \cdot 3)$, the main break on the San Andreas Fault passed through the small ridge forming the common abutment between the two embankments (Fig. 1). The main embankment dam was moved bodily, approximately $2.5 \mathrm{~m}$ north relative to its east abutment and the saddle dam. A tunnel in the east abutment was twisted about $3 \mathrm{~m}$ out of line, but there was no damage to the dam. The 20 million $\mathrm{m}^{3}$ reservoir was full and no leakage or other alarming symptoms developed (Lawson, 1908).

From a statistical point of view this experience is a special case because the dam was constructed directly across the main fault valley of the major San Andreas Fault (Fig. 2). It was done more than 100 years ago at a time when very little was known about earthquakes and faulting. At the present state of knowledge such major faults as the San Andreas can be easily recognized as active faults, and the fault valley would not generally have been considered a suitable dam site.

The Crystal Springs Reservoir of the San Francisco water supply system is also located in the main San Andreas Fault Valley, a few miles south of the San Andreas Dam. This reservoir was crossed by a road embankment (Fig. 3) which had formerly been a dam (Upper Crystal Springs Dam). At the time of the 1906 earthquake this embankment was not being used as a dam but as a roadway. During the earthquake the main fault break passed through the central portion of the embankment approximately normal to the longitudinal axis. The embankment was offset approximately $2.5 \mathrm{~m}$ with the west side moving north with respect to the east side. Both longitudinal and transverse cracks were observed on the crest extending to a depth of at least one meter (Sewell, 1907). Since there was water on both sides there was 
no tendency for a leak to develop through the fissured zone and it is not known how the embankment might have behaved had it been performing as a dam. The Lower Crystal Springs Dam, a concrete gravity dam of $43 \mathrm{~m}$ height, constructed in 1888, was not damaged by the earthquake or fault displacement, although located about $200 \mathrm{~m}$ from the fault break.

Figure 4 shows an offset (about $2 \mathrm{~m}$ ) of yet another small dam (Old San Andreas Dam). This abandoned dam was submerged under the north arm of the Crystal Springs Reservoir at the time of the 1906 earthquake and was only exposed in 1931 when the reservoir was lowered (Louderback, 1937).

\section{West Yellowstone earthquake}

The second example of a 'near miss' was at the Hebgen Dam, Montana, during the West Yellowstone earthquake of 17 August $1959(M=7 \cdot 1)$. The $27 \mathrm{~m}$ high, $210 \mathrm{~m}$ long earth dam, constructed in 1914, retained a 370 million $\mathrm{m}^{3}$ reservoir with a length of about $25 \mathrm{~km}$. The reservoir was full at the time of the earthquake. Movements occurred on a number of major faults with primarily vertical displacement (Fig. 5). The aggregate length of all the main fault breaks was more than $75 \mathrm{~km}$. The main Hebgen Fault break traversing the north wall of the reservoir, about $200 \mathrm{~m}$ from the right end of the dam had a vertical displacement of about $5 \mathrm{~m}$ at this point, with the north side of the fault going up relative to the south side (Figs 6-8).

Associated with the faulting there was a general subsidence of the bedrock underlying the reservoir, with maximum of about $22 \mathrm{ft}(6 \cdot 7 \mathrm{~m})$, (Fig. 5). The bedrock under the dam (and the whole dam, spillway and outlet conduit) went down approximately $3.0 \mathrm{~m}$ in a remarkably uniform fashion. The 'average' subsidence of the large reservoir was about $3 \cdot 2 \mathrm{~m}$, so that the dam and water surface remained at the same relative elevation.

The earthquake shaking caused moderate slumping and some cracking in the dam but no threat of serious trouble developed (Sherard, 1959; Sherard et al., 1963), and the fault breaks did not influence the dam. The dam was repaired at relatively little cost and has continued in operation.

\section{All American Canal}

Figure 9 shows the resulting fault breaks through a large canal in 1940, illustrating particularly that for breaks on strike-slip faults (with primarily horizontal movement) the zone of fracturing is limited to a relatively narrow zone.

\section{BALDWIN HILLS RESERVOIR FAILURE}

Failure of Baldwin Hills Reservoir, California, in 1963 was caused by progressive erosion of an initial leak along a fault (Jansen et al., 1967). No earthquake was involved. The fault moved a few inches sometime between construction of the dam and failure, breaking the compacted clay reservoir lining. The reservoir bottom and natural abutments consisted of a horizontally stratified deposit of cohesionless fine sand, silt, and clay of Lower Pleistocene and Upper Pliocene age. The fault was recognized during construction, passing through the formations.

The leakage water entered the crack along the fault and emerged as a concentrated leak on the downstream sloping surface of the natural abutment. The clay layers were sufficiently cohesive to form arches over erosion tunnels and the erodible fine sand and silt was washed out. The cause of the movement at the fault is strongly debated because of nearby relatively large ground surface subsidence related to oil withdrawal (Leps, 1972; Casagrande et al., 1972; Castle and Youd, 1972). The experience emphasizes the hazard of uncontrolled concen- 


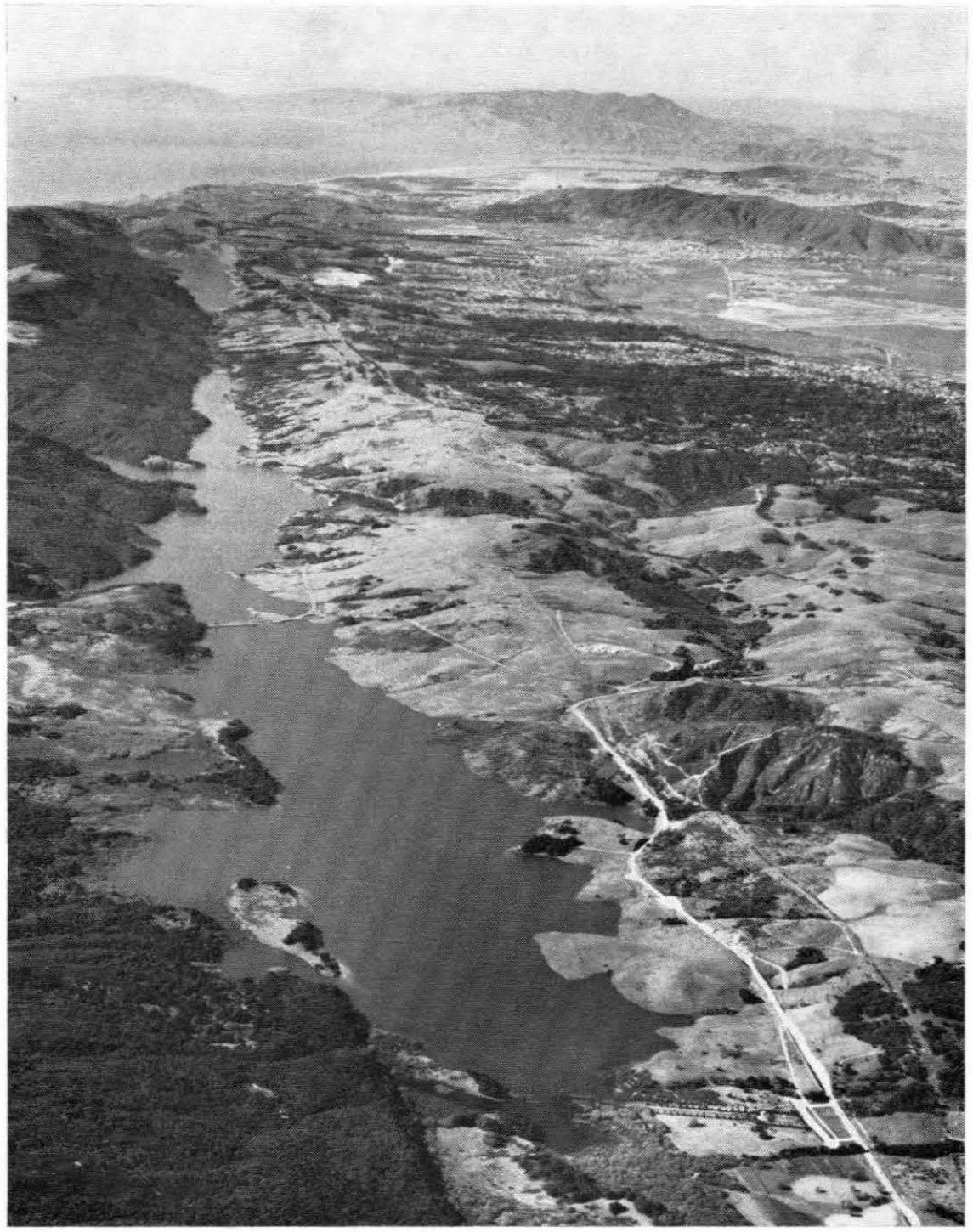

Photo: Sunderland Aerial Photographs

Fig. 2. Looking north along the main rift valley of the San Andreas Fault. The city of San Francisco is in upper right. Two reservoirs are shown in the fault valley; the San Andreas Reservoir in the distance and the Crystal Springs Reservoir in the foreground. The 1906 fault break went up the valley through the centre of both reservoirs. The embankment of the old Upper Crystal Springs Dam (now serving as a highway) offset in 1906 is shown running across the Crystal Springs Reservoir in the centre. The valley is typical of fault valleys of 'master', strike-slip faults seen in many parts of the world (see also Figs 10, 19, 22, and 25) 


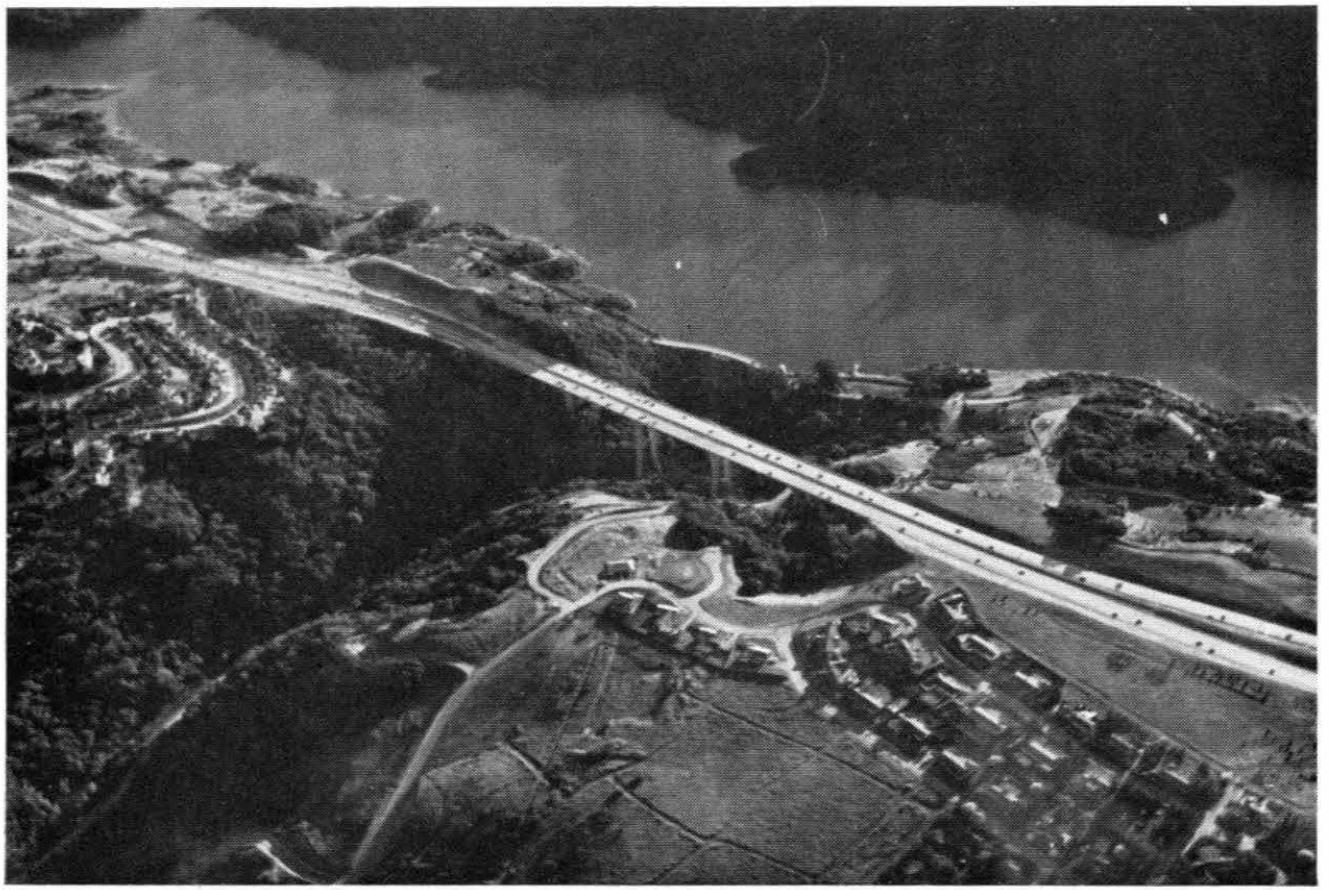

Photo: L. S. Cluff

Fig. 3. Looking west at the Lower Crystal Springs Dam. The $43 \mathrm{~m}$ high concrete gravity dam retains a 65 million $\mathrm{m}^{3}$ water supply reservoir in the north-south rift valley of the San Andreas Fault. The dam closes a gorge in the east wall of the valley and is off the fault. The $\mathbf{1 9 0 6}$ break on the fault passed near the centre of the reservoir, running parallel with the longitudinal axis of the dam about $200 \mathrm{~m}$ upstream

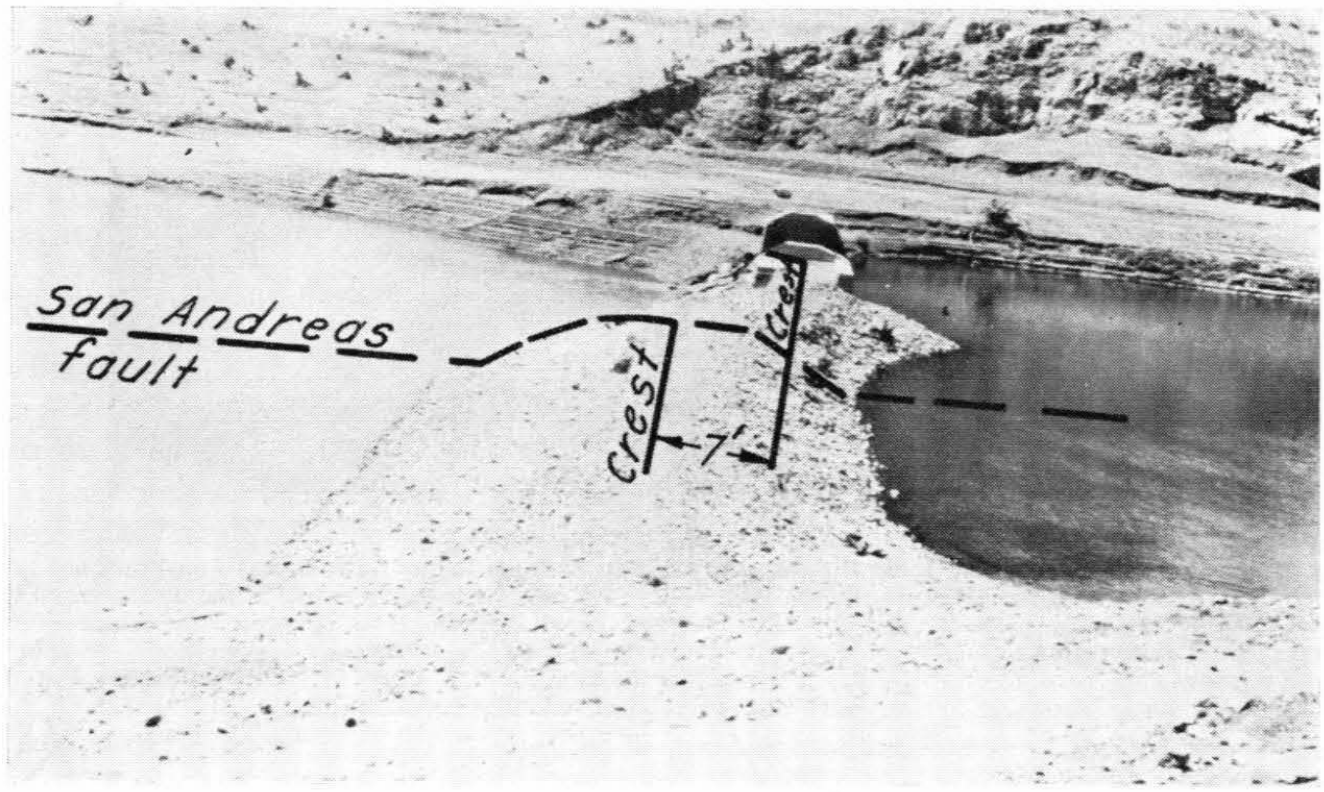

Fig. 4. Old San Andreas Dam showing offset of embankment caused by 1906 break on the San Andreas Fault. At the time of the earthquake the dam was abandoned and submerged in the north arm of the Crystal Springs Reservoir. The photograph was taken in 1931 at a time of low reservoir level (after Louderback, 1937) 


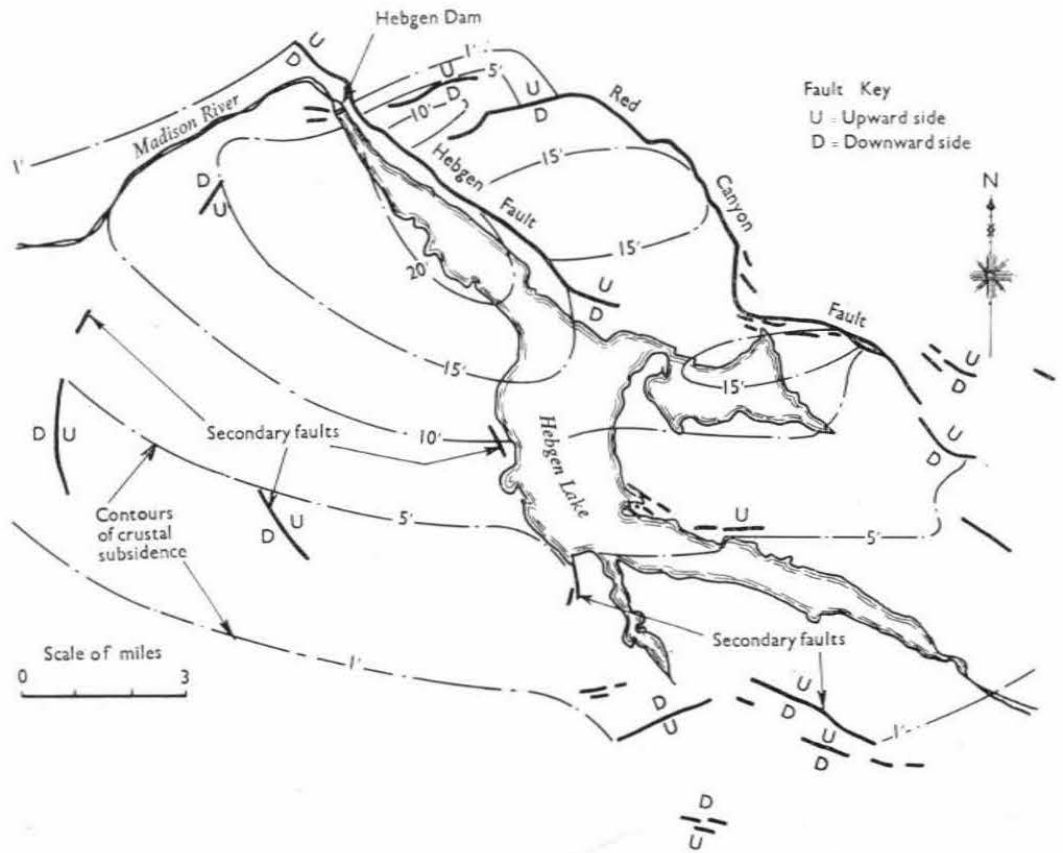

Fig. 5. Fault breaks and crustal deformation near Hebgen Lake, Montana during the August 18, 1959 earthquake (after Witkind et al., 1962)

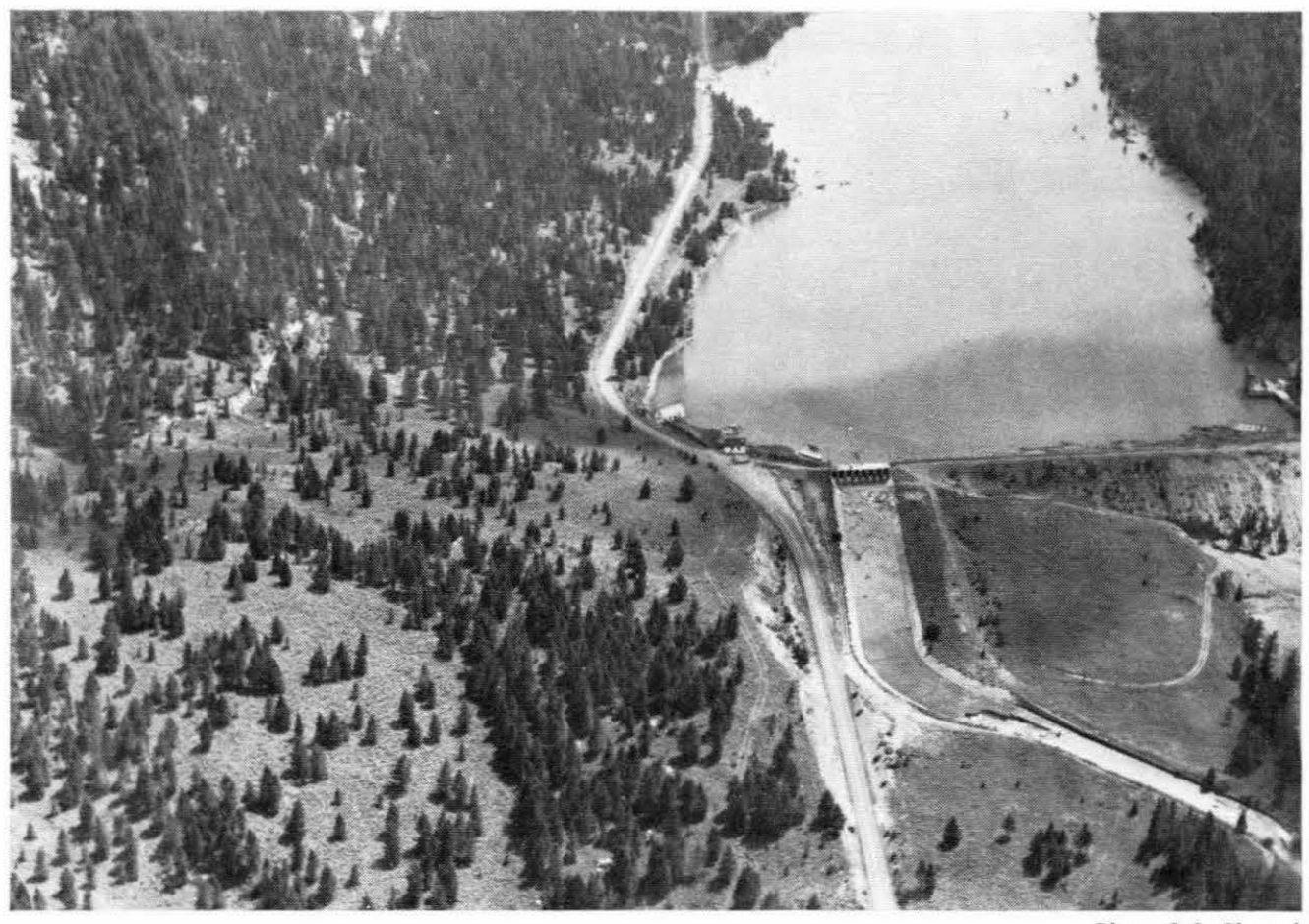

Photo: J. L. Sherard

Fig. 6. Looking upstream with Hebgen Dam in foreground, three days after the earthquake. The main Hebgen Fault break is clearly visible in the trees running along the valley wall parallel to the lakeshore on the left side of the photograph 


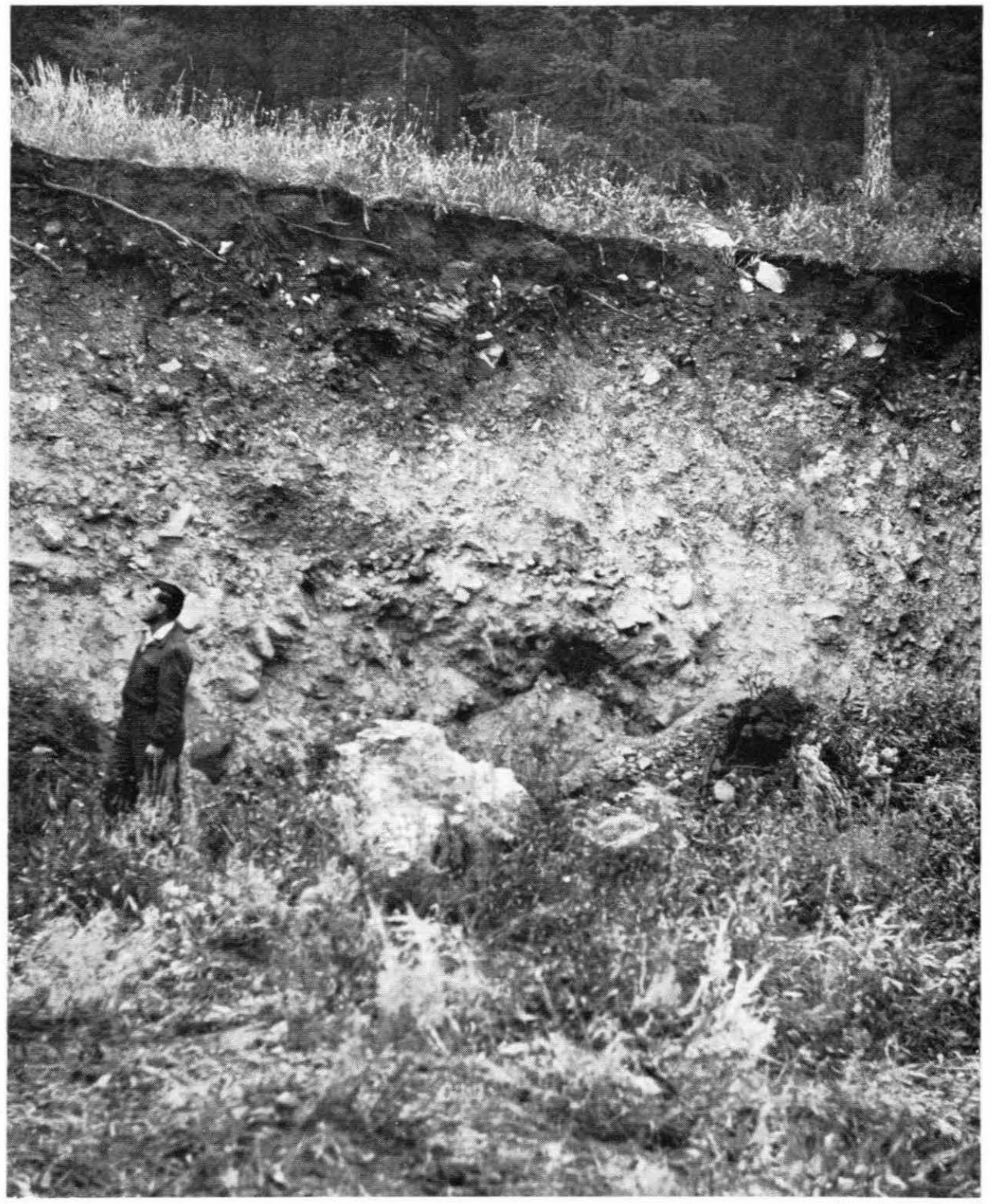

Photo: J. L. Sherard

Fig. 7. Break on Hebgen Fault directly opposite dam; approximately $5 \mathrm{~m}$ vertical displacement 


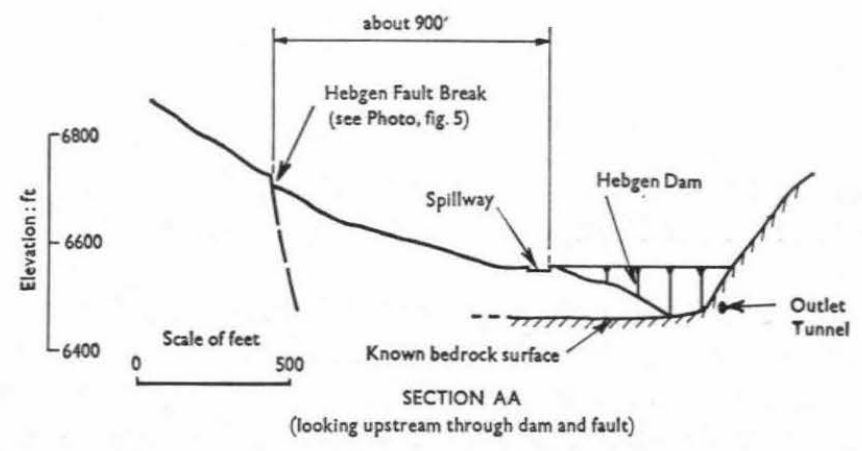

Fig. 8. Hebden Dam-longitudinal section through dam and fault looking upstream

trated leaks through foundations in abutments consisting of alternate layers of erodible, finegrained, cohesionless soils with interbedded clay layers. The combination allows the cohesive soil to form roofs over erosion tunnels in the sand layers, so that very large leakage channels can develop. If the foundations had consisted wholly of the cohesionless fine sand, it is probable that no leakage channels could have developed, since the sand would have caved in and closed any temporary openings caused by the fault movement.

Eroded caverns ('bear caves') observed by investigators of the failure in some of the thick clay layers are difficult to explain (California Department of Water Resources, 1964). Recently it has been shown that these clays belong to the family of 'highly dispersive' (erodible) clays, whose existence has been recognized only in the last few years (Sherard et al., 1972). This dispersive clay undoubtedly had some role in the failure, and conceivably the dominant one.

\section{CURRENT AND PAST DESIGN PRACTICE}

While there are notable exceptions, in common practice faults in dam foundations in earthquake regions have not been extensively studied. Usually they have been investigated by exploratory borings, pits, etc., and by detailed geological studies only in the immediate vicinity of the dam. Also, a cursory examination is commonly made of the general geology of the region (within a radius of $10-30 \mathrm{~km}$ ), mainly by review of existing geological literature. These investigations frequently provide little or no evidence concerning the possible activity or lack of activity of faults.

For these commonly encountered faults, for which little or no evidence of activity is available, it has been considered reasonable practice to proceed with the dam construction. Underlying this practice are the tacit assumptions that it is highly improbable that the fault will break during the lifetime of the dam, and that if it should break, the amount of movement would probably not be great enough to damage the dam seriously.

In current practice where active faults are diagnosed in foundations, other sites have usually been chosen. There have been very few cases where dams have been built on sites at which active faults were believed or suspected to exist in the foundation. The Authors know of only a few cases.

\section{Coyote Dam}

The $38 \mathrm{~m}$ high Coyote Dam, retaining a 30 million $\mathrm{m}^{3}$ reservoir, was constructed in 1936 near San Jose, California, at a site where the foundation is underlain by the main branch of 
the Calaveras Fault (Fig. 10). The nearby Hayward Fault broke last in 1868 causing an earthquake with a probable magnitude of $6 \cdot 5$ to $7 \cdot 0$.

As a part of the design studies geologists predicted that the fault would move again within the lifetime of the Coyote Dam and recommended that it be assumed the fault might move about $6 \mathrm{~m}$ horizontally, $1 \mathrm{~m}$ vertically, and that the distance between opposing sides of the fault might increase as much as $300 \mathrm{~mm}$, forming an open fissure in the foundation (Louderback, 1950).

A consulting board of eminent authorities agreed that an earth dam could be safely constructed at the site, with general design details as follows: a thick, compacted earth core should be used, as opposed to a reinforced concrete, upstream-facing, concrete-core wall, or narrow clay puddle; the earth core should have a thickness equal to at least five times the water head; extra freeboard should be provided; a layer of sand and gravel should be placed against the rolled earth impervious core, so that if an opening should occur, the sand and gravel would limit the amount of water which could enter.

The dam was constructed according to these recommendations. As shown in Fig. 11, it has a crest width of $100 \mathrm{ft}(30.5 \mathrm{~m})$, freeboard of $22 \mathrm{ft}(6.7 \mathrm{~m})$ above normal water level and zones of sand-gravel and rockfill both upstream and downstream.

This design is described here primarily for historic interest; however, it is basically consistent with the writers' opinions for such a dam as described later, except that the writers would place greater emphasis on the cohesionless transitions and less emphasis on the need for such a wide core.

No fault displacement has occurred since the dam was constructed and the dam continues in service without problems.

\section{Cedar Springs Dam}

Cedar Springs Dam was completed in 1971 for an important reservoir in southern California as part of the main California Aqueduct System (USCOLD, 1970). The site is in a region of expected strong earthquakes, with the main San Andreas Fault about eight kilometres away. During the foundation explorations in 1964, several faults were discovered trending across the river valley and running parallel with the longitudinal axis of the proposed main dam, but crossing the dam from upstream to downstream on the left end (Fig. 12).

Test trenches excavated through several metres of recent alluvium down to the top of bedrock, showed that the alluvium had obviously been displaced vertically $3-5 \mathrm{ft}(0 \cdot 9-1.5 \mathrm{~m})$ indicating that the fault had moved since the deposition of the alluvium (Fig. 13). It was not possible to judge if, or how much, horizontal movement was associated with the vertical movement.

The upstream fault (fault 1) was at the boundary between two geological formations. Upstream of fault 1, the bedrock was a slightly cemented sandstone (Harold Formation) that could be excavated with earthmoving equipment. Downstream of fault 1 the foundation was hard granite.

The observations in the test pits left no doubt that the faults were active. Much consideration was given to the prudence of building a dam at the site. Finally, with the concurrence of two independent boards of consultants (one for earthquake analysis and one for earth dam design) it was decided that it was reasonable to build a conservative dam at the site. The design was the responsibility of an experienced group of dam engineers of the California Department of Water Resources, working in a region and at a time when it was considered imperative that no real risk to safety could be taken. Following discovery of the faults, a 


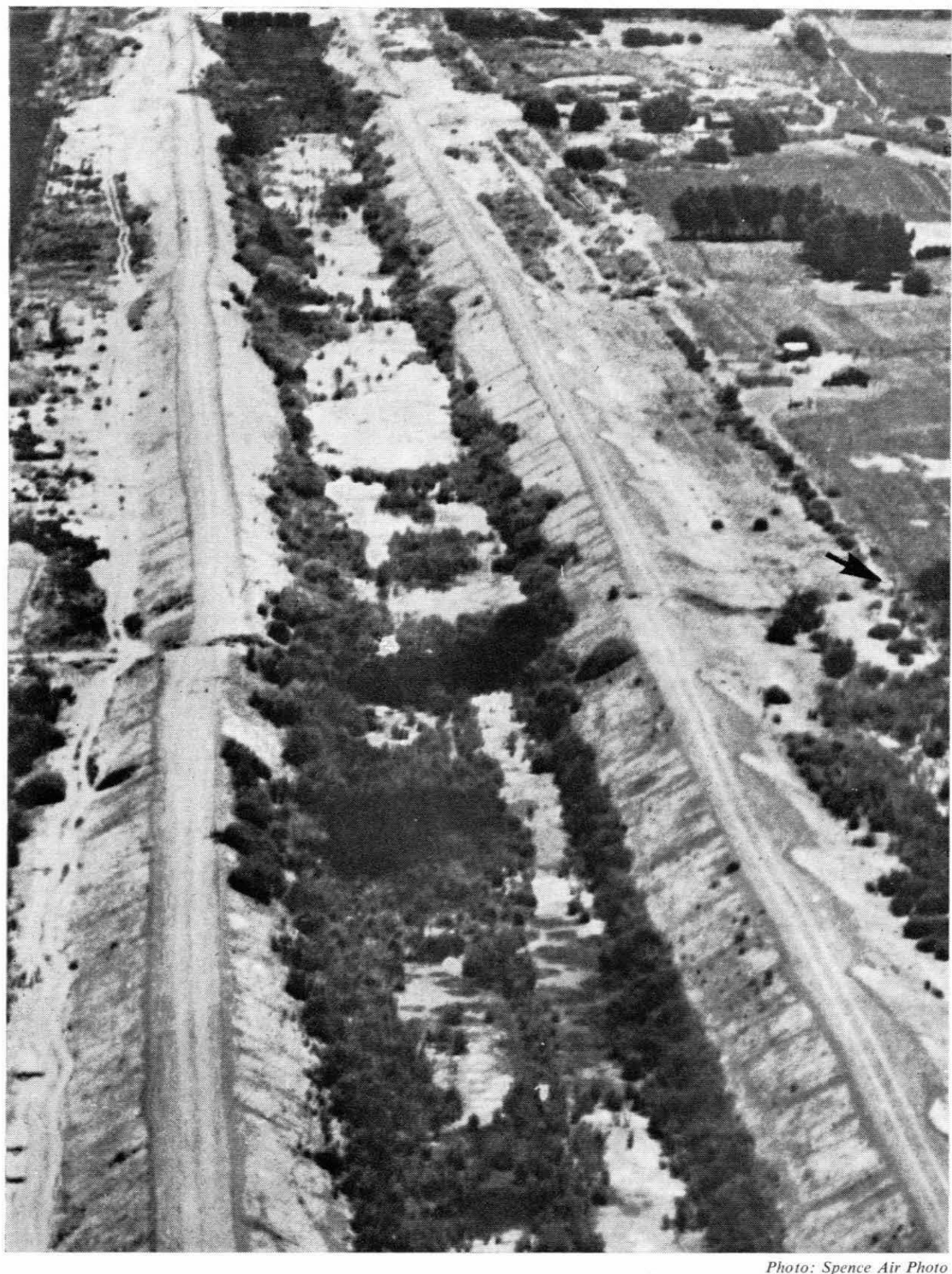

Fig. 9. Break on the Imperial Fault displaced the All-American Canal during the 1940 El Centro earthquake $(M=6 \cdot 7)$. The fault offset was nearly completely horizontal (strike-slip), approximately $4 \cdot 3 \mathrm{~m}$. The canal was nearing completion of construction but not carrying water at the time of the earthquake. Note that the fractured zone between offset canal embankments is relatively narrow 


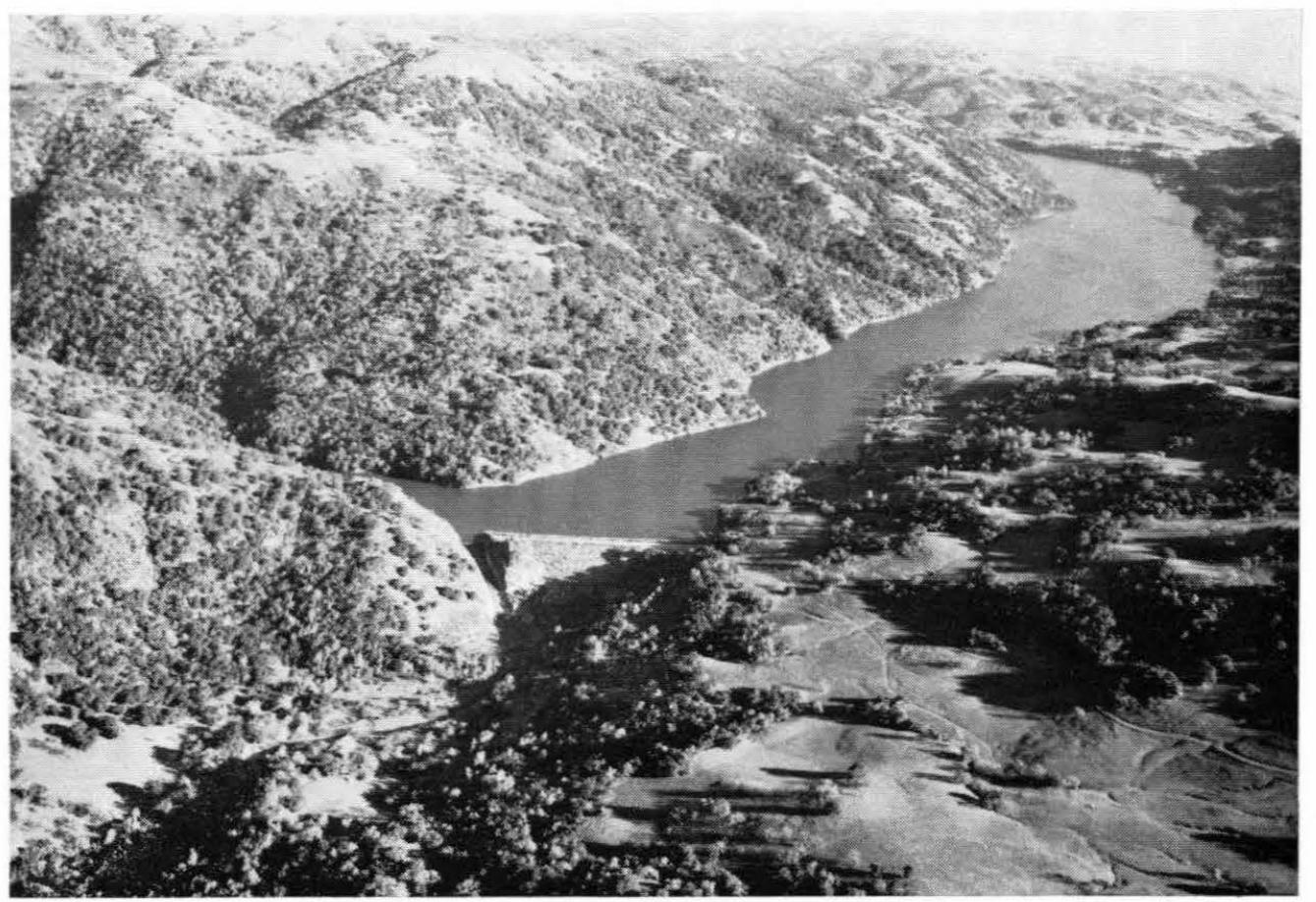

Photo: L. S. Cluff

Fig. 10. $38 \mathrm{~m}$ high Coyote Dam built across the rift valley of the Calaveras Fault, California. Note typical narrow valley of strike-slip fault

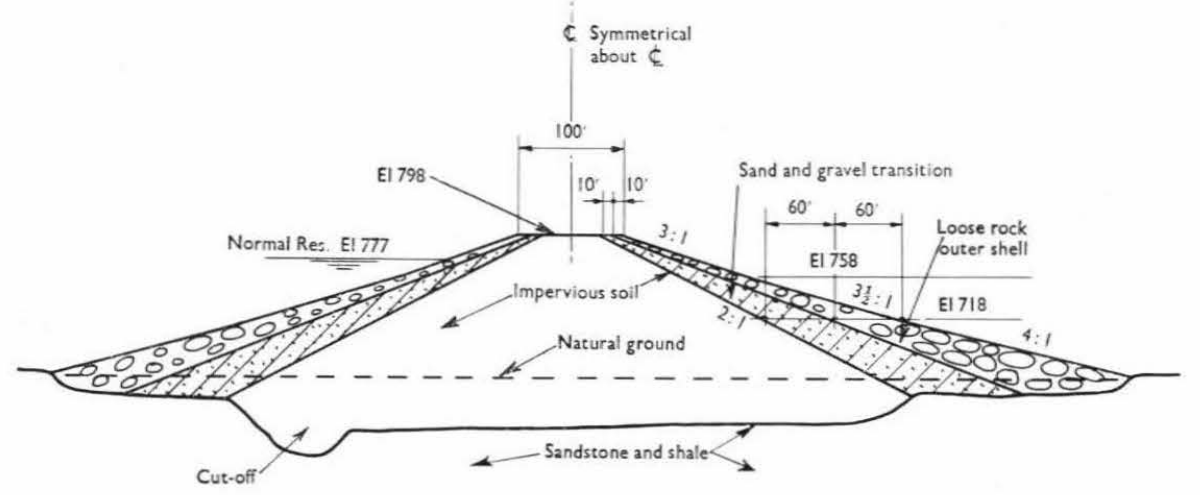

Fig. 11. Coyote Dam (after Tibbetts, 1936) 


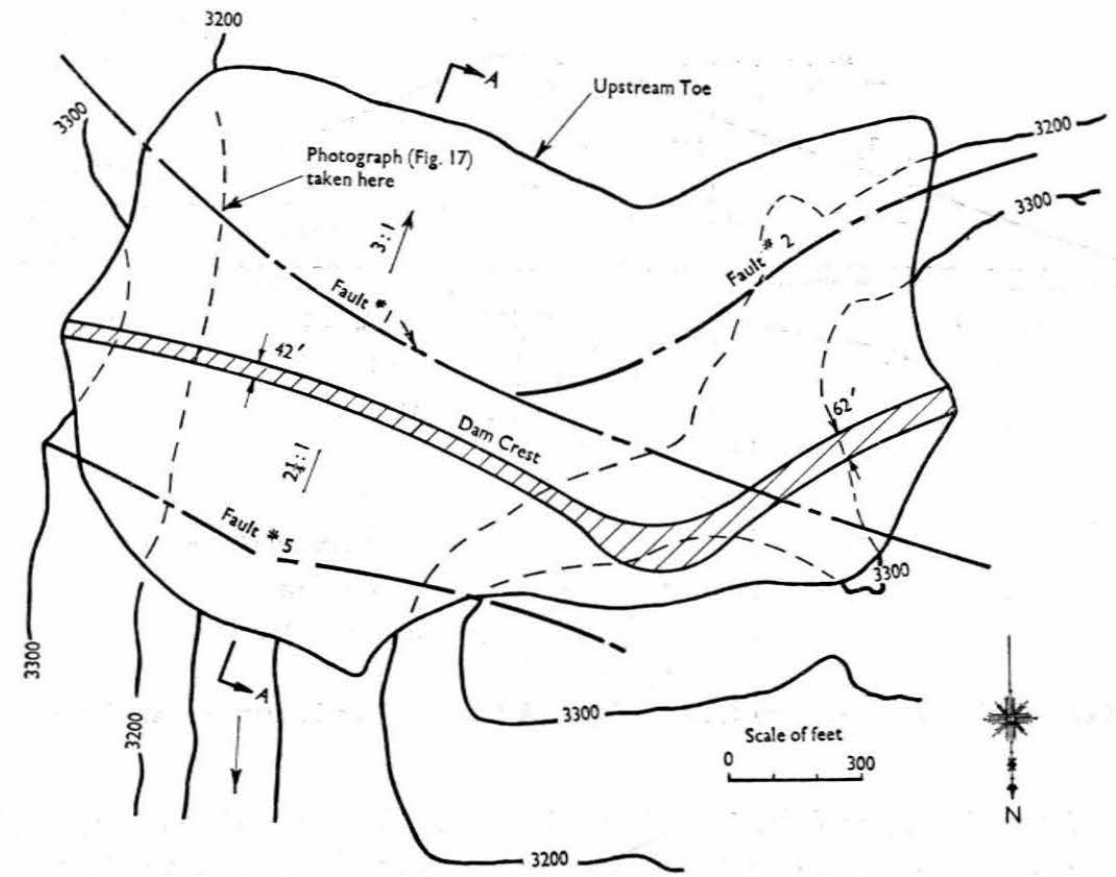

Fig. 12. Cedar_Springs Dam-plan view and fault locations
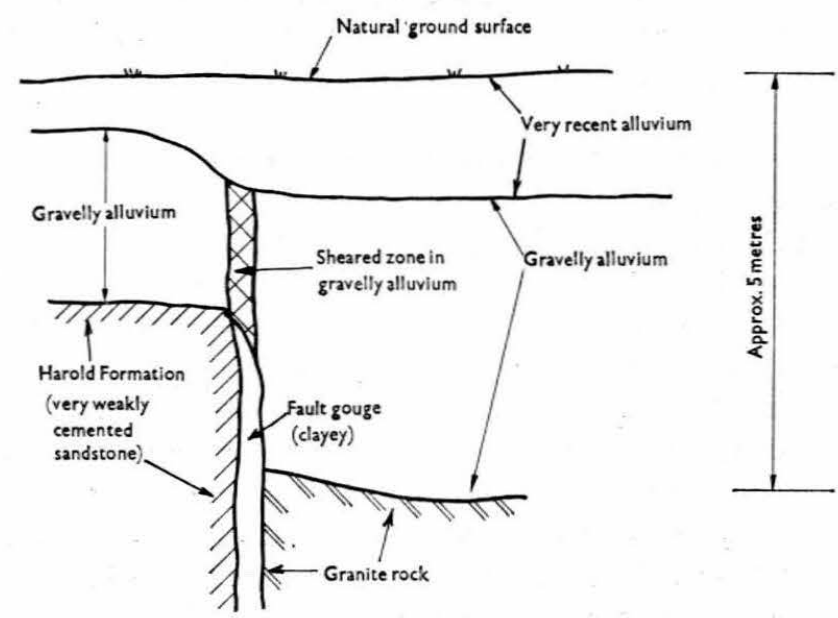

Fig. 13. Cedar Springs Dam; appearance of small active fault exposed in exploratory test trench

number of changes were made in the previously existing plans, and the main design details for the new project were as follows. The dam height was reduced to the minimum possible value consistent with the project needs, from about $300 \mathrm{ft}(92 \mathrm{~m})$ to $215 \mathrm{ft}(66 \mathrm{~m})$, reducing the reservoir storage volume from about 160 to 60 million $\mathrm{m}^{3}$. The axis of the dam was moved so that the entire contact between the clay core and the foundation of the dam (in the main river valley) was on the granite formation. The embankment dam cross-section was changed completely from an ordinary zoned dam with narrow chimney drain, to a thoroughly zoned dam with thick exterior shells of quarried hard rock and thick transitions of well graded, 


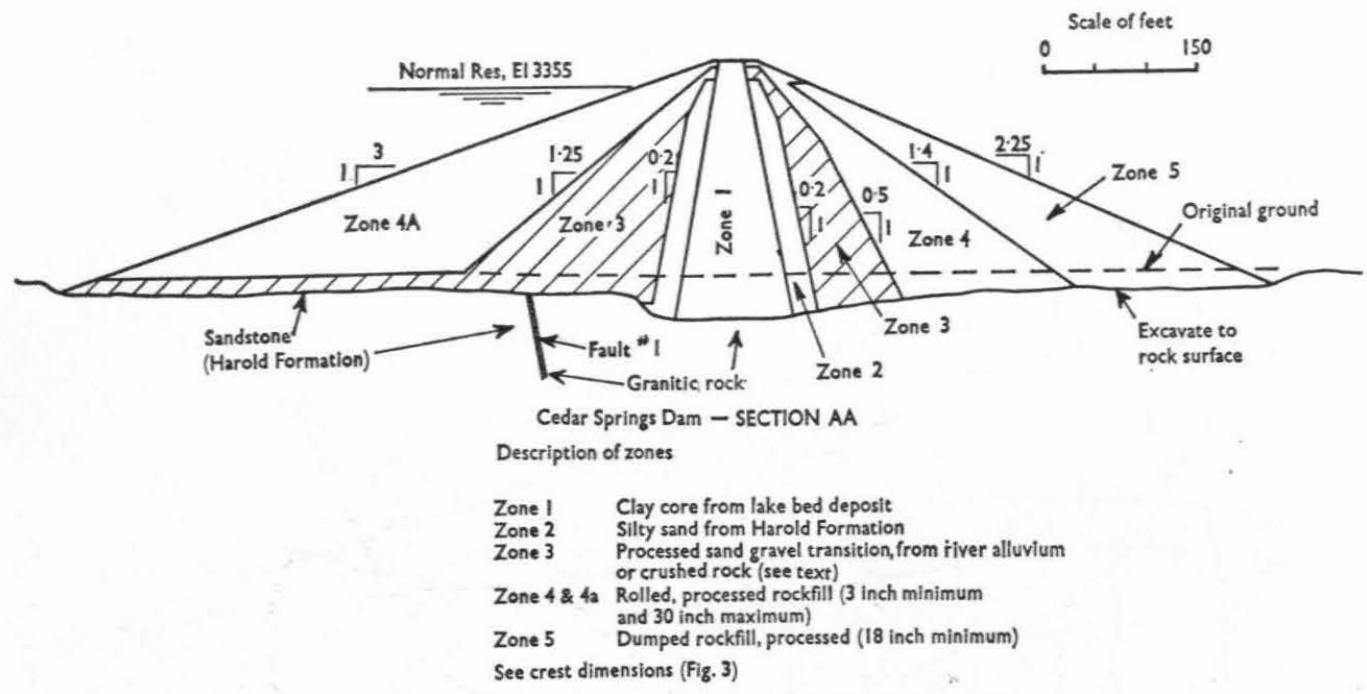

Fig. 14. Cedar Springs Dam-typical cross-section A-A (after California Department of Water Resources, 1968)

coarse, sand-gravel mixture (Fig. 14). Instead of using locally available silty sand for the core, a lake-bed clay, of especially tough and apparently erosion-resistant nature, was hauled from a distance of about $50 \mathrm{~km}$. A wide crest was used for the main dam with generous widths of clay core and transition zones at the top of the dam. In the portion of the dam (west end) where the fault crosses the dam from upstream to downstream, the crest width was increased to $62 \mathrm{ft}(19 \mathrm{~m})$, or probably twice the width that might otherwise have been employed (Fig. 12).

The dam design is considered illustrative of the kind of dam which is inherently safe against damage from displacement of faults in the foundation.

The well graded, sand-gravel zone 3 is the main line of defence. Gradation specifications for this zone are shown in Table 1.

The material was composed of well graded river gravels (in which case an 18 in. maximum size was allowed) or quarried rock fines (in which case the material had to pass a vibrating screen with 3 in. square openings). This zone 3 material is too clean and cohesionless to allow an open crack to exist. Even neglecting the influence of the sandy zone 2 the amount of water that could get through an open crack in the clay core following fault rupture would be limited by the permeability of the zone 3 material to a quantity which would be controlled safely with complete confidence by the thick downstream rockfill shells.

Figure 15 shows a view of the construction surface looking downstream with the clay core (zone 1) in the foreground and zones 2, 3, 4 and 5 at progressive distances. Fig. 16 shows a

Table 1

\begin{tabular}{c|c}
\hline Size & Percent finer \\
\hline 18 in. & 100 \\
3 in. \\
1.5 in. & $50-100$ \\
$\begin{array}{c}40-90 \\
\text { sieve }\end{array}$ & $20-70$ \\
$\# 200$ sieve & $0-8$ \\
\hline
\end{tabular}




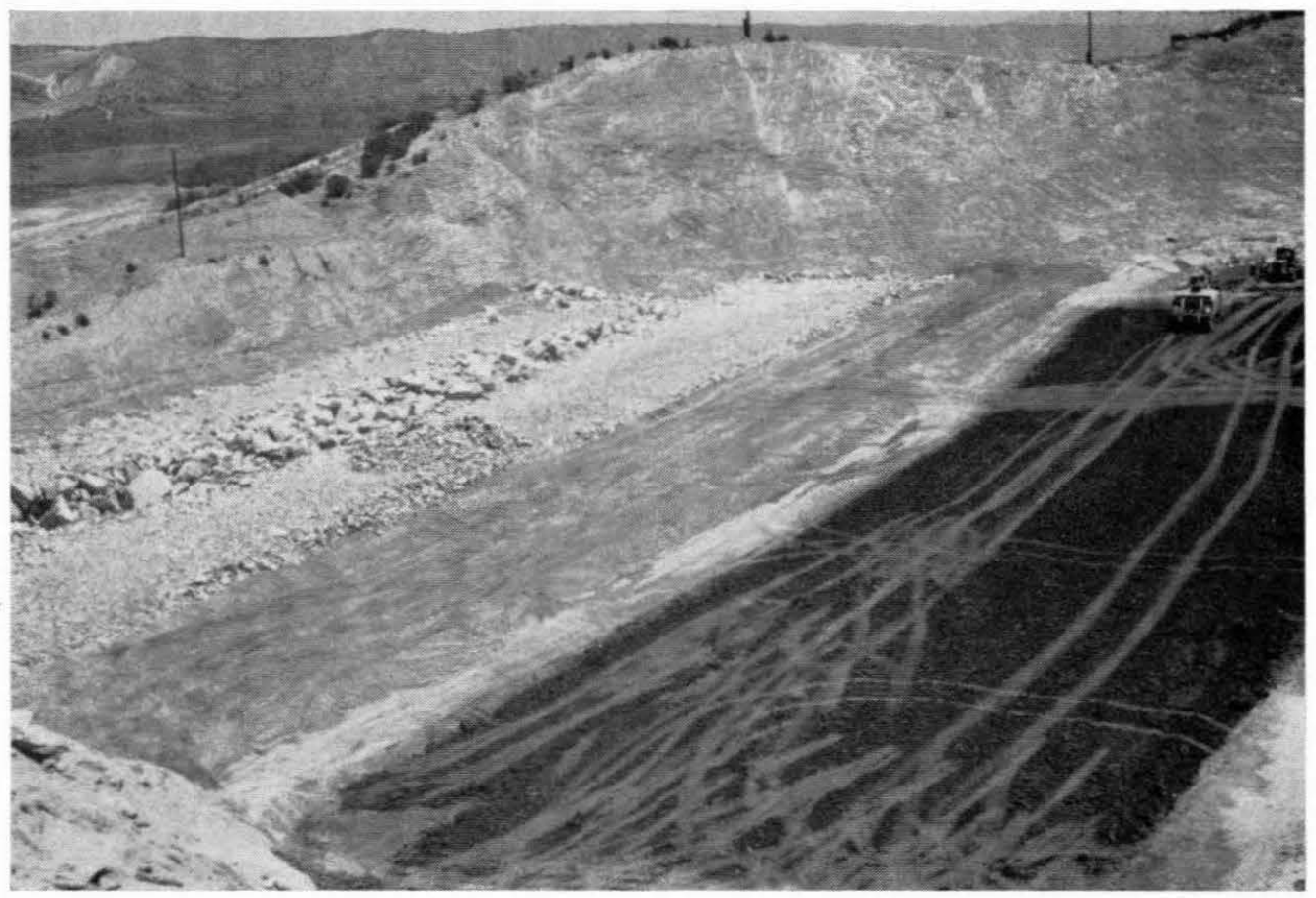

Photo: J. L. Sherard

Fig. 15. Cedar Springs Dam during construction, looking downstream showing core at right and zones 2, 3, 4 and 5 progressively downstream 


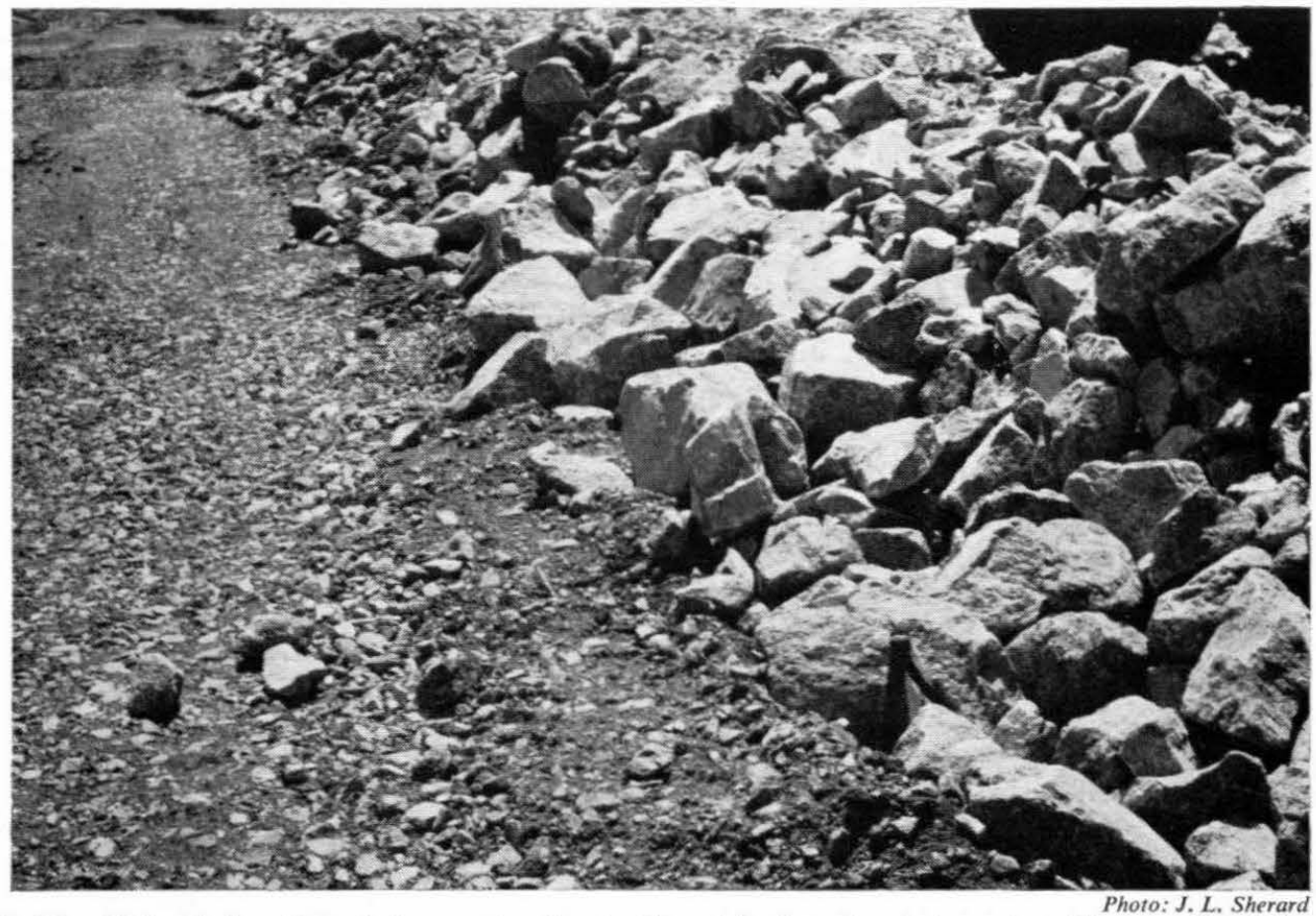

Fig. 16. Cedar Springs Dam during construction, looking at the boundary between transition zone 3 and downstream rockfill zone 4 . It is apparent that the permeability of rockfill zone $\mathbf{4}$ is several orders greater than that of zone 3

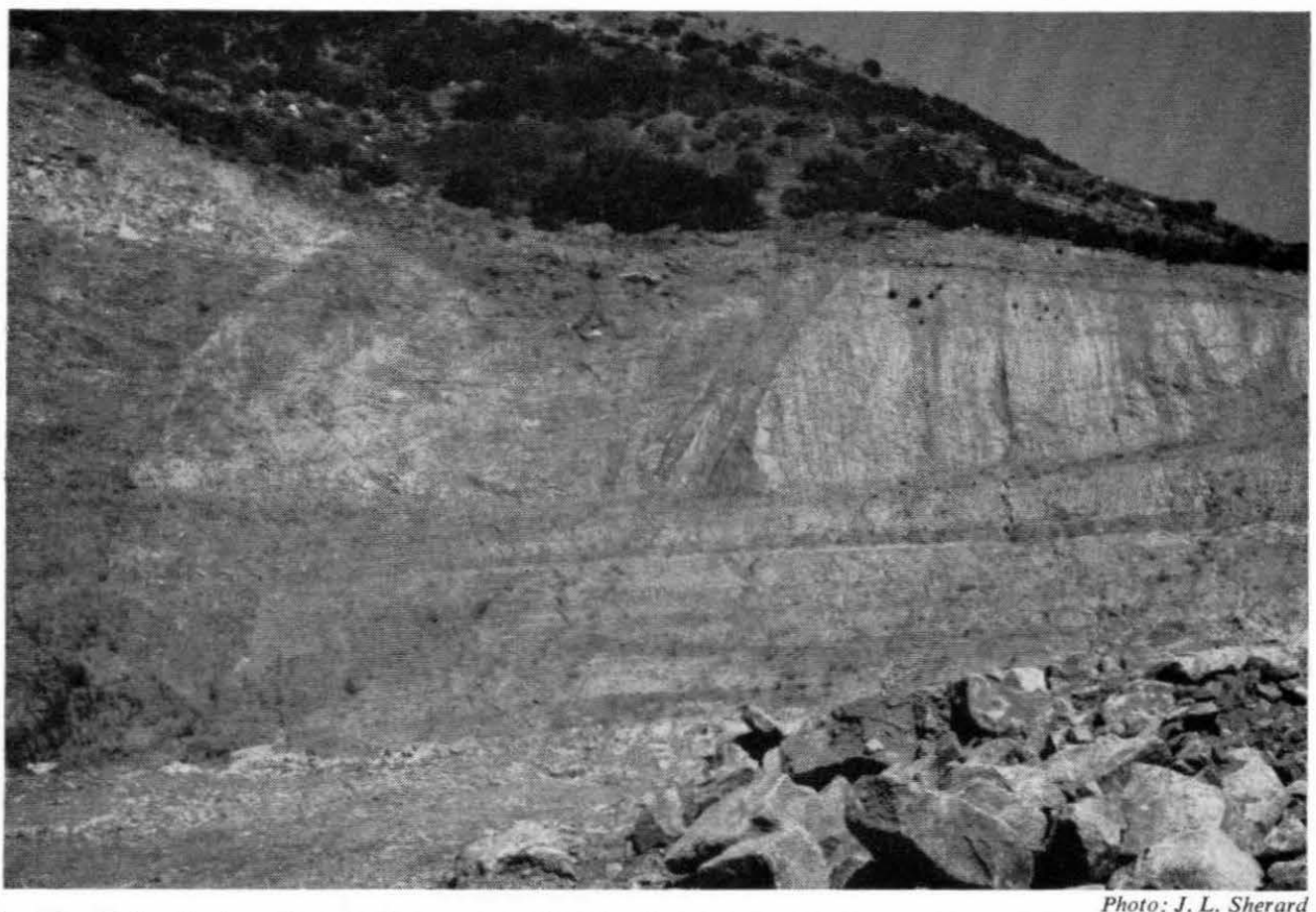

Fig. 17. Cedar Springs Dam during construction showing fault No. 1 exposed in excavation in east abutment at location shown in Fig. 12 


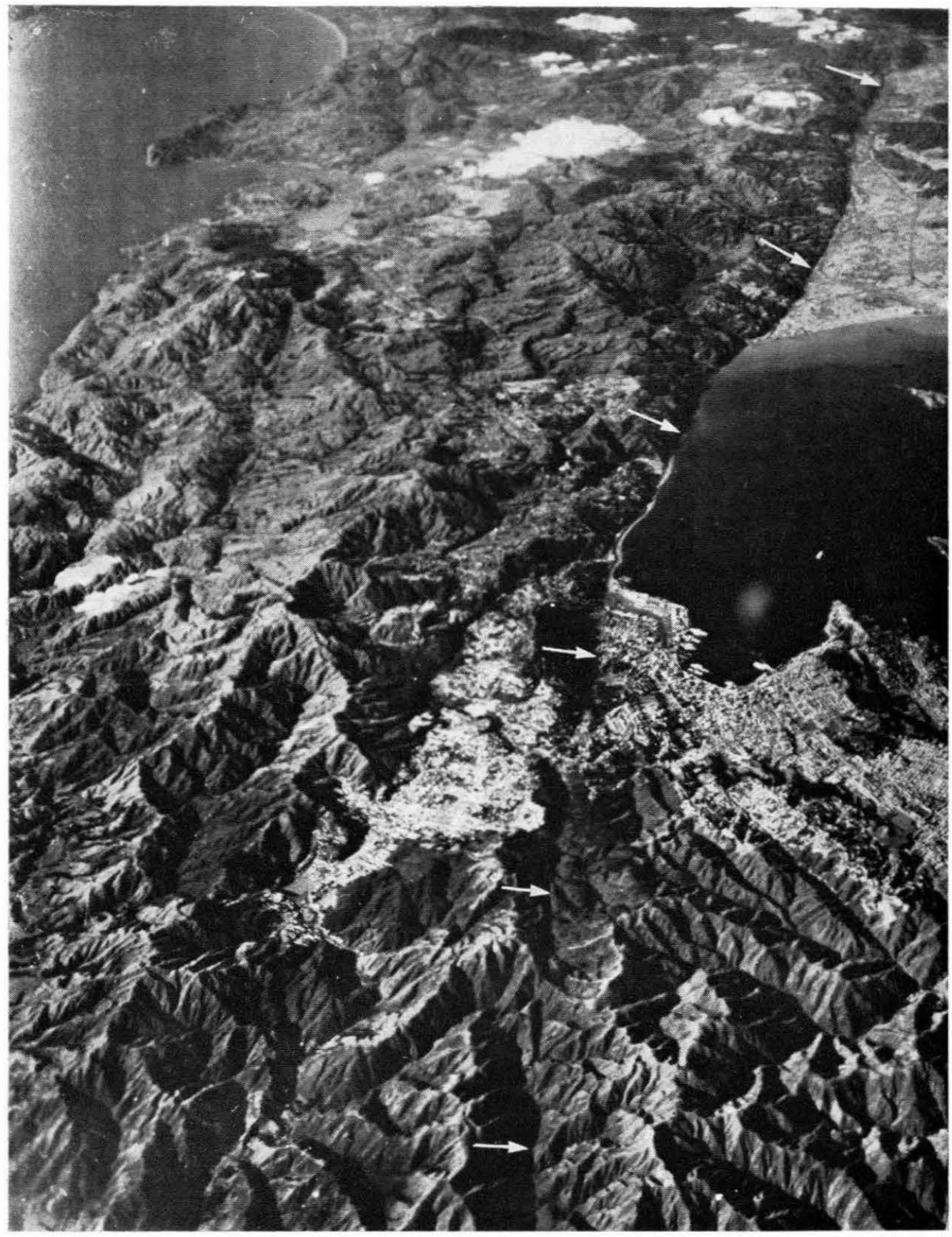

Photo: C. R, Allen

Fig. 18. Wellington Fault (arrows), New Zealand: one of the several parallel major active faults traversing the north island. City of Wellington in centre of photograph 


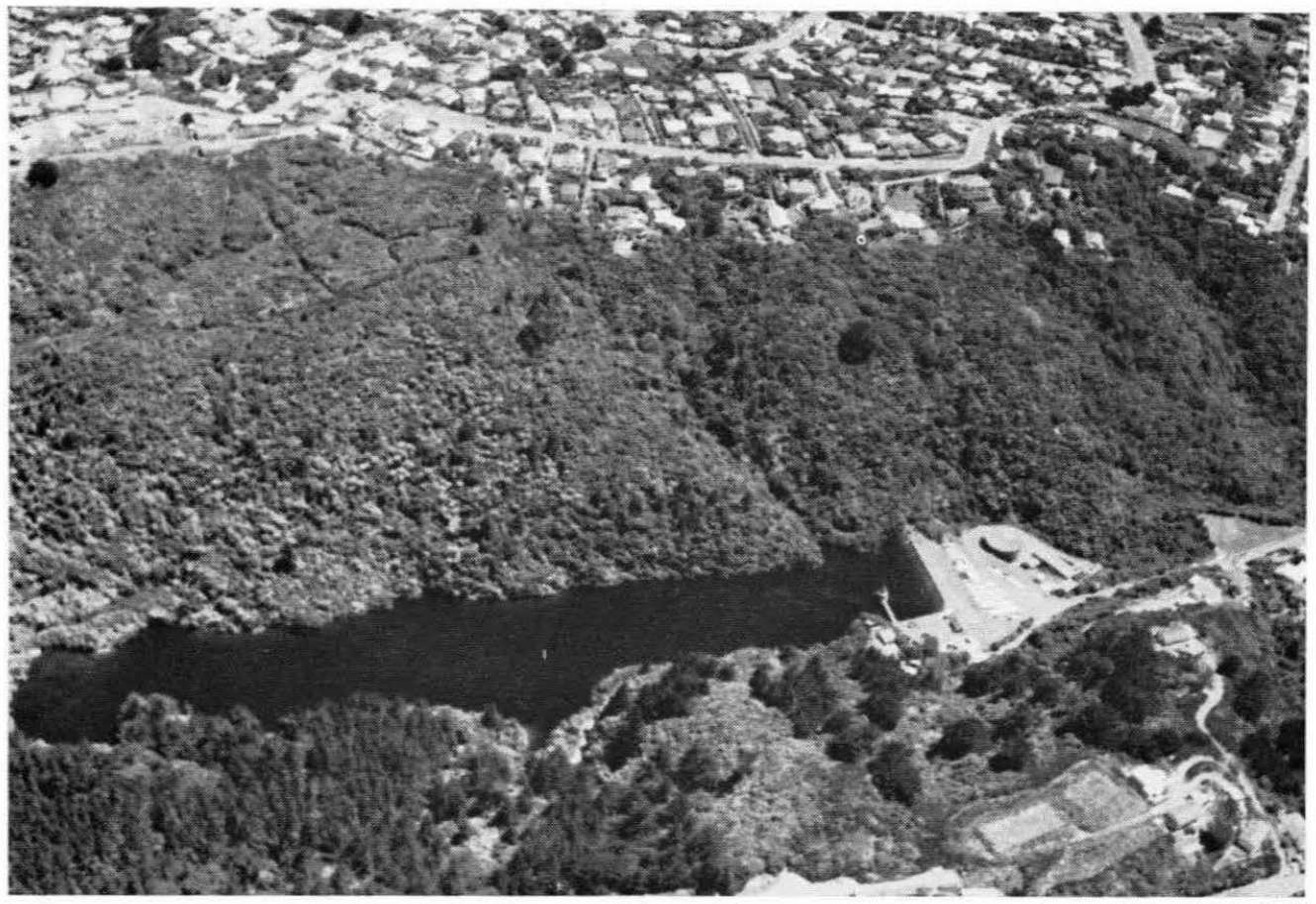

Photo: L. S. Cluff

Fig. 19. Lower Karori Dam: $25 \mathrm{~m}$ high earth dam across the active Wellington Fault near Wellington, New Zealand. The reservoir is in the photograph of Fig. 18 but too small to be seen. Note the typical narrow reservoir in valley of strike-slip fault

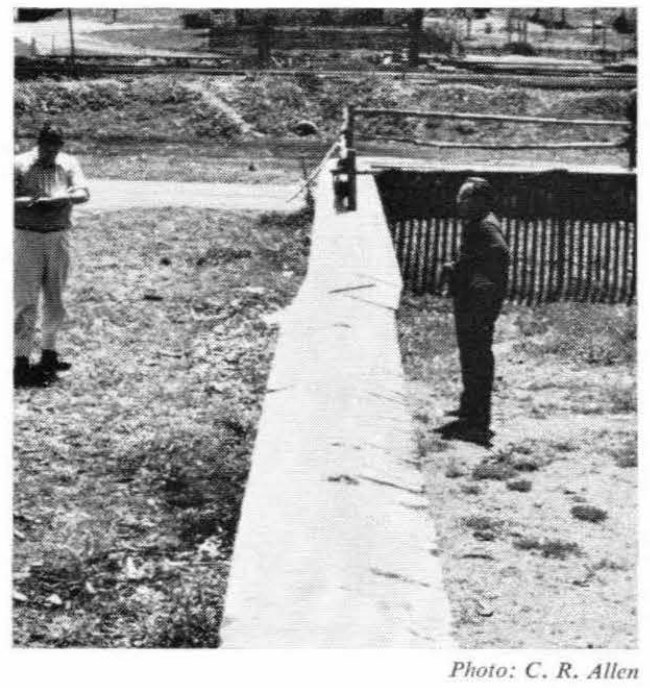

Fig. 20. Horizontal offset of wall by creep along North Anatolian Fault, Ismetpasa, Turkey. It is reported that creep is progressing at 1-2 cm/year since the photographs were taken in 1969 (Nason, 1972). During the 1944 Bolu earthquake $(M=7.6) 1.5 \mathrm{~m}$ of horizontal displacement took place at this same location 

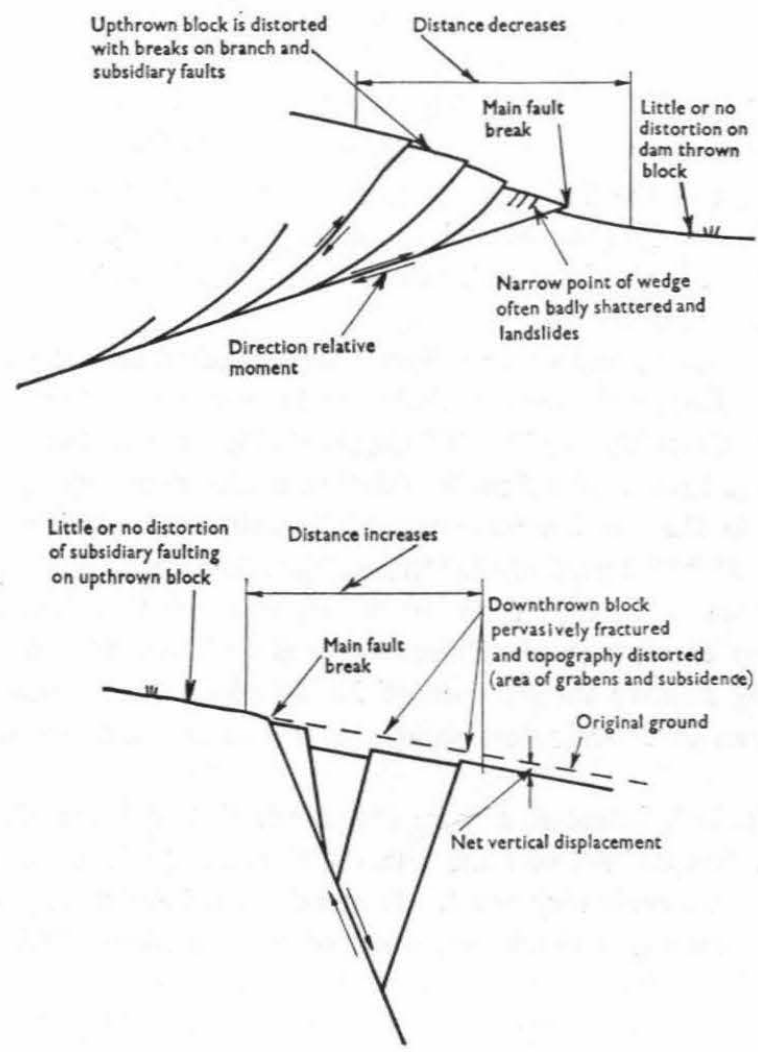

Fig. 21. Characteristics of thrust and normal faults

typical view during construction of the juncture between zones 3 and 4 of the downstream shell, which gives confidence that any amount of water that could get through the zone 3 material would percolate away into the downstream rockfill safely.

During construction the active faults as observed in the excavations were only a few inches wide and resembled the minor faults commonly seen in many dam foundations in tectonized regions (Fig. 16).

In the design stage the clay for the impervious core was chosen because its visual appearance gave confidence that it would not erode rapidly, even if a leak through a crack developed. Particularly, it was very tough and hard at water contents near the plastic limit. At the time of design there was no laboratory test available to evaluate the erosion resistance of the clay in a reliable manner. Later, after construction was under way, laboratory tests using the newly developed procedures and criteria for evaluating 'dispersive clays', indicated that the clay is in fact highly non-dispersive and resistant to erosion (Sherard et al., 1972).

The dam is in operation with no problems.

\section{Palmdale Dam}

In 1891 , a $10 \mathrm{~m}$ high earth dam, retaining a small reservoir of about 8 million $\mathrm{m}^{3}$ for irrigation and domestic water supply, was built across the rift valley of the San Andreas Fault near Palmdale, California. No movement on the fault has occurred at the site since the dam 
was constructed (although displacement of many feet almost certainly occurred during the great 1857 earthquake).

Starting about 1955 , the question of vulnerability to fault displacement was raised, as part of general practice of review and strengthening of older dams in California. The State Division of Safety of Dams suggested that the dam be strengthened substantially or that a new reservoir be constructed to replace it. In an interim period a storage level restriction was imposed below which sag pond depressions in the fault valley downstream would store a significant portion of the water released if a failure occurred.

Other possible dam locations and other schemes were studied to obtain storage elsewhere. No suitable alternative storage sites were available and the dam was completely reconstructed in 1969 at the same site (Cortright, 1970; USCOLD, 1967). It was the opinion of geologists and seismologists that the fault in the dam foundation could be expected to break during the lifetime of the dam, that the displacement would be primarily horizontal with magnitude probably not exceeding $20 \mathrm{ft}(6.2 \mathrm{~m})$ and that there might be a vertical component of displacement of $2-3 \mathrm{ft}(0 \cdot 6-1 \cdot 0 \mathrm{~m})$. The new dam has a very conservative design including a $40 \mathrm{ft}$ $(12.2 \mathrm{~m})$ crest width, flat exterior slopes, interior zones wide enough to remain intact even after being displaced by relative movements of $30 \mathrm{ft}(9.5 \mathrm{~m})$ horizontally and $5 \mathrm{ft}(1.6 \mathrm{~m})$ vertically, transition zones of cohesionless sand and gravel and a large downstream rockfill zone.

This example is particularly interesting from the standpoint of illustrating current practice. The dam is crossed by a 'major' active fault with the likelihood of $3 \mathrm{~m}$ or more of movement during the lifetime of the reservoir very great. It was designed and constructed in the last few years by experienced engineers, with the approval of the California State Division of Dam Safety.

\section{Morris Dam}

Morris Dam is a concrete gravity dam about $80 \mathrm{~m}$ high, constructed in 1935 in southern California for water supply. During design it was concluded that a foundation fault might be active and the dam was designed with a special joint at the fault which would allow fault displacement without distress (Louderback, 1937 and 1950). During construction it was found that the alluvium covering the fault had not been displaced and it was concluded that the fault was probably not active. Nevertheless the dam was built with the joint. The dam continues in good service with no indication of fault displacement. This example is included for historic interest. The Authors have not studied this case, have not seen details of the joint in the dam and have no opinion regarding the dam, except for the general opinions concerning concrete dams and faults described later.

\section{CURRENT PRACTICE}

Current practice requires that every effort be made to avoid sites with active faults. As illustrated by the foregoing examples, however, where no alternative site is available and where a reservoir is deemed vitally important, it has been considered reasonable practice to build dams on active faults. With the exception of the Morris Dam, conservatively designed embankment dams with internal cohesionless transition zones for leakage control have been employed.

While the examples given are all in California, the conclusions drawn are considered representative of general thinking and conservative practice in the industry. In fact, dam building practice in California is generally more conservative than the typical practice in the United 
States of America. Following the failure of the St Francis Dam in 1928, with about 400 deaths, the State legislature established the Division of Safety of Dams for the purpose of requiring conservative practice for dams and this organization has become increasingly more influential over the years. All proposed new dams in California are now studied independentiy in great detail by the Division's staff of dam engineers and engineering geologists. In general only the more conservative designs are permitted. No other states exercise comparable control over dams.

The examples of Coyote, Cedar Springs (Fig. 17), Palmdale and Morris are believed to comprise practically all the experience in the profession in which dams were constructed on demonstrably active faults and where the designer, owner and official agencies were all consciously aware of the situation. In addition, however, it can be confidently assumed that there have been many other unpublicized cases where dams have been built at sites crossed by faults for which the designing engineer suspected possible activity and where he quietly assumed the fault might move several feet and proceeded with the construction of a conservatively designed embankment dam.

Undoubtedly there are many dams in various parts of the world with foundation faults which would be shown to be active by adequate geologic study, and some cases have been discovered after many years of reservoir operation. One example is the Wellington Fault in New Zealand (Fig. 18). Two dams were built in the fault valley for water supply reservoirs about $1 \mathrm{~km}$ apart. The Upper Karori Dam is a concrete dam built in 1908 and the Lower Karori Dam is an earth dam built in 1872 (Fig. 19). Both dams are about $25 \mathrm{~m}$ high and both retain very small reservoirs (about $250000 \mathrm{~m}^{3}$ ). It is now recognized that both these old dams straddle the active fault. They are kept in service nevertheless because it was concluded that the flood from release of the small reservoirs by dam failures would be impeded by a culverted road embankment and reach Wellington harbour without hazard of loss of life or property damage.

\section{DETAILS OF FAULT BREAKS}

The main lessons of value to the dam engineer from observations of surface fault breaks during historic time are summarized in the following. Judgements as to the nature of events that are likely to happen in the future are determined almost entirely by our knowledge of the kinds of things that have happened in the recent past, including both historical observations and geological evidence of prehistoric events.

\section{Number of historic breaks}

There have probably been in the order of 100 to 200 surface fault breaks during the past 150 years that have been noticed by geologists, although most of these have not been adequately described in the published literature. Judging from the fact that a large part of these incidents has been reported during the past ten years alone, it is reasonable to assume that hundreds of additional surface breaks have occurred in the past 150 years that have gone unnoticed and unreported by geologists. It would be misleading to estimate the number of fault breaks throughout the world solely on the basis of the occurrences that have been described in the literature.

Until a few years ago, it was thought that surface fault breaks occurred only in association with very large and infrequent earthquakes, but recent intensive field studies have revealed that surface displacements are far more common than was once thought. Not only have ruptures been observed in association with relatively small shocks, but continuous slippage-known as 
fault creep-has recently been recognized in several parts of the world (Fig. 20). Furthermore, it is now known that earthquakes resulting from displacement and energy release on one fault can sometimes trigger small displacements on other unrelated faults many kilometres distant.

\section{Breaks on existing faults}

In almost all known instances of historic fault breaks, the fracturing has occurred along a pre-existing fault that could have been recognized by geologists prior to the earthquake, and in most cases the fault could have been recognized as active. Many historic fault breaks occurred exactly along easily recognized scarps of previous breaks which occurred in prehistoric but very recent geological time.

There have been a few recorded instances of more than one historic fault break along nearly the same fault line, such as near El Centro, California, in 1940, 1966 and 1968 (Allen et al., 1972), near Parkfield, California, in 1901, 1922, 1934 and 1966 (Brown and Vedder, 1967), and probably numerous events dating back to AD 10 along portions of the North Anatolian Fault in Turkey (Ambraseys, 1970).

While it seems probable that a given fault would break again on the exact location of the last break, this cannot be concluded with certainty. In 1954, fault breaks occurred on the Gold Fault near Fairview Peak, Nevada, along the same general lines as breaks that had occurred in 1903 . But in detail the 1954 faulting generally criss-crossed the earlier faulting and was frequently more than $50 \mathrm{~m}$ from it (Bonilla, 1970). All the 1954 breaks, however, occurred on existing faults, whether or not they had broken in 1903.

Every fault must, of course, have originated as a 'new' fault at some time in geological past, but the statistical chances of a new fault breaking previously unbroken rock within the life of an engineering structure are so remote that they can be reasonably neglected, except in unusual situations such as near the tip of the wedge of an active thrust fault (Fig. 21). Similarly, old faults are sometimes 'healed' or cemented, by metamorphic or intrusive processes at depth. Because healing probably indicates great age since the last movement, and because the healed zone is probably no longer a weak surface, it is also reasonable to ignore the possibility of movement on healed faults.

\section{Fault types and nature of breaks}

The relative movements between the walls of a fault during an earthquake may be primarily vertical (dip-slip) or horizontal (strike-slip), depending on the local stress system in the earth's crust that caused the earthquake. Historical observations as well as mechanical considerations suggest that most faults fall into one of three distinct categories.

Strike-slip faults. These involve primarily horizontal displacements. The fault planes are typically near vertical and are markedly linear in plan view, master faults of this type often appearing as linear 'scars' on aerial photographs (Figs 22 and 23).

Thrust faults. These involve vertical displacements caused by horizontal compression. The distance between points on opposite sides of the fault decreases as a result of the displacement (Fig. 24). The fault planes tend to have a shallow inclination (dip) from the horizontal -typically $20-40^{\circ}$. Because of the shallow dip, thrust fault traces tend to be sinuous in plan view through hilly terrain. Many major mountain systems of the world are bounded by thrust faults, such as the Andes and Himalayas, and most of the world's great earthquakes have been caused by thrusting in the oceanic trenches where the ocean floor is being thrust beneath the continental edges. The great 1964 Alaska earthquake and the 1960 Chile earthquake are typical results of breaks on such fault systems. 


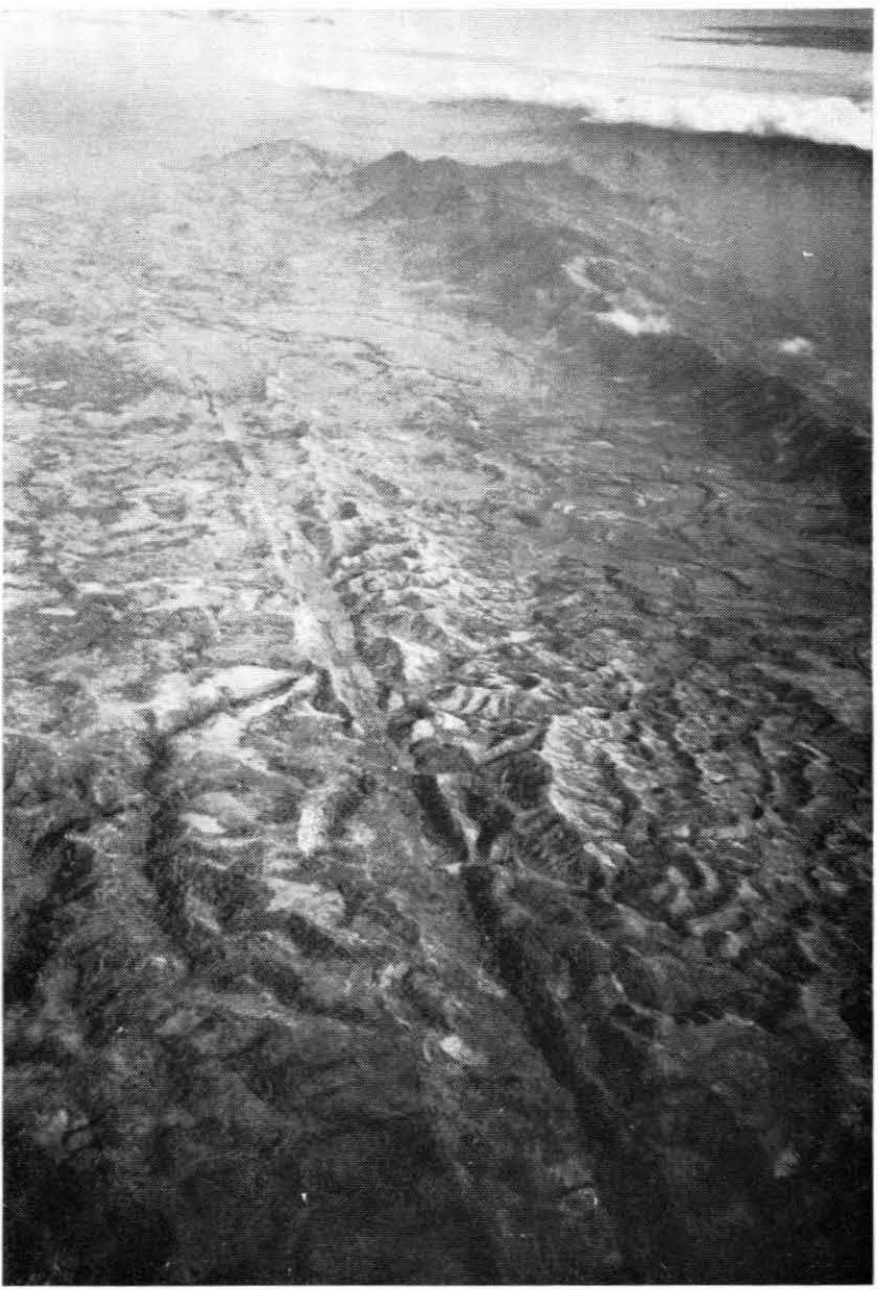

Photo: C. R. Allen

Fig. 22. Philippine Fault in northern Leyte: master strike-slip fault of more than $1000 \mathrm{~km}$ length. Note tendency of streams to erode along the fault valley. No historic displacements are known along this segment of of the fault, but a $3.2 \mathrm{~m}$ displacement occurred on the fault $400 \mathrm{~km}$ further north, during the 1973 Ragay Gulf earthquake (Morante and Allen, 1973) 


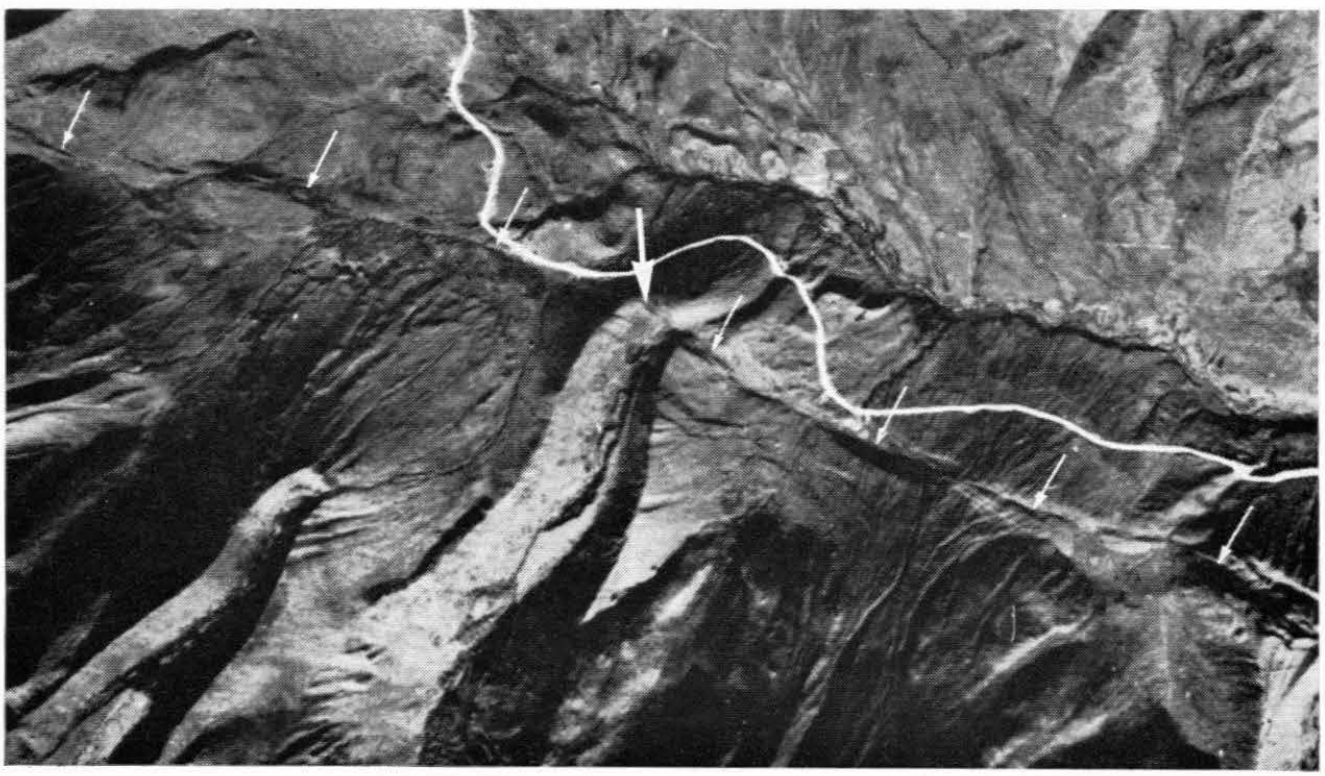

Fig. 23. Scarps (arrows) showing recent displacements on the Boconó Fault (strike-slip) in Merida Andes, Venezuela, a master fault of more than $500 \mathrm{~km}$ length which probably broke during the $M=8$ earthquake in 1812. Amounts of offset of 10000 -year-old glacial moraines (large arrow) suggest $M=8$ earthquakes and fault displacements occur every 200 years. Fault in photograph is on drainage divide between two major rivers, but lies within river valleys over most of its course, passing through several potential dam sites (see Fig. 26)

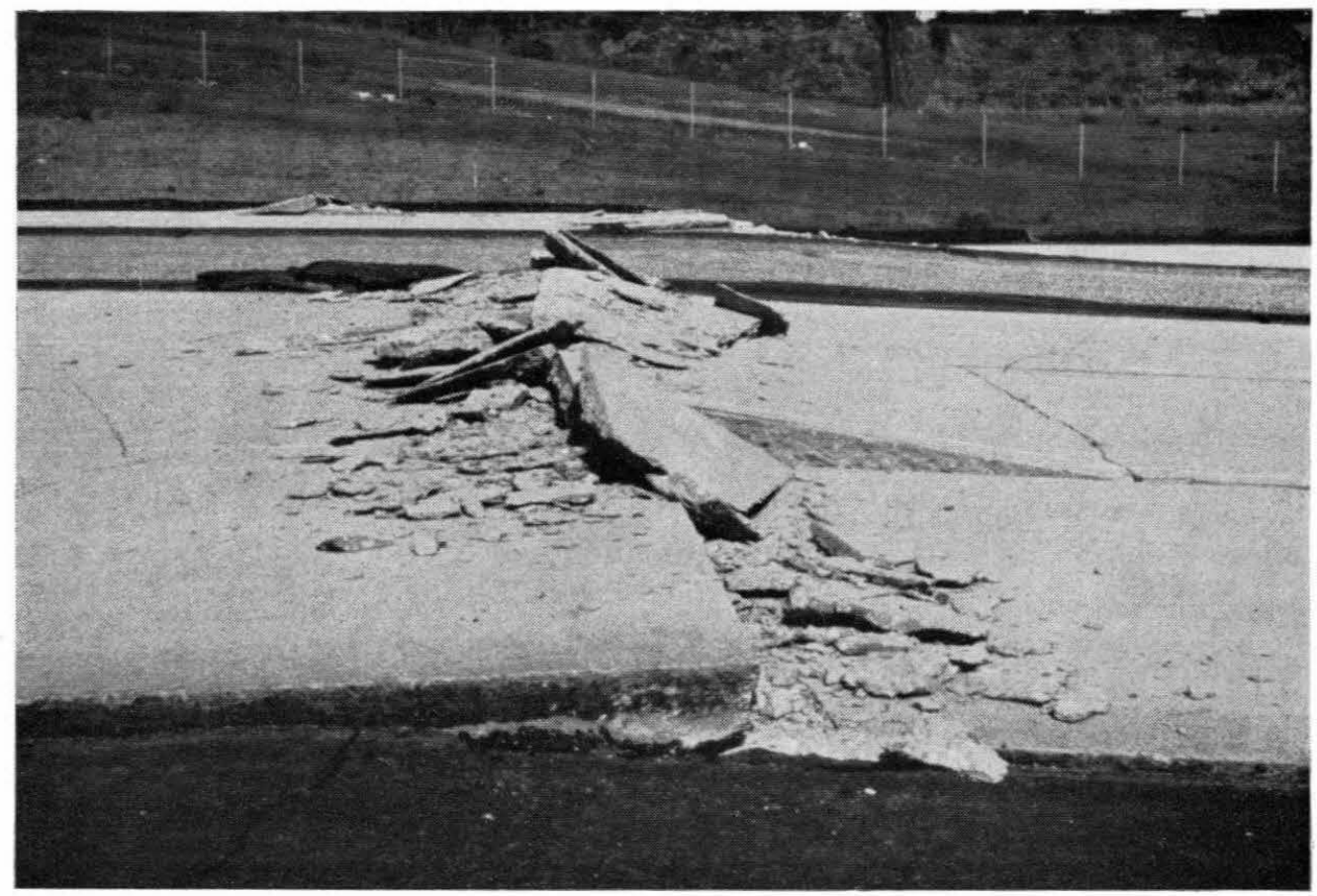

Photo: L. S. Cluff

Fig. 24. 1971 San Fernando, California thrust fault break passing through concrete pavement showing buckling resulting from shortening of a distance between points on opposite sides 


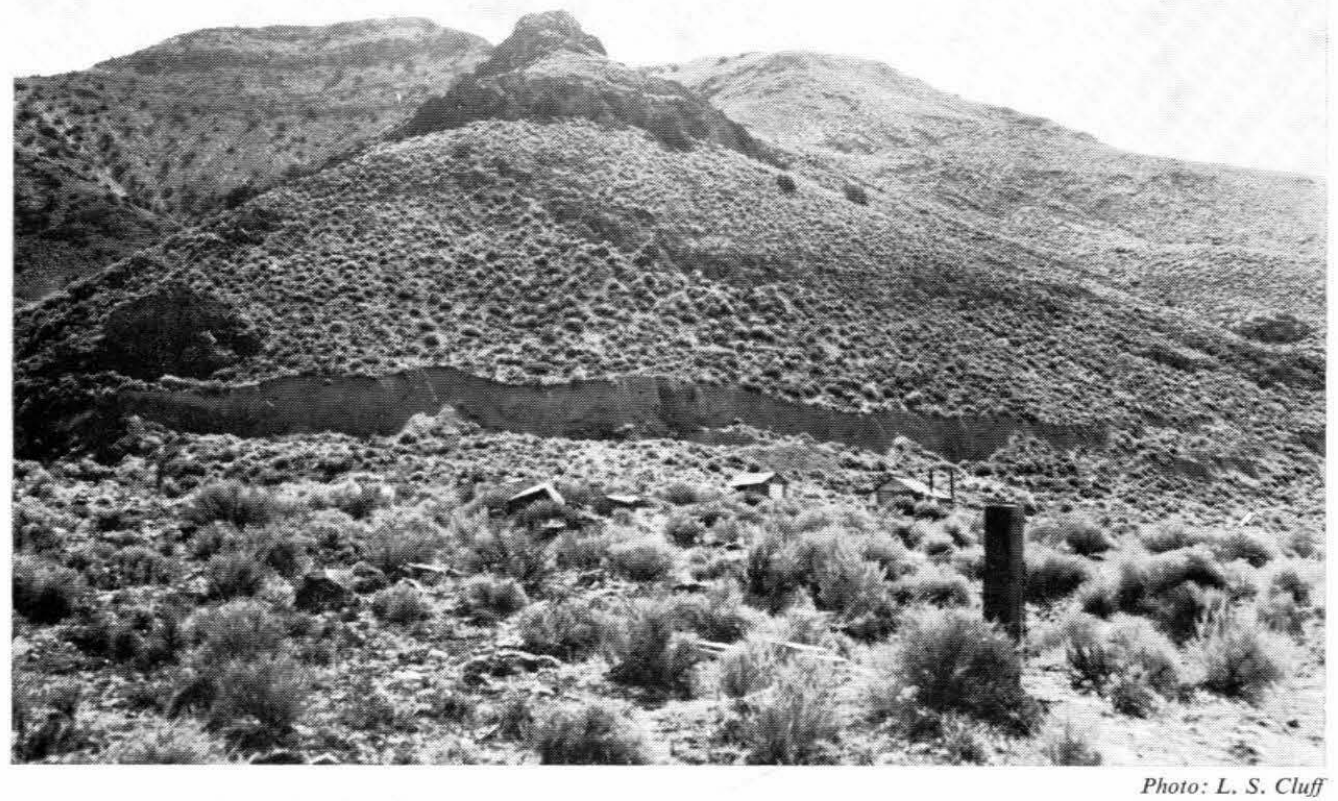

Fig. 25. 1963 photograph of 1915 break on the Pleasant Valley Fault (normal fault) Nevada. Fault scarp is exceptionally well preserved in the arid climate

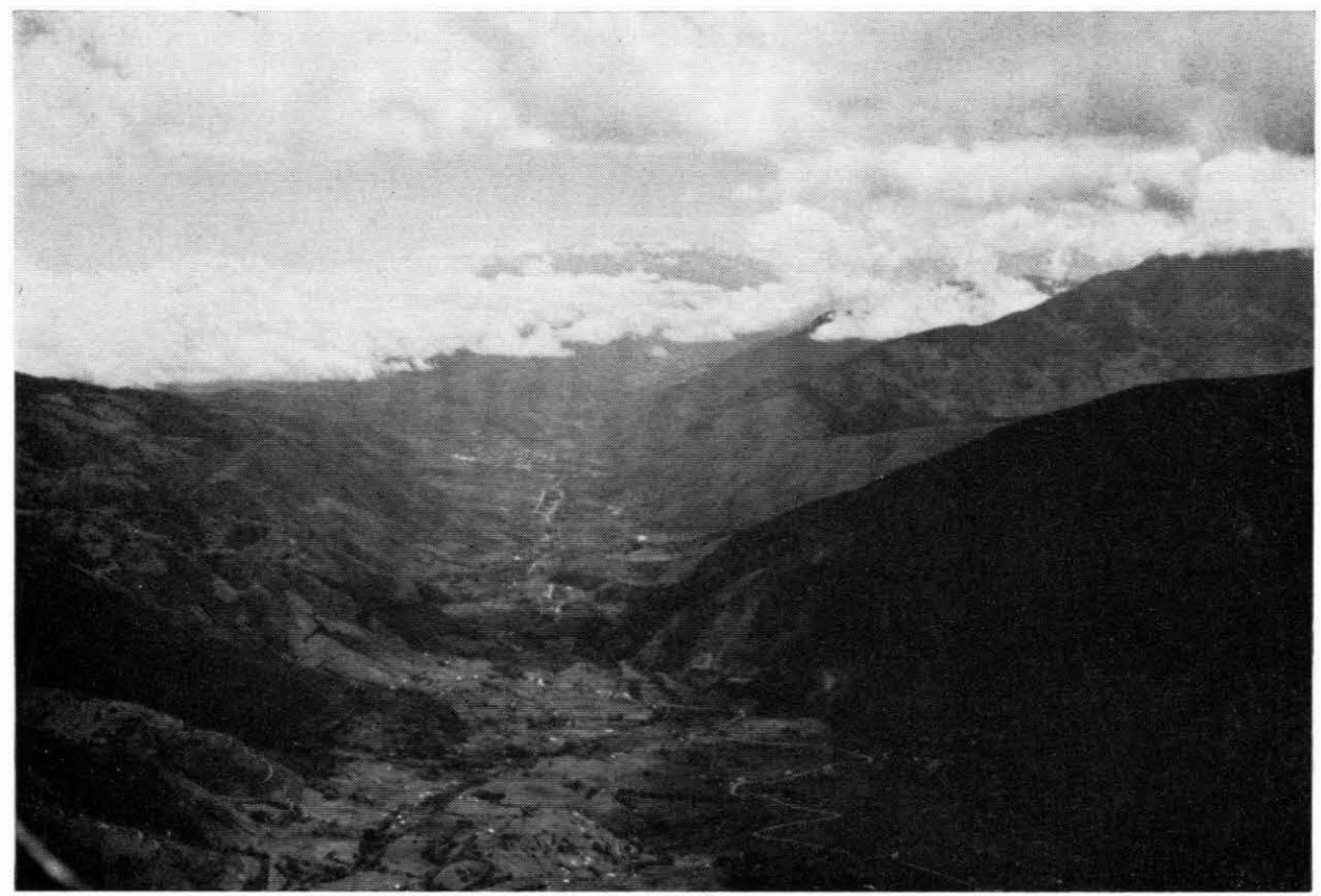

Photo: L. S. Cluff

Fig. 26. Main rift valley of Boconó Fault, Venezuela (master strike-slip fault) with length of at least $\mathbf{5 0 0} \mathbf{~ k m}$, looking northeast from Lagrita towards Merida in the far distance 


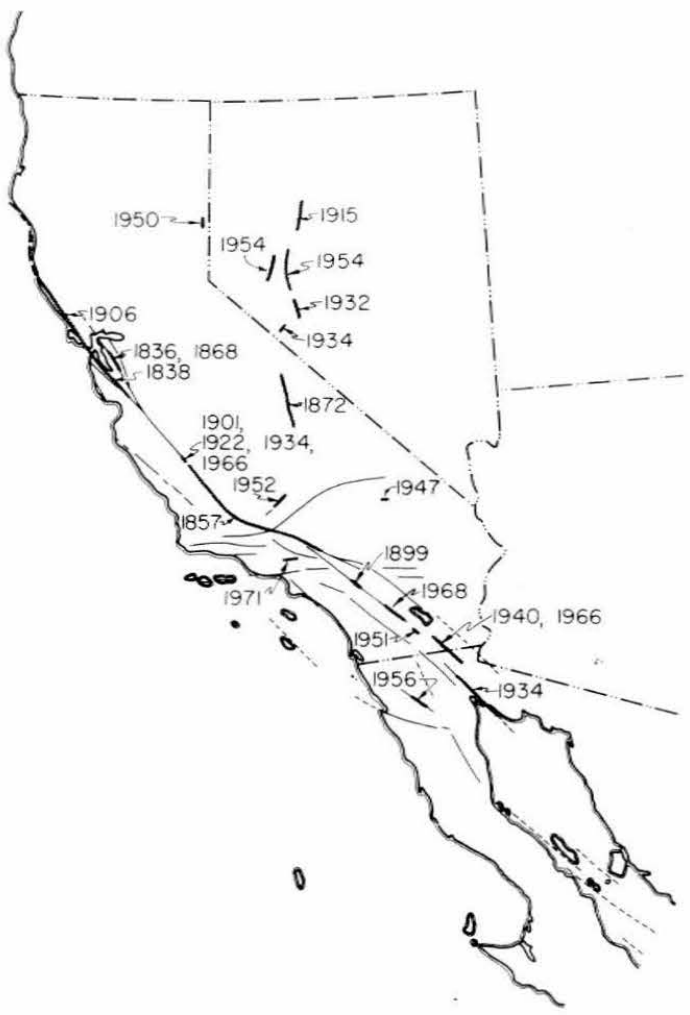

Fig. 27. San Andreas and associated fault zones in California, Nevada and northern Mexico. Zigzag lines show where surface of ground was broken during historic earthquakes and the dates of the breaks

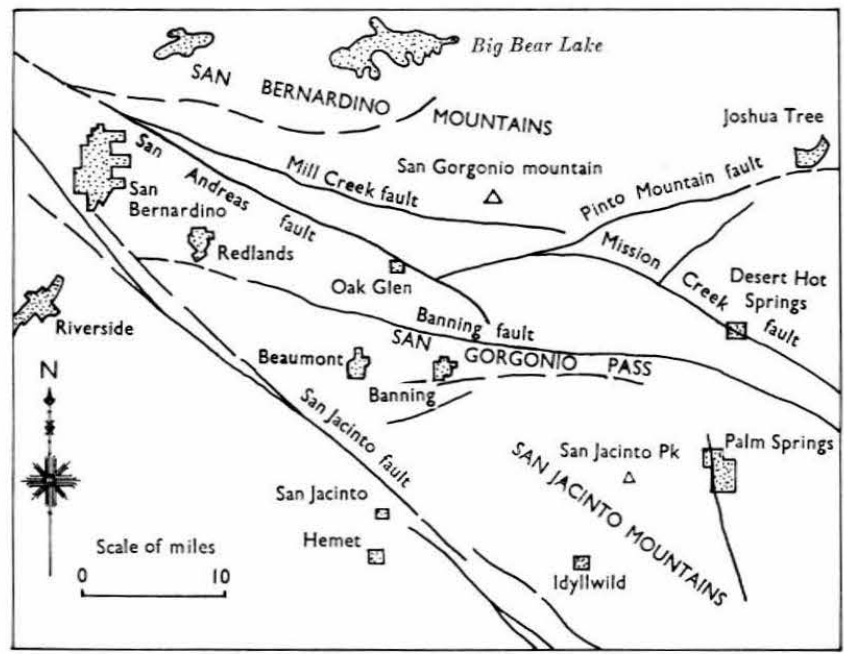

Fig. 28. The fault pattern in the San Andreas Fault zone approximately $100 \mathrm{~km}$ east of Los Angeles (after Allen, 1957) 
Normal faults. These involve vertical displacements caused by horizontal extension (Fig. 21). The distance between points on opposite sides of the fault is increased by the fault displacement. Normal faults tend to dip steeply (typically about $60^{\circ}$ from the horizontal) and their traces are moderately complex in plan view. They are less frequently found on the land masses than the other fault types; most of the areas of crustal extension in the world are along the mid-ocean ridges. Three areas of pervasive normal faulting in continental areas are the so-called basin ranges of the western United States (Nevada, Utah and adjacent regions), the great rift valleys of East Africa, and the Shansi Graben area of China.

The nature of ground fracturing caused by displacements on the three types of faults varies markedly and is of very significant engineering import. Since the strike-slip fault slips with primarily horizontal displacement, there is no consistent tendency for the ground on one side to be higher than on the other. Therefore, it is more common that streams may be captured by the fault and follow along it, creating a long narrow valley. For the thrust and normal faults, which generally cause a consistent change in the relative elevation of the ground on opposite sides, the fault commonly runs along a contour on the lower slope of a hill or mountain. For these faults therefore, it is not common for a stream or river to follow them for any distance. The streams coming out of the hills may cross the faults or may run parallel to the fault at a lower elevation. The main faults in the vicinity of the Hebgen Dam are normal faults running along parallel with the river on the hillside about $300-600 \mathrm{~m}$ from the river (Figs 5 and 6).

Fault breaks on strike-slip faults tend to be relatively simple and well defined, with fewer branching and subsidiary fractures than for the other two types. By observing physiographic evidence of where previous breaks have taken place along strike-slip faults, it is often possible to predict within a very few metres exactly where the next break will occur, inasmuch as breaks tend to repeat faithfully along the same lines.

Thrust faults represent a much more difficult engineering problem. They are more difficult to recognize in the field, both because of the sinuosity of the fault trace and because of pervasive landsliding that tends to cover the trace. Furthermore, the exact locations of individual breaks are difficult to predict for a thrust fault; the upthrown block tends to be distorted and to break up pervasively on subsidiary fractures and faults, particularly in the narrow point of the wedge close to the surface trace of the fault (Fig. 21). In addition, the differentiation between an active and an inactive thrust fault may be difficult, inasmuch as fault scarps resulting from geologically recent movements are very rapidly obscured by landsliding and erosion.

Normal faults are generally intermediate between thrust and strike-slip faults in their ease of recognition and their potential engineering hazard. Scarps are generally better preserved than for thrust faults (Fig. 25). In contrast to thrust faults, it is the downthrown block of normal faults that tends to be broken up and subject to slumping and the formation of grabens bounded by subsidiary fractures. For normal faults the ground is not usually fractured to the same degree or to the same distance from the main fault as is typical of thrusts (Fig. 21).

\section{'Master' fault systems}

There are certain major active faults of great length which have been moving for millions of years and have displaced the ground on opposite sides by tens to hundreds of miles. These 'master' faults, particularly of the strike-slip type, may dominate the topography to such an extent that they can be easily recognized on aerial photographs by the lay person (Fig. 26). In general, displacements of these master faults are those which generate the very strongest world earthquakes. 
The San Andreas Fault in California is a classic and probably the most intensely studied example. Geological evidence suggests that it has been moving with primarily horizontal displacement for at least 100 million years and that the total displacements caused by the repeated movements during this time may exceed 300 miles. As seen in Fig. 27 it runs nearly the full length of California and extends into northern Mexico. In some places it comprises a single fault zone but in southern California it comes into conflict with a great system of east-west structures causing a complex faulting pattern. Where the San Andreas Fault passes about 70 miles east of Los Angeles, it splits into many branches (Fig. 28). Epicentral locations of earthquakes leave no doubt that the zone as a whole extends into the northern end of the Gulf of California, but the fault frays out into a number of great branches and it is not clear which, if any, of the branches truly deserves the parent name.

The N. Anatolian fault system, which trends east-west across Turkey with a length of about $1000 \mathrm{~km}$ is another master (strike-slip) fault with characteristics and historic experiences which are very similar to those of the San Andreas Fault. At the west end, its location becomes indistinct and it probably frays out into many individual faults in a little understood pattern in western Turkey and northern Greece. The Boconó fauit system (strike-slip) trending with a length of at least $500 \mathrm{~km}$ northeast-southwest across western Venezuela is another with similar feature (Figs 23 and 26). Many other such master faults are known to exist including the Alpine and Wellington Faults, New Zealand (Fig. 18) and the Philippine Fault which trends northwest through the entire Philippine archipelago for $1200 \mathrm{~km}$ (Fig. 22) and the Atacama Fault, which runs north-south for $1000 \mathrm{~km}$ in northern Chile (Fig. 29). Many of these faults extend beyond the land unknown distances into the oceans.

Although these master faults are easily identified by geologists accustomed to studying active faults, it is also true that master faults in various parts of the world have not been recognized during geological studies for nearby structures, primarily because the local geological literature made no mention of them and because the geologist studying the site was not orientated towards the study of active faults or did not examine the geology far enough from the dam site. In fact, many of the main known active faults in the world have only been called to the attention of the profession in the last $10-15$ years, and it is believed that there are others yet to be recognized. Some of these major faults have not broken in historic time, but are nevertheless easily identified as active faults.

In portions of these master faults where the rupturing is generally confined to one main fault zone, such as the San Andreas Fault in northern California (Figs 2 and 27), there is no problem in locating and identifying the activity of the fault. It is unlikely that dams would be built across the fault in these locations, except for small reservoirs in special circumstances such as described earlier for the Palmdale Dam. The main problems of identification and evaluation occur along those portions of the system where the main fault branches out into many individual faults.

The most obvious master faults, such as those mentioned in the foregoing, are strike-slip faults because of the clear topographic expression. However, active thrust fault systems likewise may be master faults of great hazard, such as the frontal fault of the Himalayan range which has been the source of many damaging earthquakes. Although of similar tectonic significance, these are not as easily recognized, and are much more complicated. Some active faults have combined action with nearly equal horizontal and vertical movements (Fig. 30).

\section{Crustal deformations, subsidiary faults and 'triggered' faulting}

Large fault breaks and strong earthquakes are accompanied by deformations of the surround- 
ing ground surface, and often by breaks on branch and subsidiary faults (Fig. 31). The deformed crustal area often extends a few miles or tens of miles from the fault. In major earthquakes on master faults, crustal deformation may occur over greater distances. In the great 1964 Alaska earthquake $(M=8 \cdot 5)$, it is conservatively estimated that at elast $200000 \mathrm{~km}^{2}$ had appreciable vertical movement, about half going up and about half going down, with a maximum upward movement of about $12 \mathrm{~m}$. These crustal deformations occur at about the same time as the fault break, and are part of the same action.

Breaks on branch and subsidiary faults generally occur in areas of greatest crustal deformation and are more commonly associated with breaks on thrust and normal faults than on strike-slip faults. The main breaks on thrust and normal faults usually have breaks on adjacent subsidiary faults, while for major breaks on strike-slip faults, there are sometimes essentially no branch or subsidiary fault breaks.

More than half of the historic fault events in North America have had a substantial amount of subsidiary faulting (Bonilla, 1970). For thrust faults most of the crustal deformations and breaks on subsidiary faults occur on the upthrown block, with often no great disturbance to the ground surface occurring on the downthrown block, for example the 9 February, 1971 break on the San Fernando Fault (thrust) in southern California $(M=6 \cdot 4)$. Essentially no ground surface movement was measured on the downthrown block to the south of the main fault break, whereas there was considerable distortion and upheaval (more than $2 \mathrm{~m}$ ) on the upthrown block. Many small faults broke on the upthrown block, mainly concentrated within one kilometre of the main break (Fig. 32), but one break with $150 \mathrm{~mm}$ displacement occurred at a distance of about $2.5 \mathrm{~km}$ from the main fault break.

For normal faults, crustal distortion and breaks on subsidiary branch faults is generally concentrated on the downthrown block (Fig. 33). This is well illustrated by the experience of the 1959 earthquake near Hebgen Dam, discussed earlier. As shown in Fig. 5 there was large crustal settlement and many subsidiary faults on the downthrown block (to south of main fault breaks) for at least 10 miles $(16 \mathrm{~km})$ from the fault break. On the upthrown block north of the main faults, there was no subsidiary faulting and the ground surface went up only a few centimetres.

In areas of severe crustal distortion there have been experiences where structures founded on bedrock have been tilted by crustal strains, although no fault displacements were seen. In the September 1954 earthquake near Orléansville, Algeria $(M=6 \cdot 75)$, there was considerable vertical crustal deformation. Surveys showed that some rock tunnels were lifted by as much as $1.5 \mathrm{~m}$. The Ponteba Dam, about $4 \mathrm{~km}$ from the epicentre, a $20 \mathrm{~m}$ high concrete gravity dam with a length of $80 \mathrm{~m}$, was rotated vertically so that after the earthquake one end was $550 \mathrm{~mm}$ higher than the other (Thevenin, 1955). Apparently the dam remained tight on its bedrock foundation and the block of bedrock directly underneath tilted. To cause such sharp rotation of the bedrock, there must have been some movement on closely spaced minor faults. The dam itself was not severely damaged; the abutment blocks were cracked and spillway gates were twisted, could not be opened, and had to be removed by cutting them out.

A recent example of similar crustal distortion at a dam site occurred on the upthrown block during the break on the San Fernando (thrust) Fault, California, in February 1971. A new dam (Los Angeles Dam) is proposed to be built just upstream from the Lower San Fernando Dam, which has been badly damaged by the earthquake. Comparison of surveys on benchmarks before and after the earthquake showed that the bedrock comprising the left abutment of the proposed new dam was heaved up $0.55 \mathrm{~m}$ while the right abutment went up only $0.32 \mathrm{~m}$, for a tilt of $0.23 \mathrm{~m}$ in a horizontal distance of the order of $400 \mathrm{~m}$ (Yerkes et al., 1973).

Breaks on subsidiary faults have occurred at distances as great as $25 \mathrm{~km}$ from the main fault 
break; however, the further the distance from the main fault, the lesser the magnitude of the displacement. Bonilla (1970) has shown that displacements on branch and subsidiary faults located more than $3 \mathrm{~km}$ from the main fault break are generally less than $20 \%$ of the main fault displacement. Most breaks on branch and subsidiary faults have occurred along faults with previous histories of recent geological movement which could have been recognized as active faults.

Earthquakes do not, in general, seem to trigger one another around the world. There are some examples to show, however, that strong earthquakes originating on one fault have caused small displacements on other faults at considerable distances (other than on branch subsidiary faults). The 1968 Borego Mountain earthquake in California $(M=6 \cdot 4)$ triggered small displacements $(10-20 \mathrm{~mm})$ on three other independent faults at distances of 45,50 and $70 \mathrm{~km}$ from the causative fault (Allen et al., 1970). The small 'triggered' displacements occurred on faults that had been recognized as being active from independent geological evidence.

It is not known how often small displacements may be triggered on independent faults by strong earthquakes on the causative faults, or how often small fault movements occur in zones of strong crustal deformation. The above experience makes it necessary, however, to suspect that small adjustments could occur on the myriad of small faults in seismic areas. Fairly wide occurrence might be difficult to recognize, since small movements on minor faults and shears would be difficult to differentiate from the many superficial cracks which develop on the ground surface during strong earthquakes from other causes, such as slumping and incipient landslides. From the standpoint of dam design, these possible widespread small fault displacements are mainly of interest for concrete dams, where even a centimetre or two of differential movement at a critical location can be unacceptable.

\section{Amount of displacements and lengths of breaks}

Individual fault breaks during single earthquakes have ranged in length from less than a kilometre to several hundred kilometres.

The displacements have ranged from only a few millimetres to a maximum of the order of $10 \mathrm{~m}$. The largest fault displacement known during a single earthquake is about $11 \mathrm{~m}$, which was the vertical displacement on the Chedrang fault reported by Oldham (1899) at the time of the 1897 Assam earthquake $(M=8 \cdot 7)$. The largest corresponding horizontal displacement is $8.8 \mathrm{~m}$, measured at the Bogdo Fault after the great 1957 Mongolian earthquake $(M=8 \cdot 3)$ (Florensov and Solonenko, 1963). Still larger movements have been associated with regional deformation during large earthquakes, such as changes of elevation of more than $14 \mathrm{~m}$ at the 1899 Alaskan earthquake $(M=8 \cdot 5)$ (Tarr and Martin, 1912), but the maximum observed displacements across discrete fault lines are believed to be those above. There is no reason to think that they will not be exceeded as more intensive observations are made in the future, although the fact that earthquakes appear to have a maximum magnitude of about 8.9 implies that there is also an upper limit to the amount of fault displacement that is credible during a single earthquake.

A number of investigators have compiled statistics regarding fault breaks in historic time. Two of the more comprehensive compilations are given by Ambraseys (1969) and Bonilla (1970). For both of these compilations the investigators went back to the original records or literature, written by the man who actually studied the fault break in the field, in order to avoid errors introduced by second or third-hand reporting. Also, they included only records that they considered reliable. These compilations were made independently and include many of the same faults. The Ambraseys compilation contains 63 records between 1847 and 1967. Both compilations include faults occurring in all parts of the world (Table 2). 


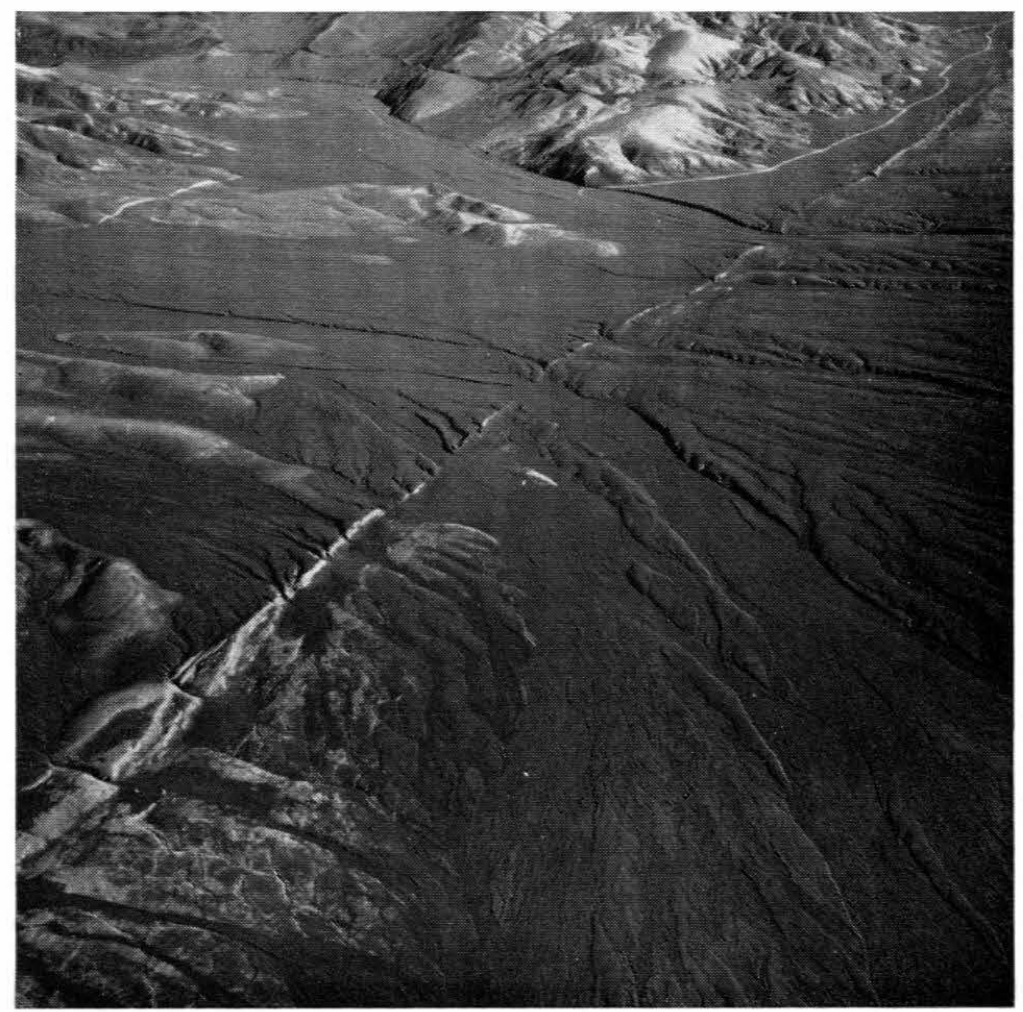

Photo: R. E. Wallace, U.S. Geological Survey

Fig. 29. Atacama Fault near Antofagasta, Chile. No historic breaks are recorded on this fault but geologic evidence that it has offset all but the youngest alluvium indicates conclusively that it is active 


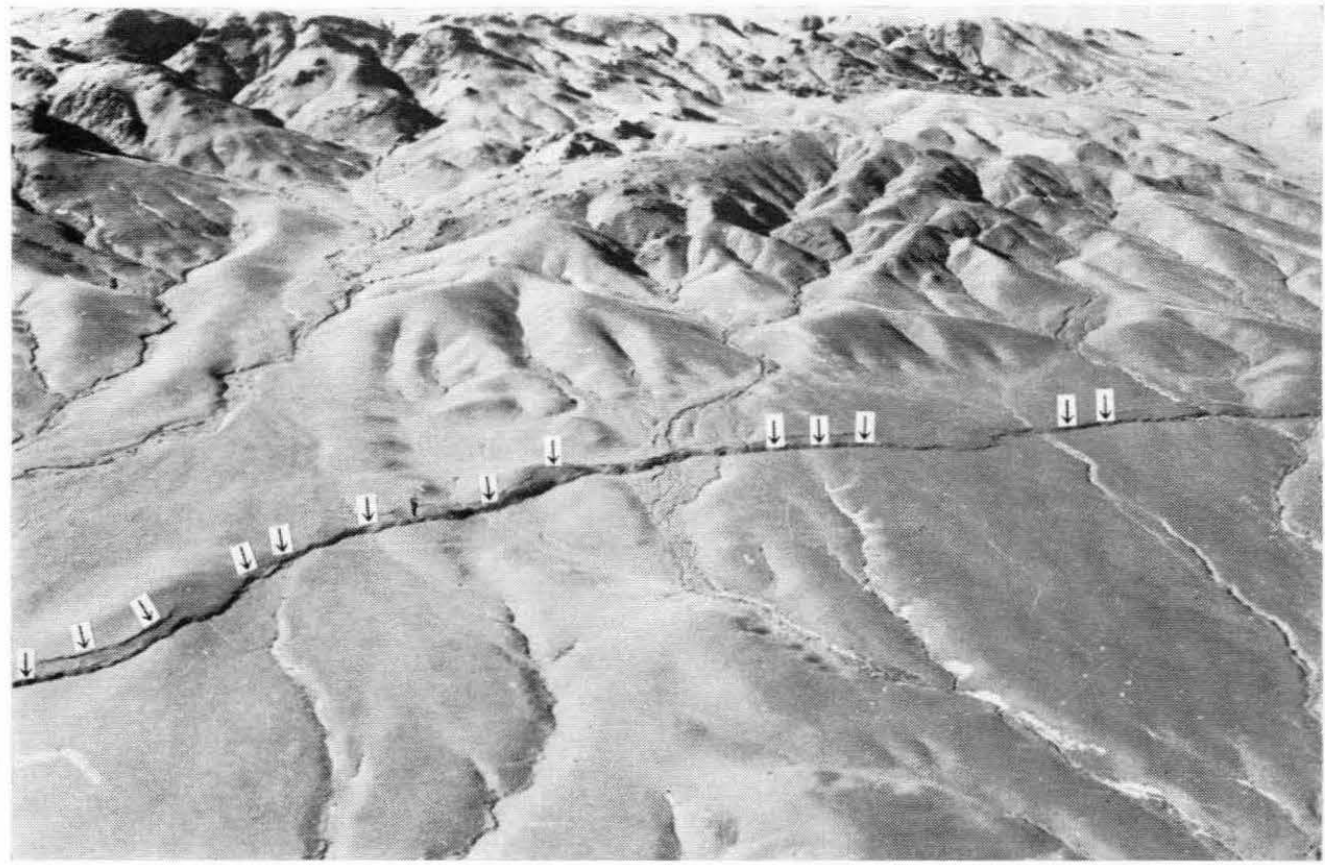

Photo: V. Solonenko

Fig. 30. Scarp (arrows) of 1957 Gobi-Altai earthquake $(M=8 \cdot 3)$ in Mongolia. Average fault break displacement in area of photograph was $5 \mathrm{~m}$ horizontal component and $5 \mathrm{~m}$ thrust component

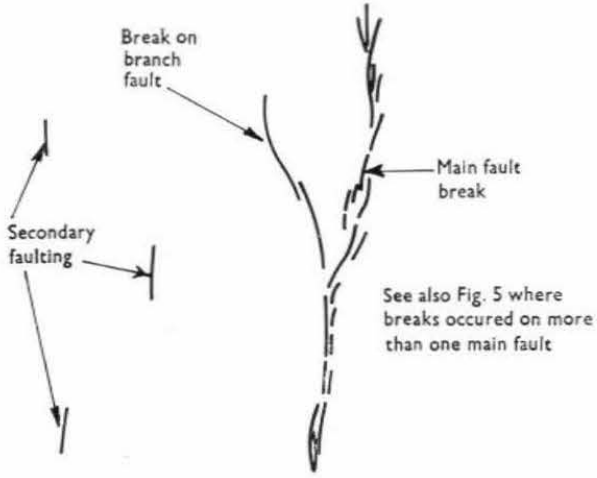

Fig. 31. Schematic relations among breaks on main, branch and secondary faults (after Bonilla, 1967) 


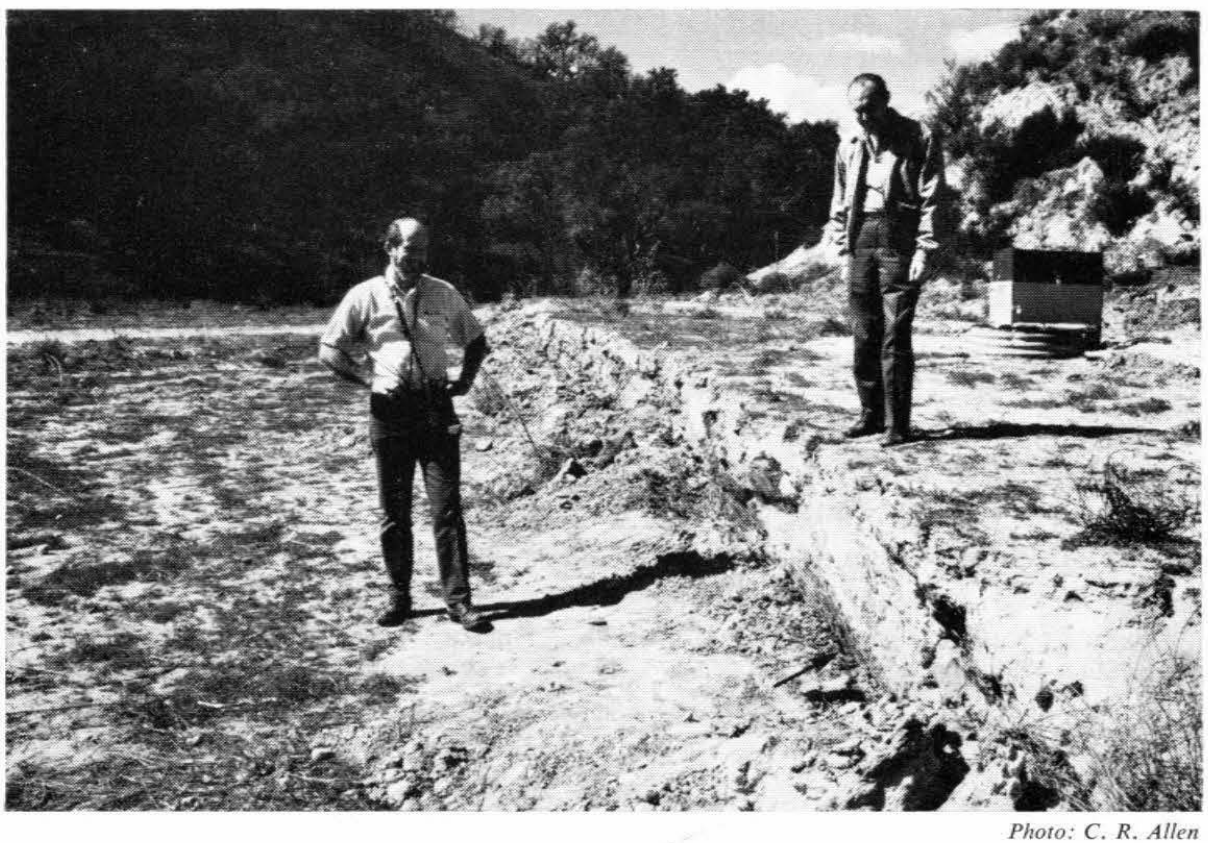

Fig. 32. Thrust fault that broke during 1971 San Fernando, California earthquake $(M=6 \cdot 4)$. This is a secondary fault in the upthrown block, about $1 \mathrm{~km}$ from main fault break. Fault plane dips about $60^{\circ}$ with the horizontal (black arrow in lower right hand corner)

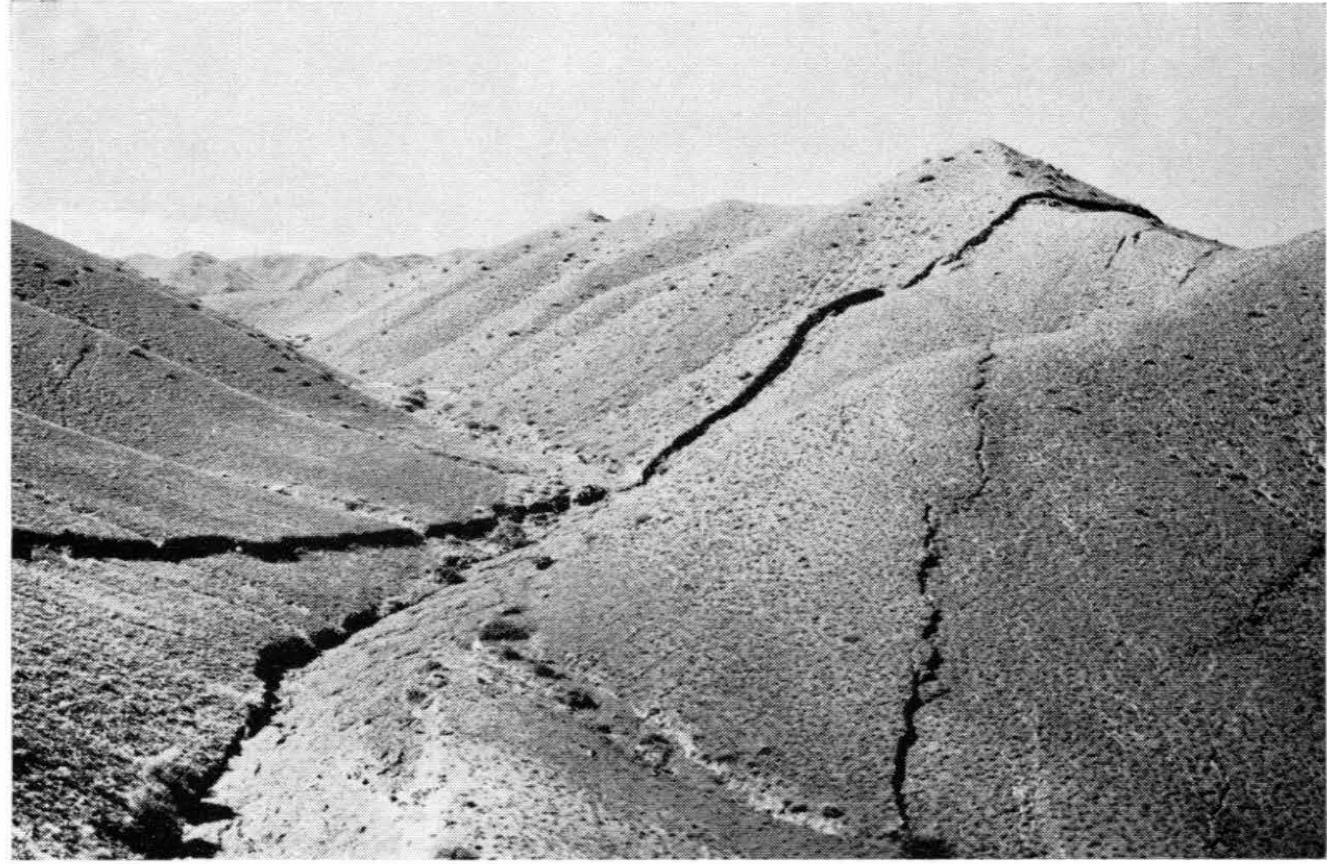

Photo: N. Florensov

Fig. 33. Break on a secondary normal fault with a displacement of about $1.0 \mathrm{~m}$ during the $1957 \mathrm{Gobi}-\mathrm{Altai}$ earthquake, Mongolia $(M=8 \cdot 3)$. Several branch faults are broken on the downthrown block 


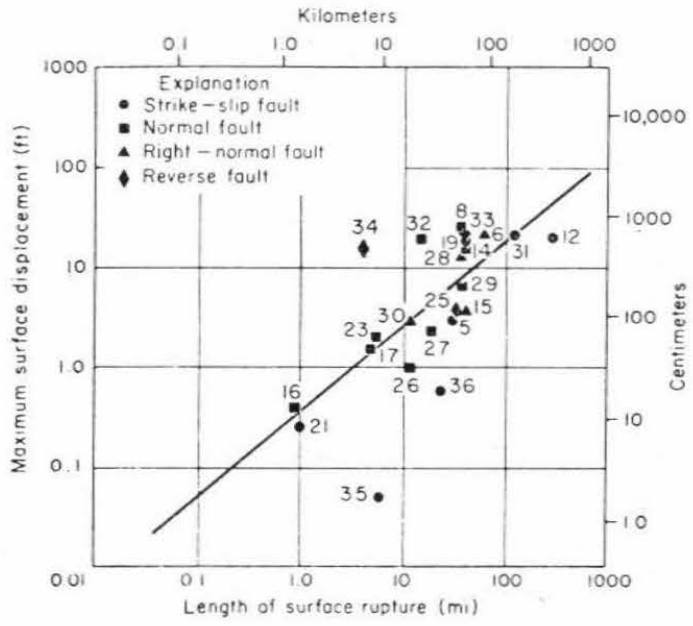

Fig. 34. Rough correlation between length of break and maximum relative displacement of ground on opposite sides (after Bonilla, 1970; numbers on chart refer to individual faults in the Bonilla tabulation)

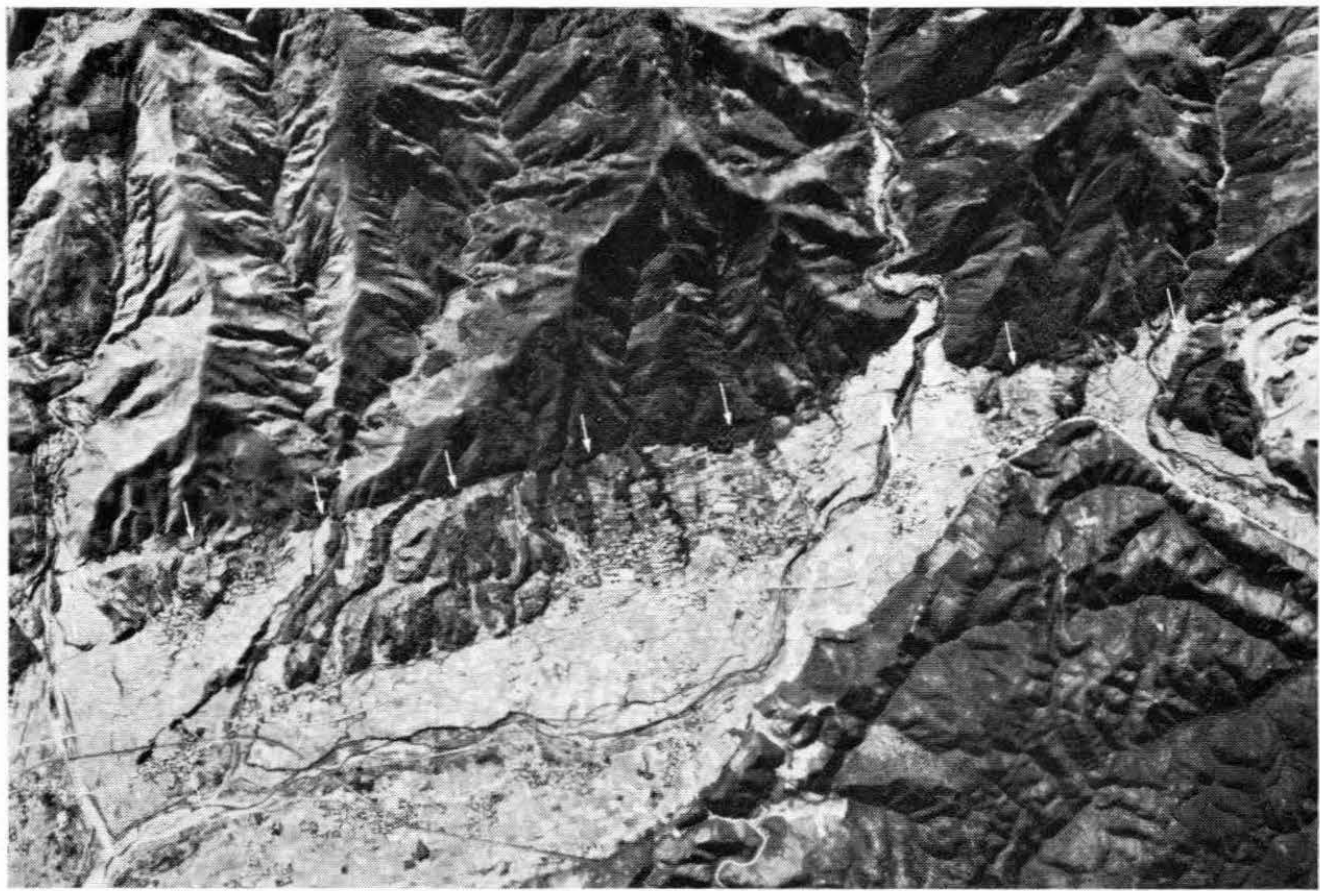

Photo: C. R. Allen

Fig. 35. $700 \mathrm{~km}$ long master fault near Niihama, Shikoku, Japan. No major historic earthquakes or fault breaks have occurred along this fault for at least 1500 years, and there is no indication from instrumental measurements that the fault is active, leading to considerable controversy over its potential hazard. Obviously the fault has broken in recent geologic time as indicated not only by the abrupt relief of mountain front (reflecting vertical displacement) but also cutting of very young stream terraces, as show at the point of the large arrow 
While there is some difference between the two compilations, it is seen that they show the same basic trend; that is, the smaller the fault displacement, the greater the number of observed fault breaks. Both the Ambraseys and Bonilla compilations contain a considerable total number of faults, for practical purposes including all the breaks for which reasonably reliable records are available.

Table 2 shows the maximum displacement measured on the main fault. The average displacement across the fault breaks was considerably less. In his study, Ambraseys (1969) made a rough attempt to study the distribution of the displacement along the break. For half the total number (27 of 54) of historic fault breaks included in his compilation, he found enough information given to make an estimate of the average displacement. The ratio of average to maximum displacement ranged roughly between 0.2 and 0.7 with an average of about 0.4 .

From these figures it is seen that for the great majority of fault breaks, the maximum displacement was less than 5 or $6 \mathrm{~m}$. The average displacement along the length was less than $50 \%$ of the maximum. These figures constitute one of the main sources of confidence that one can build safe embankment dams at sites with active faults. This is true because we are dealing with offset displacements generally of less than $3 \mathrm{~m}$ and there is a practical maximum value of the order of 7 to $8 \mathrm{~m}$. These are values for which a conservative embankment dam can be designed to withstand, simply because the critical zones in the dam can practically be made much larger than the fault offsets.

There is a rough relationship in observed historic fault breaks between the length of the fault break and the amount of the movement, and both are related to the magnitude of the earthquake produced. The longer fault breaks have the greater displacements and generate the larger earthquakes. The plots showing these relationships, prepared by Bonilla (1970), are used as a guide to judgement for the geologist in predicting the probable maximum displacement on a given fault (Fig. 34).

The length of the fault break during a particular earthquake generally is only a fraction of the length of the fault as it can be traced on the ground. The length of historic breaks in southern California has been shown to range between 20 and $50 \%$ of the length of fault system on which the earthquake occurred (Albee and Smith, 1966). Although this is a very rough and tenuous correlation, it is employed by geologists to guide the estimate of displacements which might occur on a given fault under investigation.

Table 2. Magnitudes of historic displacements

\begin{tabular}{c|c|c}
\hline $\begin{array}{c}\text { Maximum } \\
\text { displacement, } \\
\text { m }\end{array}$ & \multicolumn{2}{|c}{ Number of fault breaks } \\
\cline { 2 - 3 } & Bonilla & Ambraseys \\
\hline $1-1.00$ & 15 & 18 \\
$1.01-2.00$ & 16 & 13 \\
$2.01-3.00$ & 8 & 4 \\
$3.01-4.00$ & 8 & 7 \\
$4.01-5.00$ & 4 & 5 \\
$5.01-6.00$ & 4 & 2 \\
$6.01-7.00$ & 4 & 2 \\
$7.01-8.00$ & 1 & 1 \\
$8.01-9.01$ & 1 & 0 \\
$9.01-10.00$ & 1 & 0 \\
$10.01-11.00$ & 1 & 0 \\
$11.01-12.00$ & 0 & 1 \\
$12.01-13.00$ & 0 & 54 \\
\hline
\end{tabular}


Discrete fault displacements have now been recognized in association with earthquakes as small as magnitude 3.6, with displacements in the order of $1 \mathrm{~cm}$ (Brune and Allen, 1967), and more careful searches will undoubtedly uncover displacements associated with still smaller earthquakes in the future. Relatively continuous fault creep was first documented along the San Andreas fault in California by Steinbrugge and Zacher (1960), and it has now been recognized on a number of other faults including the North Anatolian Fault of Turkey (Ambraseys, 1970) (Fig. 20). Maximum reported slip rates are 1 to $2 \mathrm{~cm}$ per year. Creep may be uniform or spasmodic, and accelerated creep has been observed both before earthquakes (Allen and Smith, 1967) and after earthquakes (Smith and Wyss, 1968). It is a matter of some debate among geologists and geophysicists as to whether continuous creep on a fault is relieving strain that might otherwise build up to a large earthquake, or whether it is a manifestation of high strain that may be precursory to a large event. It is important to note, however, that all reported instances of creep are along fault traces that would be classified as active on the basis of other geological evidence.

\section{Time relationships (periodicity or frequency of fault breaks)}

Little helpful information is available to the dam engineer from historic records on this aspect of faulting. The time of record is too short.

On the master faults there can be little doubt that faulting has recurred thousands of times, and there probably is some cyclic average period. Geodetic measurements of crustal strain are providing general useful information in this regard. For example, in California it now appears that the land mass to the west of the San Andreas Fault is moving north with respect to the land east at a rate of about $3 \mathrm{~cm}$ per year. Assuming that all this strain is concentrated finally in periodic breaks on the San Andreas Fault, fault movements of 3 to $6 \mathrm{~m}$ could be anticipated at intervals of 100 to 200 years, which appears to be about the frequency being experienced.

For the breaks on lesser faults with a few exceptions no displacements have occurred in historic time and it is completely impossible to form any reliable estimate as to when the next break may occur (or when the previous prehistoric break occurred). There have been a few examples where geological studies of individual faults, utilizing carbon-14 dating techniques have shown that faults have moved several times displacing Holocene alluvium at intervals of the order of several hundred years. In several examples historic breaks have occurred on lesser faults which had been known to have broken previously in Holocene time (last 10000 years). Also, there have been a few examples, other than on master faults, where historic fault breaks have occurred twice at the same location (as described earlier).

One can conclude that some currently active faults, including the master faults, are breaking at intervals of the order of 50 to 200 years. On the other hand it seems quite probable that some active faults may move at much longer intervals, such as thousands or tens of thousands of years. This conclusion is speculative, but otherwise it would be difficult to account for the discrepancy between the relatively great number of active faults which can be recognized on the ground by geological evidence and the relatively smaller number of historic fault breaks.

From the standpoint of time there is one conclusion of considerable importance from study of historic events. Experience shows clearly that there are long periods (of 50 years or more) along certain sections of known active master faults where there is no earthquake activity which can be measured even with sensitive instruments (Allen et al., 1965). It is also known that in some areas very strong earthquakes have occurred at intervals of several hundred years, with periods of quiescence in between (Ambraseys, 1971). There are also faults with 
clear geological evidence of recent activity which have not broken or caused any earthquakes in many centuries of observation (see, particularly, Fig. 35). These observations indicate that neither the absence of instrumentally measured small earthquakes or the absence of felt earthquakes for several hundred years can in itself give assurance that a given fault is inactive.

A question of interest to the engineer is 'How long does it take for the fault break to occur at any given location?' Unfortunately there is little good evidence available on this subject, either from instrumental measurement or from direct observations. Obviously the break does not occur instantaneously or no buildings would remain standing (and there is no evidence that structures located very close to fault breaks are subjected to much greater acceleration forces than those located 1-2 km away). On the other hand, fault displacements must occur fairly abruptly, or high frequency seismic waves would not, therefore, be generated. Probably the principal fault displacement during large earthquakes takes place over a period of a few seconds to tens of seconds. In many cases only a part of the surface displacement occurs immediately during the earthquake and a second part occurs as a 'rapid creep' minutes, hours, days (or even months) after the earthquake.

\section{GEOLOGICAL STUDIES OF FAULT ACTIVITY}

\section{General}

Evaluation of potential fault activity is too large a subject for complete or extensive treatment here. Some main aspects are described with emphasis on recent practice.

For every dam where the potential activity of a fault in the foundation is being studied, generally the geologist is also studying the seismic activity of the area to form an opinion on the probable earthquake shaking to which the site may be subjected. For this latter purpose he must locate all the active faults in the area, even though they do not pass through the dam foundation. Large landslides during earthquakes along active faults are common, primarily due to the shattered condition of the rock along the faults. Hence, evaluation of possible damaging landslides also requires investigation of active faults. The same general study is made for all three purposes.

Most of the reliable evidence for evaluating fault activity comes from geological investigations. Important peripheral assistance in some cases is given by studies of locations of historic earthquakes and by instrumental measurements of small earthquakes and geodetic measurements of creep and crustal strain, but detailed geological surface evidence that there has or has not been fault displacement in recent geological time is the primary investigative tool.

Largely because of the increasing emphasis in recent years on the safety of nuclear power plants and large dams, there has been a great increase in the number of fault studies which have been made, and the effort spent on them. While no large technical breakthroughs have been made, accumulated knowledge concerning techniques for evaluating faults, and knowledge as to what can and cannot be done by extensive and detailed geological studies, is increasing rapidly. In earthquake regions, geologists are specializing and devoting their practice exclusively to the field of earthquake activity and seismic geology ('seismotectonics'), a subject which previously received the attention of only a relatively few scientists.

One important result of the recent concentration of study in this field has been to demonstrate that when a fault has been thoroughly and competently investigated, geologic evidence can usually be found suggesting whether it should be considered active or not. The Authors' experience indicates that it is the exceptional case for which no evidence can be found to render any judgement. This conclusion could only be reached after a considerable number of extensive fault investigations had been made, and would have have been necessarily anticipated on 
the basis of the knowledge available only a few years ago (e.g., before 1970). An active fault with recurrent displacements must have an appreciable influence on the surface geology and topography, and it would not be expected that all evidence could be completely obliterated by the weathering and erosional processes.

\section{Nature of fault investigations}

Geological fault evaluation is based on the assumptions that a fault is likely to break if it has broken in the recent geological past and is not likely to move if it can be shown that it has not moved in a very long time. The date of last displacement is estimated from stratigraphic and geomorphic relations. The time since last fault displacement must be less than the age of the youngest faulted rock (or soil) and greater than the age of the oldest unfaulted rock which lies across the fault. Estimates of the probable type, amount and location of movement are guided evidence from past geological movements.

In the geological study, the first problem is to determine whether or not there is a fault crossing the proposed dam site. This may or may not be easily established during preliminary investigations of the site geology. Once the existence of one or more faults is demonstrated, study of potential activity is commenced. In a few cases, there may be geological evidence near the site which can be seen in test pits, such as the example of the Cedar Springs Dam described earlier. More commonly, a much more extensive investigation is required in order to find sufficient evidence to render a judgement. Even in a circumstance such as that at Cedar Springs Dam, where observations in the test pits at the site showed the faults are active, a more extensive investigation is desirable to evaluate the length of the faults and their relationship to the regional geological framework in order to assess maximum fault displacement (and credible earthquake).

The investigations are usually carried out in two phases. The first phase is directed towards: obtaining information on the geology, regional tectonics and seismicity of the general region, perhaps within a radius of as much as $200-300 \mathrm{~km}$; delineating major through-going structural trends that may be close enough to affect the site, assuming that the investigation is also being directed toward evaluation of the earthquake shaking potential; assembling information of all features detected from aerial photographs and other types of imagery which might represent active faults that are close enough to the dam to be of concern; planning and preparing for the detailed field study. A comprehensive review of pertinent published and unpublished literature is made during the first phase of the study. An aerial reconnaissance by the geologist in a low-flying aeroplane or helicopter is usually helpful. From the first phase it should be hopefully possible to trace suspected faults in both directions to considerable distances from the dam site, and to locate branches and related faults.

The second phase includes detailed geological mapping. Study is made of all locations where the faults can be recognized on the ground. Special aerial photographs may be obtained to assist the work. In addition to detailed surface geological studies, supplementary investigations are employed including test trenches and age dating and sometimes geophysical studies. The type of fault (strike-slip, thrust, or normal) is determined from general study of the geological features and surface evidence.

The most readily obtainable evidence for fault activity comes from surface manifestations of movement which have not yet been obliterated. Some of the more common surface features identifying active faults are

(a) scarps from previous displacements which are not obliterated by surface erosion or buried by younger deposition (Fig. 35) 
(b) off-set streams and ridge lines

(c) closed depressions (sag ponds)

(d) faults which act as groundwater barriers and have a higher water table on one side, and sometimes lines of springs

(e) lineaments of vegetation resulting from different depths to water tables on opposite sides of a fault

$(f)$ lines of landslides

$(g)$ displaced alluvial terraces.

Most of these surface features, which are usually first identified on air photos, can also have other geological origins. For example, outcrops of hard rock beds can create linear ridges very similar in appearance to fault scarps, but the difference can be readily determined from field studies. Similarly, closed depressions and ponds are sometimes created along lineaments by limestone solution. Except for limestone solution, however, there are very few actions of nature except recurrently moving faults which create closed surface depressions more rapidly than they are filled in by deposition (Fig. 36). Closed depressions are very common on active strike-slip and normal faults, and occasionally are found along thrust faults.

Groundwater barriers in alluvium are a peculiar phenomenon of active faults. For reasons not well understood faults passing through alluvium commonly become less pervious than the adjacent alluvium by inclusion of soil fines. The resultant higher ground water table on one side of the fault commonly causes a different type of vegetation. Occasionally lines of trees grow along the line of the fault, perhaps because of the different soil along the fault as well as the higher ground water. Figure 37 shows an example (taken about 25 years after the last displacement) of an active fault trace in recent river alluvium identified both because it is a groundwater barrier and because a trace of scarp remains.

\section{Studies needed over a large area}

Evidence for the last time of movement on an active fault commonly exists only at certain places along its length. Hence, conditions existing at any given small area along the length of a fault, such as in the immediate vicinity of a dam site, will rarely provide conclusive evidence. Studies must be carried considerable distances beyond the dam, along the trends of the main faults of interest. The degree of confidence with which conclusions can be drawn on a given site depends greatly on the amount of effort spent in the studies, and the distance from the dam site to which the investigations are carried. Examination of photographs and field investigations of points of interest along the faults may be required to a distance of more than $100 \mathrm{~km}$ from the dam site.

A common problem is the fault which runs down the valley through the dam site, under the river alluvium. As the river alluvium may be removed each year at flood, all surface evidence of recent fault displacement is obliterated. The evaluation of such a fault can usually only be made at locations away from the dam where the fault leaves the river valley, which may be at some distance from the dam site.

Drainage divides, where the fault trace passes from one stream system to another, should be scrutinized carefully; geomorphic features of recent faulting are likely to be particularly well preserved at such localities (e.g., Fig. 23).

In past practice, many dams with foundation faults in earthquake regions have been designed with no detailed geological study having been carried out beyond the immediate vicinity of the dam site. This should no longer be considered acceptable practice at sites where there is any question about the fault activity. 


\section{Aerial photographs and 'low sun-angle' photography}

Aerial photographs are an essential part of fault investigations; fault features can be seen on them which could not be found by ground studies. Faults appear as lineaments, reflecting various different physical conditions created by faulting (such as disruptions of the normal ground surface along the lines of previous breaks, different soils on opposite sides, different depths of water tables on opposite sides creating different vegetation, lines of landslides along the upthrown block of thrust faults, offset talus deposits, etc.). For some strike-slip master faults, the line of the fault can be easily and immediately identified (Figs 18, 22 and 29). At the other extreme, for some active faults, the surface features seen on the aerial photographs may be so small and relatively insignificant that they can only be recognized as a 'suspicious' feature by a man with considerable experience in aerial photograph fault studies.

In any event, it is emphasized that air photos are a critical tool for the geologist in the study and recognition of active faults. If for any reason, systematic aerial coverage cannot be made available, the geologist cannot normally make a competent evaluation of the problem, any more than the engineer can design the dam without exploration of the foundation.

Because there is a large element of experience and judgement in aerial photograph interpretation, and particularly for interpretation of recent fault activity, photographs of any kind should be studied independently by at least two experienced men on the team.

Until the last few years, ordinary black and white photographs have been used. Much of the entire world has been photographed by the United States Army Map Service at scales generally of 1:30000 to 1:60000. For many countries these photographs are available from local government agencies, or they can be obtained in Washington DC, with permission of the local government. These types of photographs are especially good for preliminary regional investigations and should be obtained wherever possible, because a large area is covered with a few photographs. For detailed studies, scales of 1:12 000 to 1:20000 are preferable. For stereoscopic viewing, which is absolutely necessary, $60 \%$ overlap is standard practice. Ability to interpret the photograph is dependent to some degree on the quality of the photography but to a larger degree on the quality of printing. Specifically, a recently developed printing process called 'electronic dodging' is more economical but does not provide suitable photographs for geological interpretation. Orders for prints should specify maximum contrast and specifically prohibit the use of electronic dodging.

Ordinary aerial photographs have usually been taken during the middle of the day. Starting about 1967, a research programme was carried out jointly by the University of Nevada Department of Geology and one of the Authors (L. S. Cluff) in which new photographic techniques were developed for the special purpose of studying active faults. This technique, called 'low sun angle' aerial photography utilizes photographs taken at different times of the day (and sometimes in different parts of the year), depending on the fault trend and the position of the sun (Slemmons, 1969; Cluff and Slemmons, 1972). The technique is an extension of a widely used practice among geologists in which early morning and late afternoon field observations were long known to be often superior. The purpose is to enhance shadows from fault scarps and other subdued ground surface irregularities characteristic of active fault zones. The optimum condition obtains when the sun is shining nearly perpendicularly to the trend of the fault, in the direction from the upthrown side towards the downthrown side and when the sun angle is low enough for the scarps to cast a shadow but not so low as to put large parts of the whole area in shadow.

Figures 38 and 39 illustrate the effectiveness of low sun angle photography during studies of the major active (normal) fault which bounds the west edge of the Wasatch Mountains, at a 


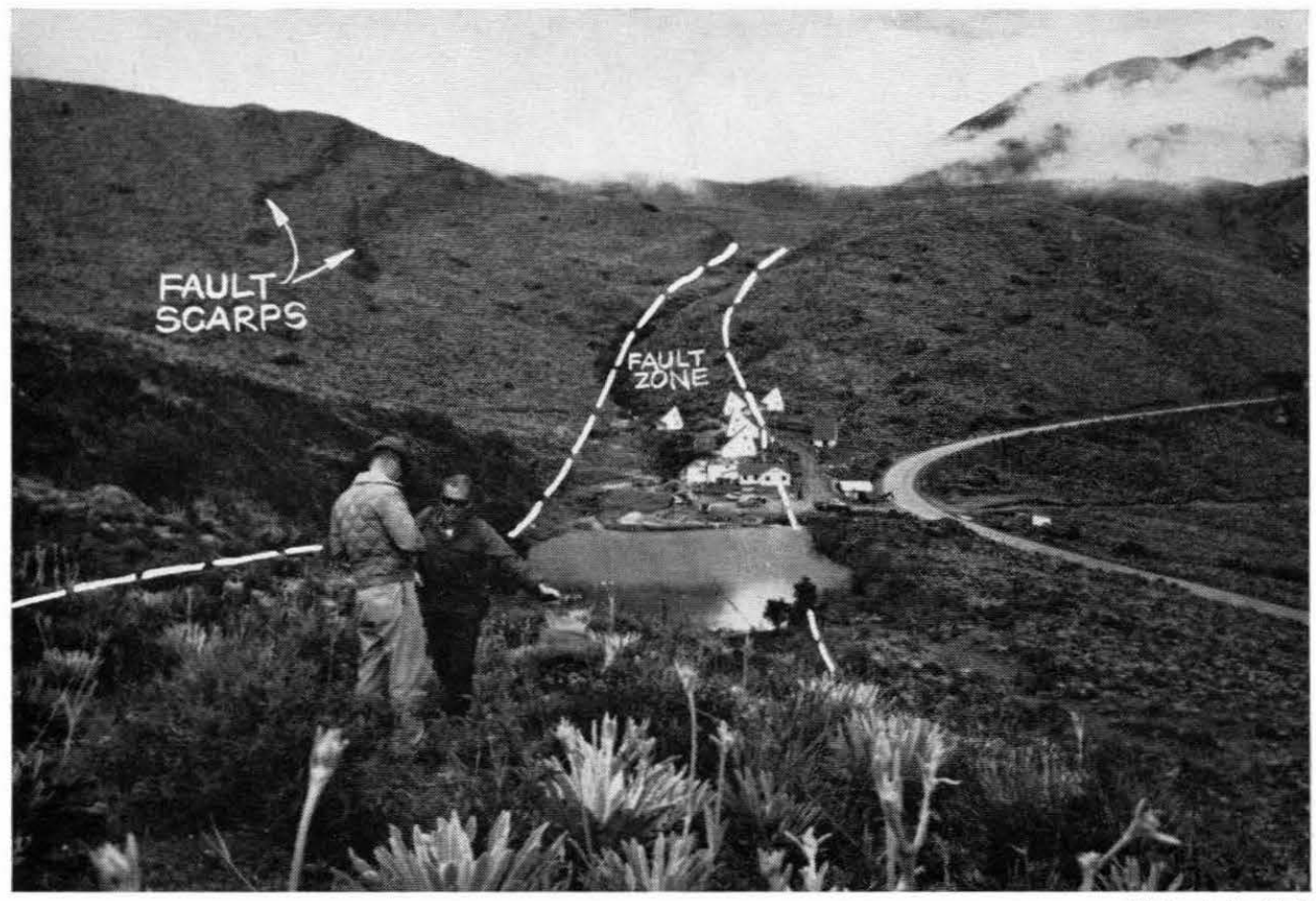

Photo: L. S. Cluff

Fig. 36. A typical sag pond in closed depression along the Boconó Fault in Venezuela, a 'master' (strike-slip) active fault. Note ancient scarps of breaks on secondary faults on hillside to left of main fault trace. Note also notch in ridge line in far distance, a common manifestation of highly active faults 


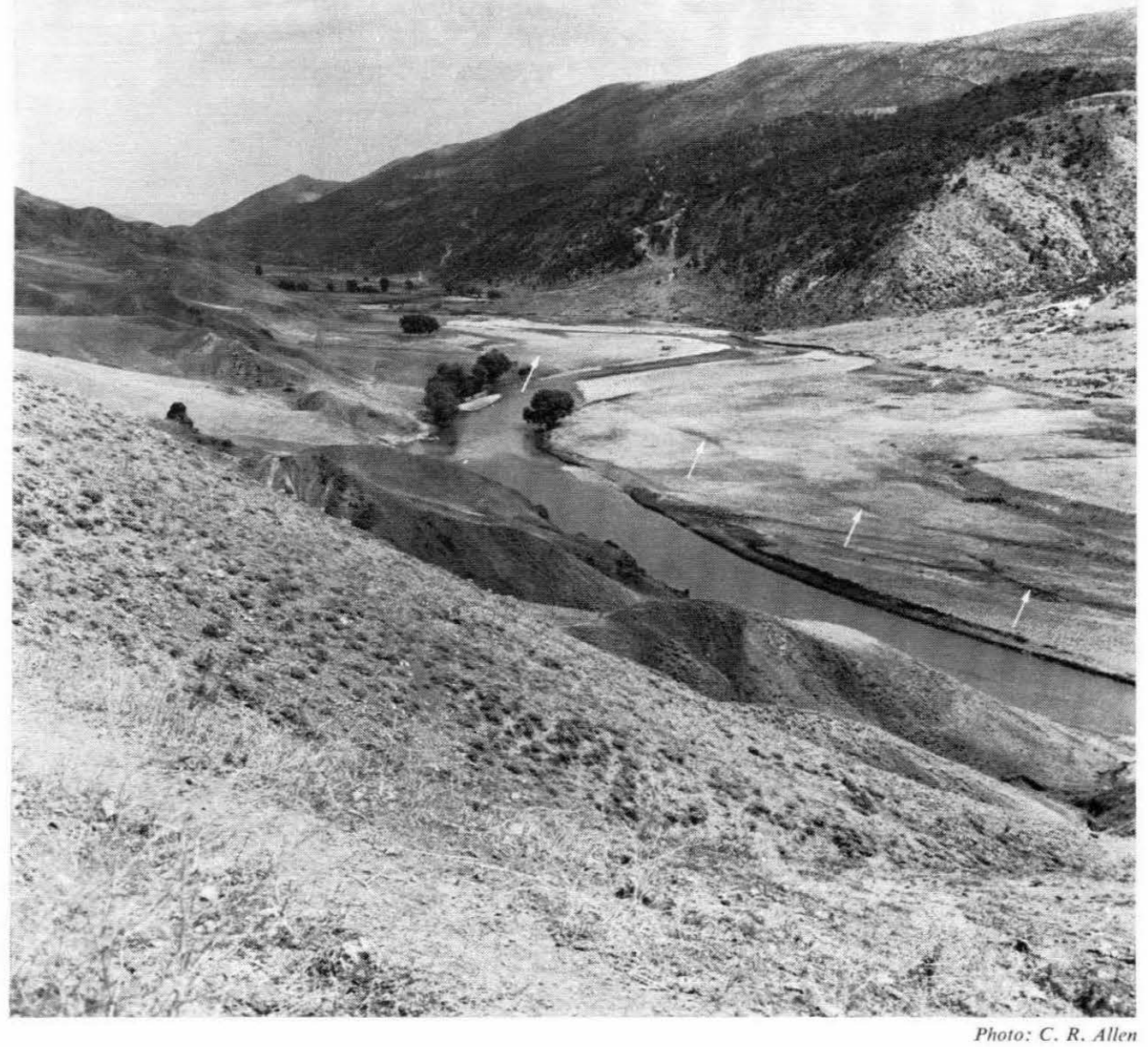

Fig. 37. Major river valley eroded along an active strike-slip fault, typical situation at many dam sites: Soganli River Canyon, Turkey, following the North Anatolian Fault. The four white arrows indicate the remnant of the last fault break during the 1944 Bolu earthquake $(M=7 \cdot 6)$. The photograph was taken 25 years after the last fault break. The fault is recognizable because of a subtle scarp which remains in the flood plain and the fact that the fault passing up through the river alluvium is evidently acting as a groundwater barrier. The last movement on the fault was predominantly strike-slip and about $1.5 \mathrm{~m}$ 


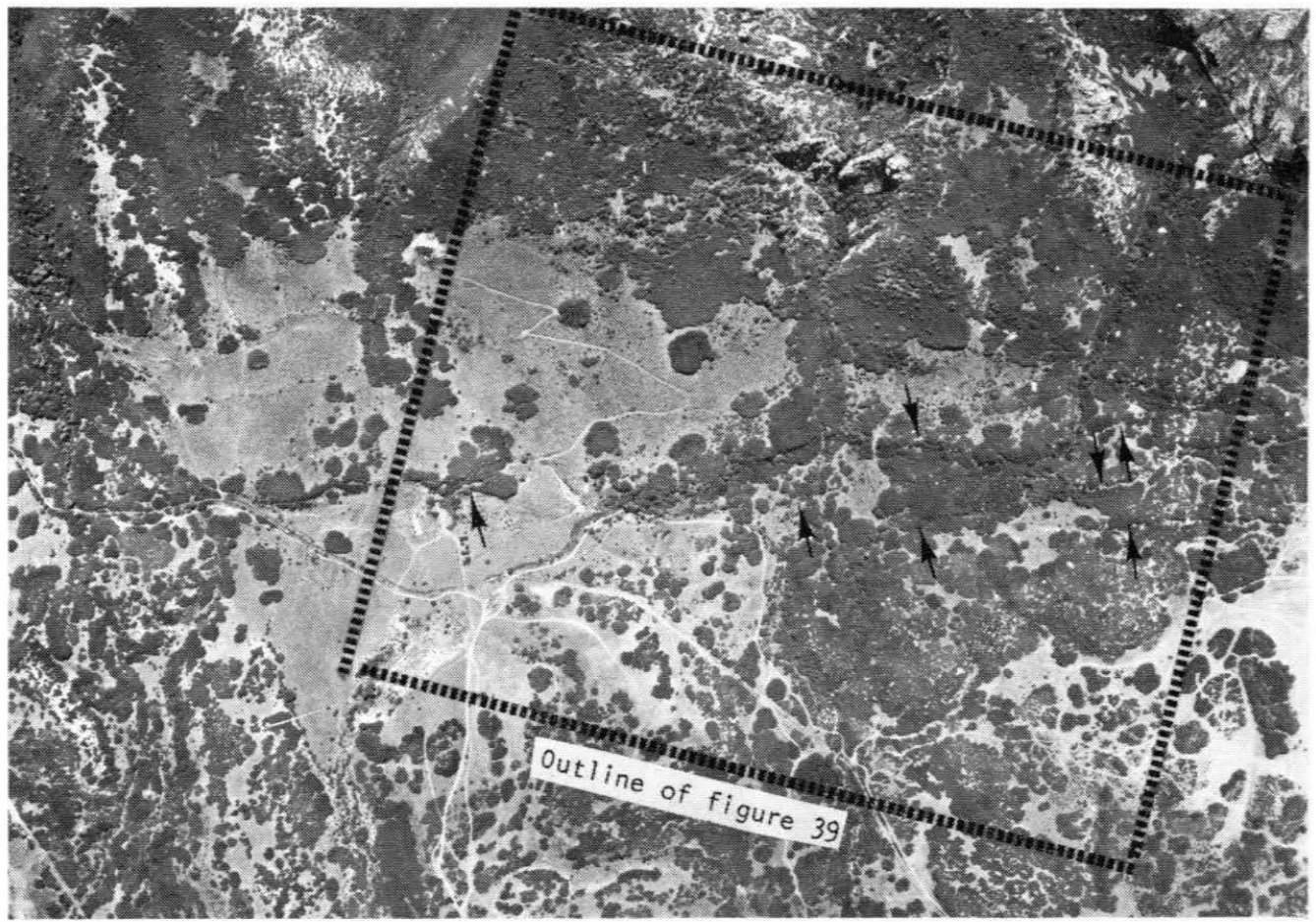

Fig. 38. Conventional air photograph showing a section of the main Wasatch Fault in central Utah, a 'master' normal fault which has not broken in historic time but is obviously active from much geologic evidence. The fault is shown by the black arrows (after Cluff and Slemmons, 1972) 


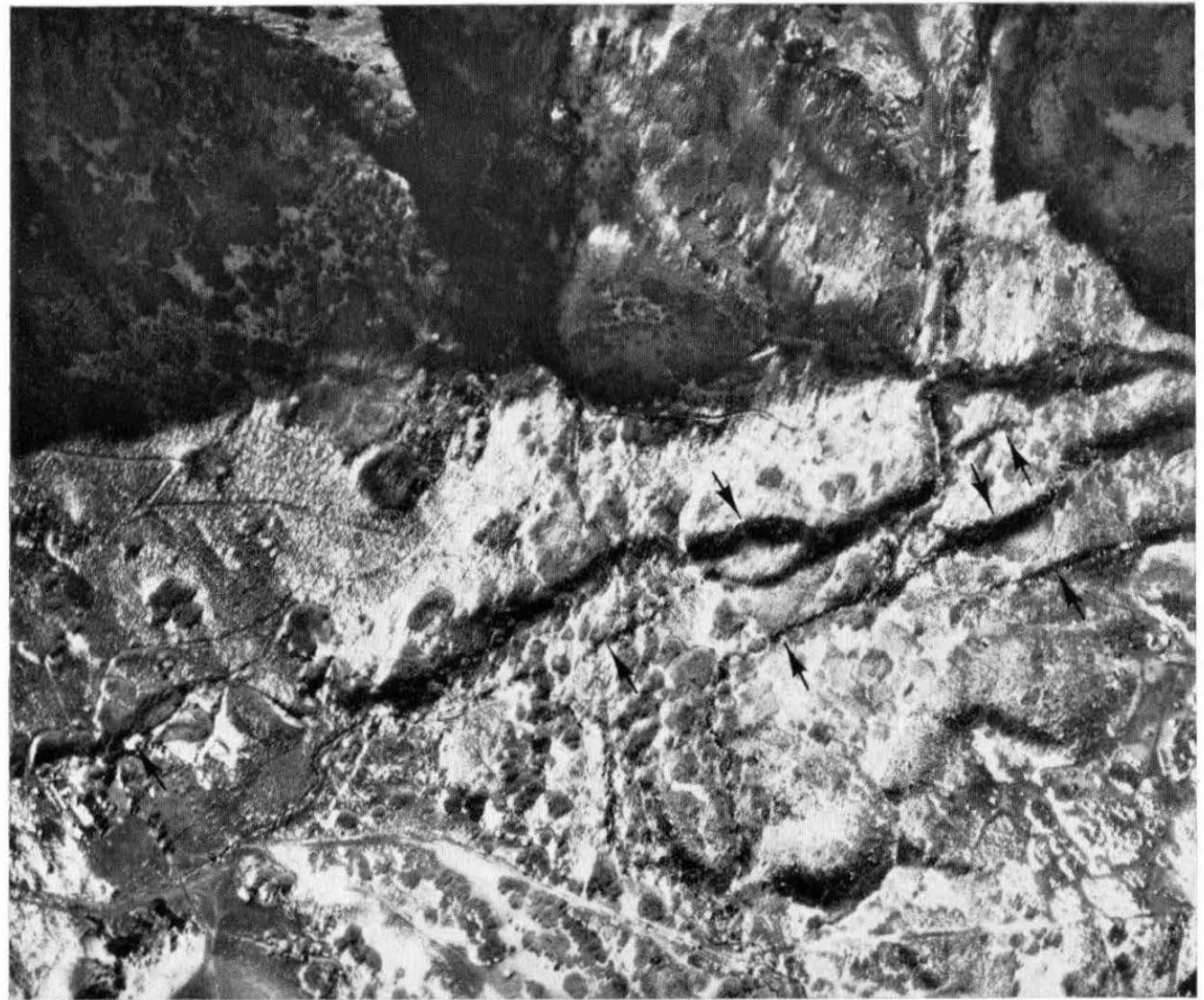

Fig. 39. A low-sun-angle photograph of the area included in the central square of Fig. 38, with the arrows in the same locations, showing how much more clearly the fault scarp can be seen (after Cluff and Slemmons, 1972)

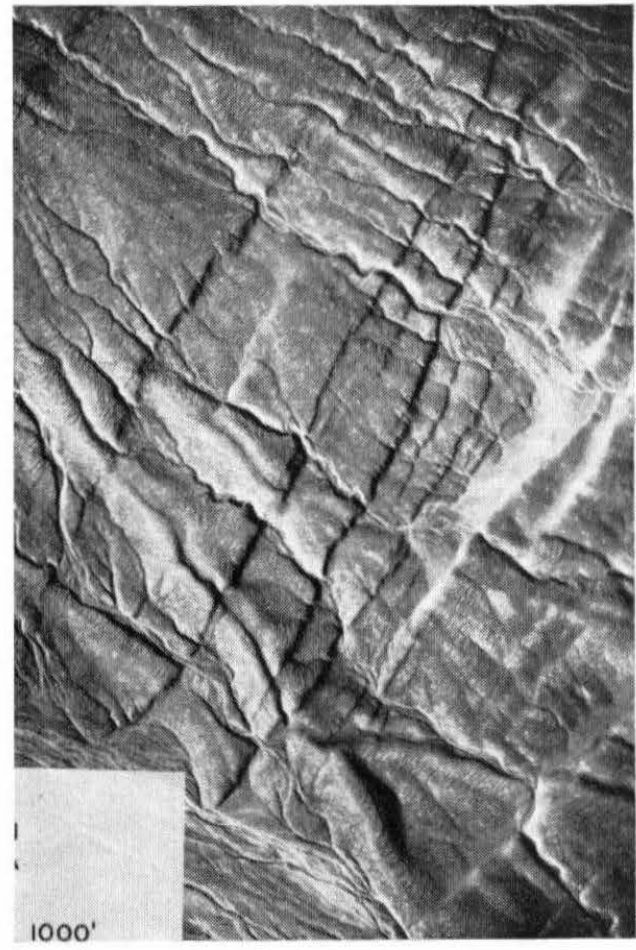

Photo: G. E. Brogan

Fig. 40. Series of parallel active faults, Fish Lake Valley, California, about $500-1500 \mathrm{ft}$ apart, showing the use of low-sun-angle photography. Some of these fault scarps are less than $50 \mathrm{~cm}$ high and would not be seen in photographs taken at midday . 
site near Salt Lake City, Utah. Fig. 38 is a conventional vertical photograph of a section of the fault. Fig. 39 is a vertical photograph of the area outlined in Fig. 38 . Fig. 38 was taken at approximately midday. Fig. 39 was taken at approximately $09.00 \mathrm{~h}$, catching longer shadows. The example of Figs 38 and 39 is not extreme. In some cases, ordinary photographs may show almost no evidence, whereas the faults stand out clearly on low sun angle photographs (Fig. 40).

Low sun angle photography has proved very helpful and has been employed successfully during the last few years by the Authors for fault studies in many projects in the western United States, Alaska, Venezuela, Peru, Chile, Italy and Iran. The value of the procedure is so well demonstrated by these experiences that it is clear that the method should be used as a routine investigatory tool. In future studies all photographs taken for fault investigations should be at low sun angle. The most universally useful scale is about 1:12000;1:6000 and 1:3000 scales are good for detailed analyses.

Other types of photograph which are occasionally helpful include infrared and colour film, and images which are now available commercially from satellites (ERTS), high altitude aircraft (NASA), and sidelooking airborne radar (SLAR). The Authors have utilized all these extensively on recent projects and have general opinions as follows.

By far the most useful type of photograph is the black and white low sun angle vertical photograph which chould be the standard procedure for this work.

The infrared photograph occasionally gives a better indication of differences in groundwater level, or vegetation changes, on opposite sides of the fault, but rarely have infrared photographs provided much additional information that was not also available from black and white low sun angle ones. Low sun angle photography is not yet widely used in the profession. Some colleagues have suggested that infrared photographs are superior to black and white photographs of any kind. The Authors' experience shows the opposite. Comparisons of low sun angle black and white photographs with infrared photographs for several active faults have led to the conclusion that the low sun angle photographs are almost always superior for the purpose.

Sidelooking airborne radar (SLAR), which has only recently become commercially available, has a considerable advantage in that $(a)$ it can be obtained in virtually all weather conditions; (b) the direction and depths of 'shadows' can be controlled by the flight patterns; $(c)$ it reduces the contrast between different types of vegetation, thus representing the ground surface more clearly. Coverage by SLAR is considerably more expensive than ordinary photos. Even in the last year or two (1974-74), there have been large improvements in SLAR imagery; however, it is currently available only at a scale of $1: 250000$, and enlargements are fuzzy and of limited usefulness. Hence, for current applications SLAR has value only for preliminary regional study. It is probable that recent military technical developments, not yet available commercially, will allow clear imagery at scale of 1:5000. Consequently, it can be expected that SLAR imagery will be more valuable for fault studies in future, particularly in areas of heavy vegetation (rain forests) where ordinary photographs may not be very helpful.

Colour photographs are superior to black and white photographs taken at midday and should be used wherever they are already available. Where colour photographs are not available and where photographs must be taken for the purpose of a given fault study, the Authors recommend low sun angle, black and white photographs, which are much superior to colour photographs taken at midday. Colour photography cannot be employed for low sun angle photography as it is necessary to take colour photographs near midday.

ERTS and NASA photographs can be very useful for preliminary regional studies, for identifying the problems which need more careful evaluation with low sun angle photography. 
They are not imperative, but as they are available it is desirable to use them for preliminary studies, especially in areas where good regional geological maps are not available.

Photographs for study of faults do not have to be taken with the precision required for aerial photographs used for making topographic maps. For photographs intended only for geological evaluation, the Authors have found that it is much less costly and technically preferable to lease an aircraft with pilot, photographer and camera hourly and to have the photographs taken at the direction of the geologist who accompanies the flight. Usually a reconnaissance flight is made first without taking photographs. Subsequently a flight plan is drawn up and plotted on a map for the pilot to follow and the best time chosen for low sun angle photographs. During the flight the geologist directs all activities and he may change the order of flying to improve the photographs as guided by his observation of the shadow projection. After a short time the geologist learns to operate the common cameras and much of the work is done with no photographer. Although there has been some resistance to this practice among the air photo companies, it has now become the Authors' common practice. It gives much greater flexibility in taking photos at the proper sun angle and a large cost difference.

\section{Test trenches}

A main lesson learned from the recent concentration of study in this field is that test trenches across suspected fault lines are absolutely necessary parts of routine modern investigations. In the last few years, trenching has been used with increasing frequency. Commonly there may be no surface evidence in the vicinity of the test trench but examination of the geological profile in the test trench walls may clearly indicate whether the fault is active or inactive, as in the case of Cedar Springs dam.

The main purpose of the trenches is to determine whether surface deposits lying across the fault are displaced or not. The trenches also provide opportunities to obtain samples of carbonaceous material which can be radiometrically dated. It is not usually necessary to excavate very deep; trenches $2-4 \mathrm{~m}$ deep have commonly been adequate

Interpretation of evidence in the test pit walls requires some specialized experience and observation techniques. The trench walls must be cleaned carefully with hand labour using shovels to remove disturbed material. Brushes and scrapers of various kinds are used for final cleaning to allow examination of minute details.

It is not uncommon in the walls of test trenches for clear evidence of several recurrent fault displacements to be exposed, as indicated by the fact that deeper, older deposits are offset greater amounts by the fault than the younger surface deposits. For example, in a current investigation in Nicaragua, not considered unusual, evidence has been found in a number of test trenches that surface deposits less than 10000 years old have been displaced 2-5 times by faulting at different times. Similar situations have been the subject of several careful scientific investigations. An example is the study by Clark et al. (1972) of the Coyote Creek Fault (southern California) in which analysis of evidence seen in the walls of test trenches indicates recurrent displacements of recent geological surface deposits at intervals of 150-200 years during the past 3000 years (Fig. 41).

The appearance of the fault gouge (clay-rich sheared material in the fault zone) as exposed in the test trenches may be important in forming an opinion regarding the erosion potential through the dam foundation along the fault. The apparent 'freshness' of the fault gouge cannot be used as reliable evidence of fault activity. Fault gouge below the depth of greatest surface weathering frequently has the pasty and unweathered appearance of freshly ground and crushed rock even in faults that have not moved for many millions of years. 

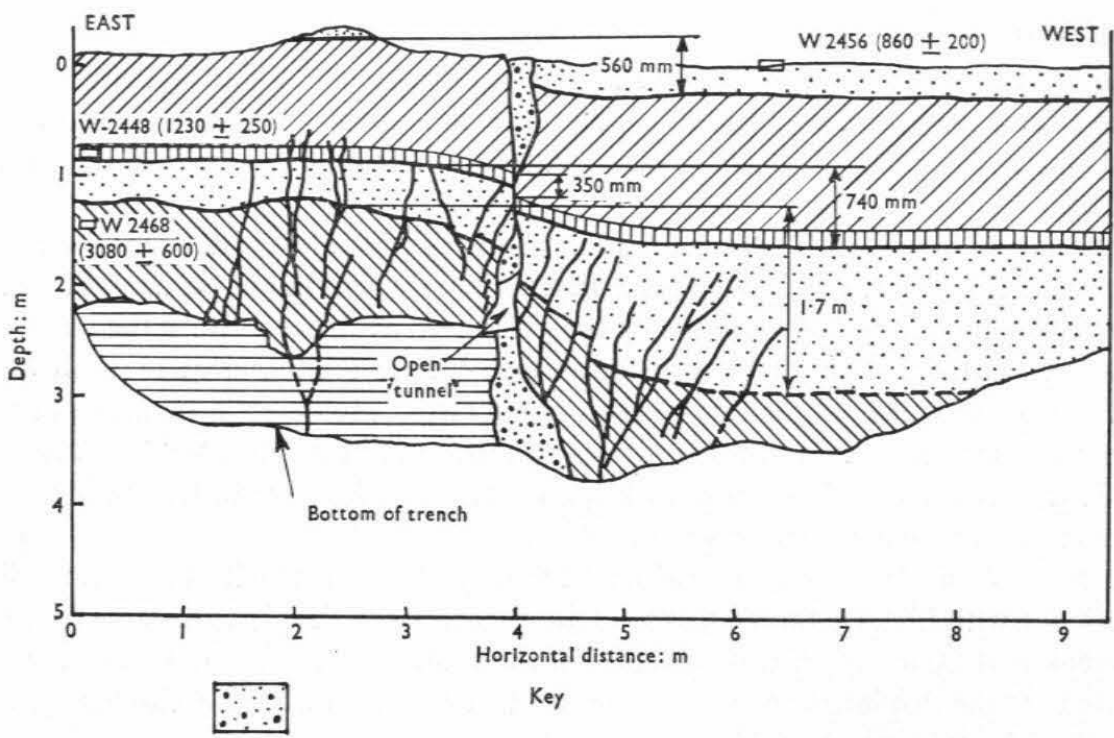

Clay, silt and sand filling fracture

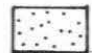

Layer A

White shelly calcareous silt

Youngest deposit of Lake Cahuilla

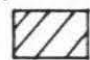

Massive light-brown clay and clay silt containing scattered mollusks and thin lime-rich layers
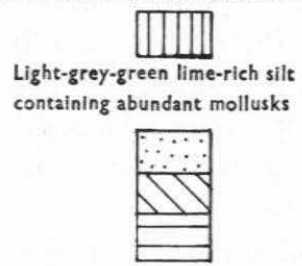

Laminated, crossbedded, or massive clay, silt and sand locally containing pebble lenses

Mollusks scattered throughout

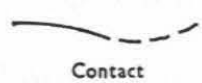

Dashed where approximately located

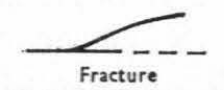

Dashed where inferred

$W-2448(1230 \pm 250)$

Radiometrically dated sampie (see table 14)

Numbers in parentheses indicate $\mathrm{C}^{14}$

age, in years before present

Fig. 41. Diagram from Clark et al. (1972) showing wall of trench excavated across one branch of the fault causing the 1968 Borrego Mountain earthquake in California $(M=6.4)$. The 1968 earthquake is represented by the small displacement of the ground surface, and deeper and older strata (note carbon-14 ages) are offset by progressive amounts. The relationship suggests that earthquakes of effective magnitude of the 1968 event have occurred about once every 200 years for the past 3000 years

Even for major active faults the width of the sheared zone in test trench walls created by the last fault movements through very recent surface deposits, may be very narrow, $10-20 \mathrm{~mm}$ or less.

The direction of slickensides and shearing striations in fault gouge can be misleading when used to predict the direction of fault movement. Near the ground surface there is tendency for the gouge to be squeezed upward in the direction of least resistance regardless of the direction of displacement of the fault. 


\section{Estimating fault displacement}

The geologist can estimate the probable amount of displacement during the next break on a given active fault in several ways, such as from previous displacements as seen in test trench walls or as estimated from displaced surface features, or from the statistical data for historic fault breaks.

It is particularly important to trace the fault as far as possible and to estimate its probable length, in order to guide the estimate of the displacement which might occur. This estimate is finally made based on judgement guided by the geological evidence. Both the length and type of fault are considered. On strike-slip faults many tens of kilometres of fault break often occur with displacement not much more than one metre. However, a thrust fault with a ten kilometre break may have two to three metres of surface fault displacement. As an example, in the 1971 San Fernando, California earthquake, the length of break was only about $15 \mathrm{~km}$ and the maximum displacement was about $2.0 \mathrm{~m}$.

Several methods are employed to estimate the displacement which may occur, all utilizing past experience with historic fault breaks. One procedure is simply to assume that the length of fault break may be an appreciable portion of the total length of the fault, such as $50 \%$, and to estimate that the displacement will be similar to that on faults of a similar type with the same length of fault break (Fig. 34).

\section{Seismological studies and epicentral locations}

What is the importance of geophysical studies, as opposed to purely geological studies, in establishing the presence and nature of active faults in a dam site area? It is sometimes suggested, for example, that a dense network of seismographic stations might reveal the alignment of epicentres of small earthquakes, which may be too small to be 'felt', along a fault of unknown activity or one whose surface expression is concealed. Except in unusual circumstances, however, thorough geological studies will reveal an active fault more directly and far more cheaply than an extensive and time-consuming geophysical programme, particularly as faults that may be seismically active at depth but do not break the ground surface are not of concern. If future surface displacements are possible along a fault, there is almost always geological evidence of similar displacements in the recent geological past.

Another difficulty with geophysical investigations is that some very active faults are not marked by an abundance of small earthquakes, as is well demonstrated by certain segments of the San Andreas Fault that apparently are wholly devoid of minor seismicity between infrequent great earthquakes (Allen et al., 1965). However, if small measured earthquakes could be shown to line up well along the trace of a fault being studied, it would provide strong evidence of activity.

For these reasons the Authors have not employed seismographs for the purpose and do not consider them to be a primary tool for study of potential fault activity. Circumstances where they might be considered desirable would include some of the following.

(a) A situation where it is very difficult to understand the geology from conventional studies, such as areas of exceedingly heavy vegetation, water cover, or river valleys covered everywhere with flood deposits.

(b) A project where two to four years of observation time can be allowed in order to obtain the results.

(c) A project where it is desired to install seismographic stations anyway for the purpose of studying the possible increase in seismic activity caused by filling the reservoir, which is rapidly becoming standard practice for all very large reservoirs. 


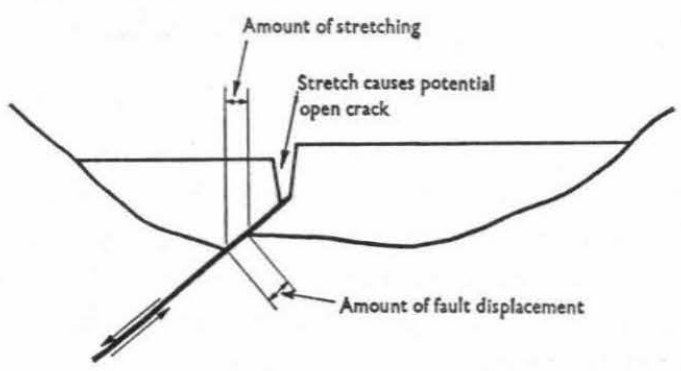

Fig. 42. Displacement of normal fault can stretch dam

In general studies of dam sites, frequently epicentres of instrumentally measured earthquakes are plotted on a map to show the general seismicity of the surrounding region. Often the epicentral locations are obtained from the records accumulated by a seismological laboratory or government agency. The locations of epicentres are computed from wave travel times and may be very rough estimates, especially when the instruments are located at considerable distances from the site. Hence, from the standpoint of fault activity studies, little reliance can usually be given to the fact that a typical epicentre map shows a general scatter of epicentres with no particular alignment along a fault. Also, unfortunately, there are many unreliable published assignments of earthquake magnitudes.

\section{ACTIVE FAULT CONSIDERATIONS IN DAM DESIGN}

\section{Fault activity evaluation}

After the geological studies are completed, the dam designer must finally decide whether he will assume that the fault may break under the dam or whether it will not. It is not possible to incorporate an intermediate decision, reflecting the geologist's uncertainty, into the design in any direct fashion. That is, if the geologist is only $50 \%$ confident that the fault is truly active, it does not make sense to design the dam for only $50 \%$ of the possible fault displacement. The decision must ultimately be one of 'go' or 'no go'.

The dam designer's decision is simple if the geologist is willing to make a flat statement of the activity or inactivity of the fault in question. However, a range of conditions may exist between these two extremes.

\section{Relative activity of faults}

In any given area, geologists can form opinions regarding the relative likelihood that various faults will break in the lifetime of a dam. The classification of relative activity has very great significance in preliminary planning and design studies to assist in the evaluation of alternate sites where the dam might be located, but such a relative classification may have little value in choosing the design details for a dam at a given site.

This conclusion is illustrated by a simplified example. Two alternative sites several kilometres apart are under consideration for a given dam, each site with a different fault through the foundation. At site A, convincing evidence exists that the fault has broken several times during the last 10000 years, and thus is clearly an active fault in the sense that futher movement is sufficiently likely to be considered in the dam design. At site B the fault is overlain by unbroken, young surface deposits (indicating that the fault has not ruptured during the past 10000 years), but there is abundant evidence of faulting prior to that time-within the past 
35000 years. This fault, too, probably must be considered active (by the AEC definition) but obviously not to the same degree as the fault at site A.

Other things being equal, site B is clearly preferable to site A; the likelihood of fault displacement during the life of a dam is far greater at site A, judging from its recent geological history. If, then, it is decided to build the dam at the safer site B, should the design be any different from that at site A, to take into account the lesser degree of activity of the fault? The answer is probably no, as both faults must be considered active, and therefore the dam must be designed to withstand the largest credible displacement at either locality, regardless of the greater likelihood of its occurrence at site A.

\section{Faults of uncertain activity}

After completion of his studies of a given fault, the geologist may conclude that there is insufficient evidence to make a firm judgement one way or the other regarding the activity of the fault. This may be either because insufficient exploration has been carried out or because no pertinent geological evidence was found to exist even after the most careful and exhaustive field investigation programme. For example, the geologist might find that mid-Pleistocene strata of 1000000 year age are broken by a fault, but that no datable younger formations are present to indicate whether the fault might have moved as recently as, say, 35000 years and therefore be an active fault by his definition. Thus the fault is of uncertain activity. Nevertheless, even if the geologist is unable to make a firm statement as to the activity of the fault, he is obliged to make some judgement, with an appropriate disclaimer as to his degree of confidence in that judgement. Assuming the absence of diagnostic local geological evidence, such as in the preceding example, 'suggestive' evidence bearing on the fault's activity is almost always available from studies of the regional geology and geomorphology, the regional earthquake history, and the instrumentally recorded seismicity. Even if the geologist can do no more than estimate that, in his best judgement, the probability is $50 \%$ that a fault has broken within say, the past 35000 years, this statement is far more meaningful to the dam designer than the simple (though honest) statement of 'I don't know.' The dam designer, in turn, must take into account the geologist's confidence in his conclusions, as well as exercising his own degree of conservatism, in reaching the final decision as to whether the dam should or should not be designed for a specified fault displacement.

In the Authors' opinion, major faults located in geological provinces where strong earthquakes have occurred (and thus are expected) should be viewed conservatively, by assuming for dam design purposes that they are potentially active unless convincing evidence exists to the contrary. This is believed to be the only reasonable and prudent assumption for critical structures such as dams, where literally thousands of lives may be at stake. Engineers have been surprised too often by unexpected engineering and geological phenomena associated with major earthquakes; if dam design is to err, clearly it should be on the side of conservatism.

\section{Faults in non-seismic regions}

In areas of the world commonly considered to be non-seismic, usually there have been few or no earthquakes in historic time, and there probably exists little evidence of fault displacements in recent geologic time. In these areas it is apparent that the likelihood of a fault displacement under a dam is very much smaller than in an area of known seismicity.

Nevertheless, the Authors believe that it is prudent and desirable to conduct reconnaissance studies to confirm the absence of active faults at and near any proposed site of a major dam in 
any part of the world. In the developing science of seismology it is being learned that there are fewer and fewer large areas of the world in which one can be wholly confident that strong natural earthquakes could not occur, and it is probable that some areas now considered seismically inactive are only areas with long quiescent periods between strong earthquakes. In many truly non-seismic areas evidence may be quickly found to demonstrate the absence of active faults, but certainly such evidence should be sought and documented. The larger the reservoir, the higher the dam, the less well known the regional geology, the greater is the need for such studies of possible fault activity even in such non-seismic areas.

A considerably lesser effort is justified in the study of possible fault activity than would be necessary for a similar site in a region of known strong earthquake activity. In the general case, the Authors would be satisfied to categorize a fault in such an area as being inactive if no suggestion of recent displacement were found from competent studies of good aerial photographs supplemented by field reconnaissance. This is in contrast to the situation in a known seismic area, where there should be a much greater tendency to consider a fault active until proved otherwise.

\section{Reservoir induced earthquakes}

Within the past few years, a number of instances have been cited in which the filling of large reservoirs has allegedly triggered earthquakes, even in some regions with little or no prior earthquake history. The Authors believe that there is now sufficient evidence to make it necessary to conclude that the reservoir filling may trigger strong earthquakes. This introduces a new dimension into seismic design considerations for major dams, particularly in areas normally considered free of earthquakes. Insofar as the subject of this Paper is concerned, several critical questions arise. If a dam for a major reservoir in a general area of earthquake activity is to be constructed across a regional fault of some length (e.g., $10-20 \mathrm{~km}$ ), should the dam be designed for possible fault displacement even if the fault is demonstrably inactive as defined in this Paper (e.g., a fault covered by unbroken Pleistocene deposits)? Also, is it credible that a major fault in a non-seismic area could become active solely because of the filling of a reservoir on or near it? These are difficult questions to answer, partly because of the limited geological evidence available from some of the localities where reservoir-induced earthquakes have been demonstrated.

It might be argued that the surface faulting under these circumstances is possible inasmuch as (a) the reservoir induced earthquakes have been as large as $M=6 \cdot 4$, which is large enough to be associated with appreciable fault displacement under normal circumstances; $(b)$ the induced earthquakes have been shallow; $(c)$ in several instances the induced earthquakes have been shown to have been on pre-existing faults; and $(d)$ focal mechanism studies at several localities have indicated convincingly that the earthquakes represented tectonic strain release rather than a direct mechanical effect of the weight of the water. Thus the argument might be made that the reservoir induced earthquakes are in every sense normal tectonic earthquakes, even those in previously quiescent areas, and that surface faulting is just as likely to be associated with these shocks as with any others in the same magnitude range. Nevertheless, none of the larger reservoir induced earthquakes reported to date are known to have been associated with surface fault displacements, although some effects at the Koyna Dam (India) have been debated. Also, the reservoir induced earthquakes have been relatively rare events, even in areas of high natural seismicity. The Authors cannot make a definite statement that surface faulting should or should not be considered credible under these circumstances but believe the possibility cannot be completely dismissed at the present state of knowledge. Clearly this is an area where 
further intensive geological and geophysical studies are necessary. The possibility remains that if competent studies were made of the main reservoir induced earthquakes in the areas previously believed to be non-seismic, evidence would be found that nearby faults are active, which the Authors would not find surprising.

\section{Embankment versus concrete dams}

Where demonstrably active faults cross the foundation, concrete dams should not be considered. This is the strong opinion of the Authors and is believed to be the general opinion in the industry. Embankment dams can be designed with confidence to withstand safely the deformations (and damaging results thereof) imposed by fault movement, whereas any design of a concrete dam on an active fault is questionable.

If a foundation fault displaces, the dam sections on opposite sides will be offset by the same general amount and direction as the fault displacement. For an embankment dam the main potential hazard is from a concentrated leak developing suddenly along the rupture surface formed in the dam. The hazard can be eliminated by the provision of adequate internal zoning to control the leakage safely. Depending on the dimensions and the conservatism of the protective zones, an embankment dam can be theoretically made safe against any conceivable fault displacement.

All types of concrete dams are rigid and brittle. With few exceptions they are founded on fairly sound rock and depend for security on the bond between the concrete and the rock foundation and/or abutments. Any foundation fault displacement with vertical component must either lift the dam off the foundation, breaking its bond with the rock, or cause a break in the concrete. For a concrete gravity dam, fault movement can break the contact between the dam and the foundation, allowing full uplift pressure to act underneath, reducing the shearing resistance along the dam base and causing failure by sliding on the foundation of the general type which resulted in the disaster at the St. Francis Dam in southern California in 1928. For a concrete arch dam an abrupt displacement of two parts of the dam of the order of $0.25-0.50 \mathrm{~m}$ in almost any direction could cause complete sudden failure by several mechanisms. The concrete could be crushed or one end of the dam lifted off its abutment, destroying the continuity of the arch.

The Authors believe that concrete dams should also generally be avoided in earthquake regions at sites with faults for which the studies of the activity are inconclusive. The main reason is simply that the possibility of fault movement exists, no matter that the likelihood may be extremely small. The greater the consequences of the failure, the greater the desirability of arbitrarily excluding the concrete dam in the preliminary design stage.

The arbitrary choice of an embankment dam has other potentially important advantages at such sites. Frequently vital additional information about the geology is obtained from exposures during foundation excavations. Conceivably additional evidence for fault activity may be obtained. For the embankment dam, modifications of the design during construction to increase the conservatism are a relatively simple matter. For the concrete dam, however, it might be necessary to abandon the work and start over again with an embankment dam design. Without even considering fault activity, many dams have been changed during construction from concrete to embankment because of conditions exposed in the excavations, but not vice versa.

Dam sites located within a few kilometres of important thrust faults on the upthrown side, and within a few kilometres of important normal faults on the downthrown side, are particularly suspect for concrete dams. Areas surrounding such sites can be expected to be dis- 
torted during earthquakes originating on the main faults, and it is impossible to be confident that small displacements could not occur on almost any existing rock shear zone or fracture, or even possibly new breaks.

\section{Magnitude and type of fault displacement}

The dam designer needs an estimate of maximum probable magnitude and direction of the fault break which might occur in order to proportion the internal protective zones. The estimate should be made by the geologist on the basis of his study, and judgement guided by historic experience with similar faults. Some general observations can be made concerning these estimates.

First, the direction of fault displacement relative to the longitudinal dam axis can be as important as the magnitude of the displacement. Particularly, inclined normal faults striking parallel with the river whose displacement would probably tend to cause portions of the dam on opposite sides to be pulled apart could result in a wider initial crack than other types of fault movement (Fig. 42).

Displacements on thrust faults (and on some strike-slip faults) result in compression on the shearing surface. However, displacement on a vertical strike-slip fault which strikes at a small angle with the dam axis (Fig. 43) could also conceivably elongate the dam and cause potentially larger cracks than similar magnitudes of fault displacements in other directions.

Estimates of fault displacement magnitudes should not be dependent on any evaluation of 'relative activity' of the faults.

\section{EMBANKMENT DAM DESIGN}

\section{Fundamental basis for confidence}

The examples of the Coyote, Cedar Springs and Palmdale Dams demonstrate that many engineers are confident that conservatively designed embankment dams can safely withstand displacement of foundation faults. The Authors agree with this general conclusion.

This confidence has two main bases. First, there is considerable experience to show (records of the many fault breaks all over the world during the last 200 years) that the magnitude of maximum displacements on faults is generally less than $5-7 \mathrm{~m}$, the average displacement along average fault breaks is $1 \mathrm{~m}$ or less and, in the extreme, displacements exceed $10 \mathrm{~m}$ only rarely and in exceptional world earthquakes on 'master' active faults. Also, while present ability to predict the maximum displacement which may occur on any given active fault has limitations, there is considerable knowledge of the subject and a reasonable estimate can be made. Second, we are confident that conservatively designed embankment dams will withstand without failure the worst conceivable damage imposed by foundation fault movements of these expected magnitudes, provided that there are materials available from which to construct thick, protective zones of cohesionless transition material.

\section{Cracks cannot exist in cohesionless materials}

Sands, gravels, sand-gravel mixtures and masses of hard rock fragments, when these materials are free of any appreciable admixtures of fine-grained soil (clays or silts), are cohesionless in the sense that each individual particle is not held to its neighbours. There is no cementation of any kind. Hence, a mass of these materials will not stand on an unsupported vertical face of any appreciable height and it is impossible for an open crack to exist in the mass. Any open 
crack which might tend to be formed momentarily by the fault displacement must immediately close by the action of the walls of the crack collapsing. Hence, internal zones of these materials act as 'crack stoppers' in dam embankments.

For any high embankment dam it is known from experience that cracks develop without earthquake or fault movement because of differential settlement (Sherard, 1973). Hence, cohesionless transition zones frequently are employed as crack stoppers in any event. The main difference in designing against fault displacement is that the zones may need to be made thicker.

For an open crack to exist in an embankment, it is necessary for the embankment material comprising the wall of the crack to have sufficient unconfined compressive strength to prevent the crack from closing. The mechanics are shown in a simplified fashion in Fig. 44. If we assume an open crack in the embankment with approximate depth $h$, the vertical stress $P_{\mathrm{v}}$ existing on the horizontal plane forming the top of the small shaded element $a$ must be approximately the weight of the column of overburden with height $h$ and density $\gamma$. As the crack is open and there is no horizontal stress on the side of element $a\left(P_{\mathrm{h}}=0\right)$. Hence, the crack can only remain open if the unconfined compressive strength $U$ of embankment element $a$ exceeds $P_{\mathrm{v}}$. Otherwise element $a$ will fail in compression and the crack must close. As shown in Fig. 41, the maximum depth to which a crack can be sustained open without collapsing is $h_{\max }=U / \gamma$. For cohesionless zones, $U=0$, and no crack can be sustained. For typical compacted fine-grained soils commonly employed for the impervious cores of earth dams, the unconfined compressive strength is generally in the range between 20 and $40 \mathrm{t} / \mathrm{m}^{2}$, and $\gamma$ is of the order of $2 \mathrm{t} / \mathrm{m}^{3}$. From these rough figures we can see that open cracks can be sustained in the cores of embankment dams to depths of the order of 10-20 m, below which the crack walls must collapse and close the crack, at least in the absence of internal fluid pressure in the crack. Hence, for high dams it is difficult to imagine that large open leakage channels could exist in the core at depths below the crest exceeding about $30 \mathrm{~m}$.

It should be acknowledged that sand and gravel deposits in nature sometimes become partially cemented and in this form are observed to stand on fairly high vertical cliffs in river banks, and man-made excavations. The question has sometimes been raised as to whether cohesionless zones in dams might become cemented in some way over long periods of time. Cementation in natural sand and gravel deposits generally results from either a sufficient quantity of clayey fines to bind the mass together or cementation by chemical deposits from groundwater flow. In the extreme, the cemented deposits are partially transformed to soft formations (sandstones, conglomerates, etc.). For most clean, natural sands and gravels and crushed hard rocks, there is no reason to suspect that they will recement themselves when compacted in an embankment. The individual fragments are hard and inert and in time spans such as 100 to 200 years, under the pressures existing in a dam embankment, no changes in the material properties occur. This is true for the normal alluvial sands and gravels which are the hardest and most durable portions of their parent rocks, after being worked by nature for thousands of years. For some badly weathered and very old alluvial terrace deposits, and some quarried soft rocks, recementation might occur in an embankment, and these materials are avoided for use in the cohesionless transition zones of dams.

\section{Large leaks can be safely controlled}

With the cohesionless transition zones acting as crack stoppers, even if a large open crack develops in the impervious core the maximum leakage will be limited by the permeability of the transition material to a volume which can be controlled safely. The leakage is controlled 


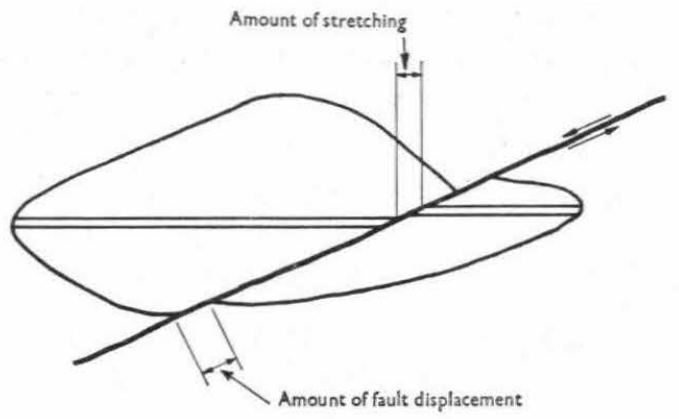

Fig. 43. Displacement of strike-slip fault can stretch dam

by providing a zone of considerably coarser and more pervious material (usually quarried rock fill or screened large cobbles) downstream from the downstream transition zone, so that the leakage must pass from the transition zone into the rockfill zone, and exit from the dam through the rockfill zone.

Since the permeability of the transition zone will always be at least an order of magnitude (and usually several orders of magnitude) less than that of the rockfill zone, the amount of leakage water will always fall well below the quantity which would tax the hydraulic capacity of the rockfill zone. Also, the relative gradation of the transition zone and the rockfill zones are made such that the individual particles of transition zone materials cannot penetrate the voids of the rockfill zone. Using these design principles, the maximum possible leakage quantity will emerge safely under complete control through the toe of the downstream rockfill zone.

There is no doubt concerning these conclusions. In addition to the theoretical considerations as outlined in general terms in the foregoing, there are many experiences in the industry in which large leaks have developed through dams with downstream rockfill zones with no danger or threat of failure. Many such examples could be described which make it completely sure that as long as the flow entering the downstream rockfill zone is controlled (choked) by the permeability of the finer transition material upstream, the flowing water entering the rockfill zone cannot cause threat of instability.

The 1964 failure of the Hell Hole Dam (California) is frequently quoted as an example of failure of a rockfill (Leps, 1973). The Hell Hole Dam failed during construction in a storm when the reservoir rose behind the partially completed dam. The water flowed through the main rockfill embankment section without control by an upstream transition zone which had not been constructed at the time of failure. If the upstream transition had been in place it is clear that no failure could have occurred.

\section{Simplified illustrative example of fundamentally safe dam}

The dam which has fundamental, unquestionable safety against abrupt rupturing caused by foundation fault displacement has two main elements. First, the cohesionless transition zone and second, the coarser rockfill zone downstream. Fig. 45 shows a simplified illustrative example of an embankment dam which consists only of these two elements, with an upstream zone of alluvial sand and gravel and a downstream zone of rockfill, with no impervious core. The leakage through such a dam would be fairly high relative to other dams, but it would be a completely safe dam. 
As an example let us consider that the upstream zone comprises coarse, well-graded sandgravel mixture, which is frequently found in river deposits (and from which many major dams have been constructed). Depending on the gradation the coefficient of permeability of embankment zones constructed of such material is generally in the range between $10^{-4}$ and $10^{-2}$ $\mathrm{cm} / \mathrm{s}$. With general proportions as shown in Fig. 45, the average hydraulic gradient through the upstream zone is of the order of $1 \cdot 0$. For a dam height of $100 \mathrm{~m}$, the quantity of seepage through the upstream sand-gravel zone would be as follows:

$$
\begin{aligned}
& \text { assume } k=10^{-2} \mathrm{~cm} / \mathrm{s}=10^{-4} \mathrm{~m} / \mathrm{s} \\
& Q=k i a=\left(10^{-4}\right)(1 \cdot 0)(100) \\
& =10^{-2} \mathrm{~m}^{3} / \mathrm{s} / \mathrm{m} \\
& Q=10 \text { litres } / \mathrm{s} / \mathrm{m} \text { of dam length }
\end{aligned}
$$

It is apparent that such leakage quantities can easily be accommodated safely in a large downstream rockfill zone.

If the dam were ruptured by foundation fault displacement, a portion of the upstream alluvial material would be displaced and sheared and possibly loosened (made less dense) increasing the permeability locally and the quantity of leakage. However, the massive hydraulic capacity of the downstream rockfill zone is so overwhelming that no hazard would result.

The fact that large quantities of water can flow safely through rockfill zones is demonstrated by many recent experiences, and by laboratory and mathematical studies. Leps (1973) presented an excellent review and analysis of several experiences in which large flows have passed through rockfill embankments, including examples of hundreds of cubic metres per second. Dams have even been built in which small spillway floods are discharged directly into the downstream rockfill zones (Wilkins, 1963; Olivier, 1967; Curtis and Lawson, 1967). Also there have been several cases where floods backed up water behind rockfill dams during construction, before the impervious element was constructed, causing very large flows to pass through the rockfill without damage. ${ }^{1}$

\section{Design principles}

At any site where a fault may displace in the foundation of a dam, it must also be anticipated that strong earthquakes may occur and the dam must be designed to resist the strong shaking motion. Since one of the main ways in which an embankment dam may be threatened by earthquake shaking is a general slumping and spreading of the embankment with associated possible cracks through the core, some of the main design measures employed to increase the security of an embankment dam against earthquake shaking also increases the safety against fault offsets. For this reason a dam which is conservatively designed against strong earthquake shaking would probably also safely withstand moderate movements of foundation faults. Opinions concerning main aspects of earthquake design have been given elsewhere (Sherard, 1967). Only a few of the main points are re-emphasized here briefly.

It is not uncommon in areas of strong earthquakes that small faults are found for the first time when the dam is under construction, during excavation for the foundation. Although they may be obviously minor features, their unexpected discovery and the need for evaluating their potential activity can cause problems and delays. For this reason, at any site for an important dam or reservoir in a general earthquake region, consideration should be given to

\footnotetext{
${ }^{1}$ One of many examples: Dix River Dam, 85 metres high, concrete faced, rockfill dam in Kentucky. Major flood during construction (1925) before concrete facing constructed. Water reached about $18 \mathrm{~m}$ depth in reservoir, flowed through dam for six days with estimated maximum flow of $85 \mathrm{~m}^{3} / \mathrm{s}$ without damage.
} 


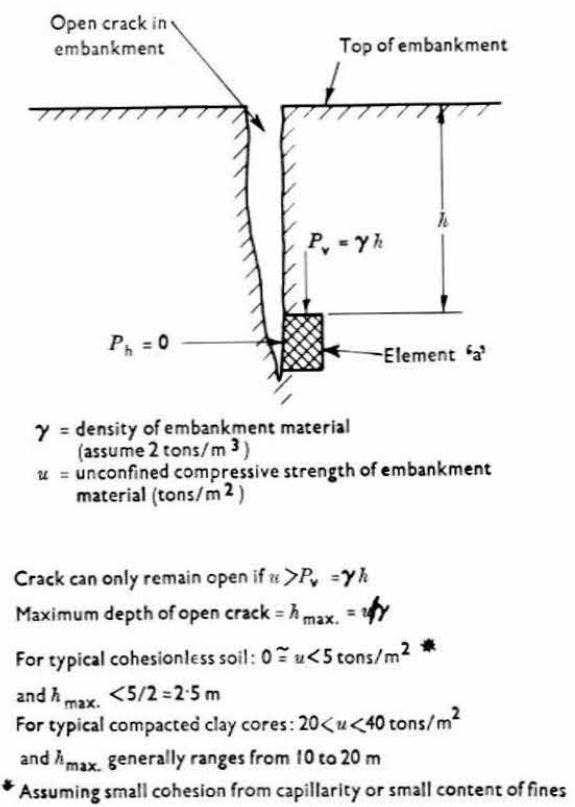

Fig. 44. Theoretical maximum depths of open cracks in embankments

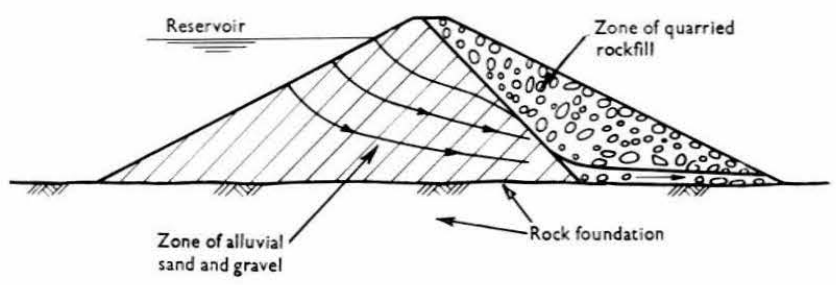

Fig. 45. Simplified illustrative example showing the two main elements of an embankment dam providing fundamental safety against foundation fault displacement

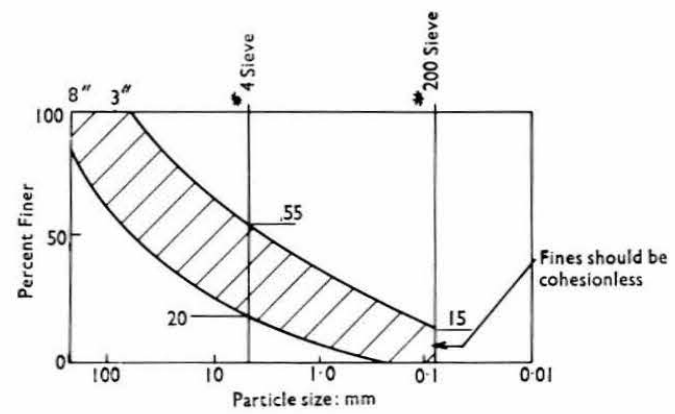

Fig. 46. Range of gradation of well-graded, coarse sand-gravel mixtures considered to be especially suitable without processing for thick transition zones 


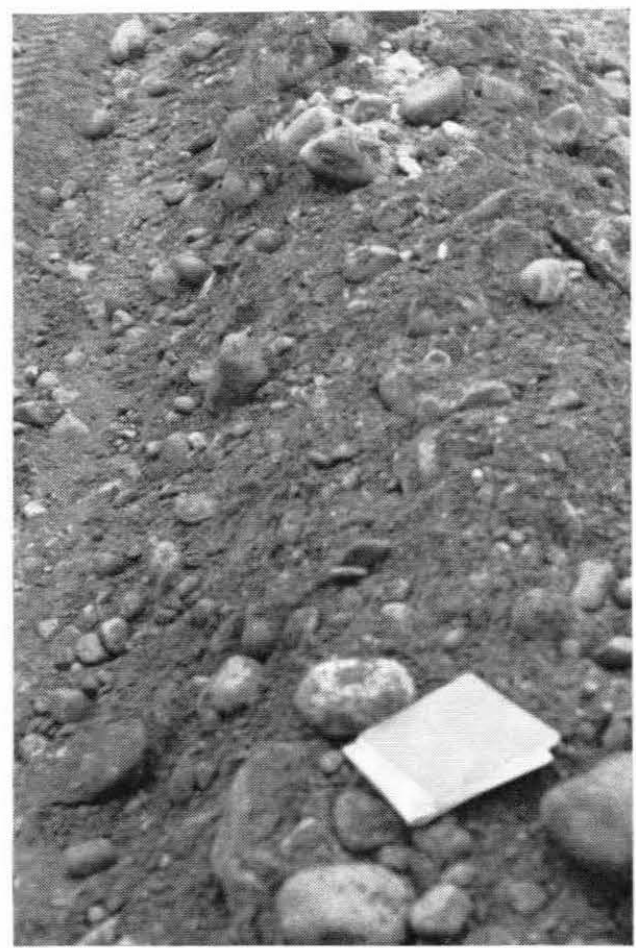

Fig. 47. Typical natural alluvial sand-gravel mixture meeting the gradation of Fig. 46. Thick zones of material of this general nature, used without processing, constitute good, self-healing and internally stable transitions 
providing a design which would be safe under a small displacement on any previously unforeseen minor fault which may be exposed during construction.

The selection of the main design details governing the fundamental safety of the dam (such as the width of the top of the dam, the thickness of the cohesionless transition zones, etc.) must be made finally arbitrarily guided by the estimate of the probable magnitude of fault displacement. While it is impossible to give quantitative guidelines, it is clear that the degree of conservatism which is arbitrarily provided in the design of these vital details should be made larger for those dams located above populated areas, and for dams with especially large reservoirs.

The top of the dam is particularly vulnerable because it is the thinnest part and has less internal pressure tending to close cracks. For any given dam design, efforts to increase the fundamental safety should consider particularly the details of the top of the dam, which especially needs good zoning and conservative width and freeboard.

The risk involved from fault offset is dependent on the erosion resistance of the foundation. For foundations other than hard rock, and particularly foundations which do not have high resistance to erosion, special design details should be employed to make the water travel a long distance through the foundation. In the extreme case, if the foundation materials are highly erodible and the potential consequences of failure are great, very conservative design details are justified.

Cohesionless transitions must always be used. Satisfactory designs range from central core dams with transitions on both sides of the core to homogeneous dams with internal 'chimneys' consisting of bands of cohesionless transitions and drainage material. The thicker the transition zones, the greater the security against a given fault displacement. The cohesionless transition zones are generally manufactured by washing, screening and blending, to provide materials with uniform and reliable properties.

At sites where cohesionless natural sands and gravels are in large supply they can be used for the transitions without processing by making the widths of the zones larger to compensate for some lack of uniformity in the properties. Natural well-graded, sand-gravel mixtures, having grain size distributions generally as shown in Fig. 46, are particularly good materials for transition zones (Fig. 47). The fine portion should be cohesionless. In common with other cohesionless transition materials, this material will act as a crack stopper. It also has the advantage that, while it is relatively pervious compared to the dam core, its fundamental permeability is not high. Another desirable attribute is the fact that it is inherently stable against internal piping, being in itself a natural filter. Also, this material is generally coarse enough so that there is no danger that any appreciable quantity of the material could be washed into the voids of adjacent rockfill zones.

Sand-gravel river deposits, with gradation in the range of Fig. 46, are one of the most common materials available for building earth dams in many parts of the world. In these areas this sand and gravel may be the most economical material available and almost the whole dam may be built of it, in which case the most economical type dam is often the fundamentally safe dam. At some sites transition materials with the desirable gradation range can be obtained economically by processing (screening and blending) alluvial soils. Suitable material of such gradation can also be made by crushing or screening quarried rock. Usually hard rock crushed to a maximum size of 3 in. or 6 in. will have suitable gradation.

The properties of the impervious core material can be considered of lesser importance. A fundamentally safe dam can be made using a core material of any type. It is preferable to spend extra money improving the transition zones rather than for bringing in impervious core material of supposedly superior characteristics from long-haul distances. Other things being equal, preference should be given to cohesionless core materials over clayey materials, at least 
in the upper part of the dam. Impervious materials with fines of dispersive clay should be avoided (Sherard et al., 1972).

\section{Central earth core rockfill dams}

The rockfill dam with central earth core and thick cohesionless soil transitions upstream and downstream, as exemplified by the design of the Cedar Springs Dam (Fig. 14), is a fundamentally safe structure. The basic type of dam is also frequently the most economical type which can be constructed at a given site, at least for high dams.

The use of the second sand transition zones at Cedar Springs Dam both upstream and downstream of the core (zone 2), certainly increases the fundamental safety. If a large leak developed through a crack in the clay core at the top of the dam, some of the sand from the upstream zone 2 would undoubtedly be washed into the crack, tending to seal it. Also, assuming that the sand comprising the zone 2 layer downstream of the core could not sustain a crack, the volume of leakage passing through the top of the dam would be limited by the permeability of this sand layer to a lower value than otherwise.

The symmetrical design, with transitions both upstream and downstream from the core, as shown in Fig. 14, has a potential advantage from the standpoint of making rapid and simple repairs if the dam were damaged by fault displacement. Because of the existence of the upstream and downstream transitions it would be possible to seal open fissures and cavities in the dam core by grouting the cracks. Cement and soil-cement grouts will not enter the transition zones. Hence, grout pumped into the core of the dam will remain in the core and fill the openings. This has been done successfully on a number of recent central-core dams where cracks and erosion channels have developed, caused by differential settlement. Examples are the recent experiences at the Yards Creek Upper Reservoir Dam in New Jersey and the Hyttejuvet Dam in Norway (Sherard, 1973).

\section{ACKNOWLEDGEMENTS}

A number of colleagues, both from the geology and engineering sides, reviewed the Paper in an earlier draft and provided suggestions for improvement. The Authors are grateful for this generous assistance and wish they could do more than simply acknowledge the reviewers, many of whom deserve far greater credit for their contributions to the Paper. Particular thanks are due to N. N. Ambraseys, Imperial College of Science and Technology, London; M. G. Bonilla, United States Geological Survey, Menlo Park, California; G. Post and P. Londe, Coyne and Bellier, Consulting Engineers, Paris; C. J. Cortright and E. W. Stroppini, California Department of Water Resources, Sacramento; O. Papageorgiou, Public Power Corporation, Athens; J. M. Wool, Los Angeles Department of Water and Power, California; J. M. Kellberg, Tennessee Valley Authority, Knoxville; G. E. Brogan, G. E. Hervert, M. K. Korringa, B. B. Gordon and D. Tocher, Woodward-Lundgren and Associates, Oakland, California.

\section{REFERENCES}

Albee, A. L. \& Smith, J. L. (1966). Earthquake characteristics and fault activity in southern California. Engineering Geology in Southern California, Association of Engineering Geologists Special Publication, October 1962.

Allen, C. R. (1957). The San Andreas Fault. Engineering and Science Monthly, California Institute of Technology, May. 
Allen, C. R., St. Amand, P., Richter, C. F. \& Nordquist, J. M. (1965). Relationship between seismicity and geologic structure in the southern California region. Bulletin, Seismological Society of America 55, 753.

Allen C. R. \& Smith, S. W. (1966). Pre-earthquake and post-earthquake surficial displacements. Bulletin, Seismological Society of America, 56, 961.

Allen, C. R., Wyss, M., Brune, J. N., Grantz, A. \& Wallace, R. E. (1972). Displacements on the Imperial Superstition Hills, and San Andreas Faults triggered by the Borrego Mountains Earthquake. US Geological Survey Prof., Paper 787, 87.

Ambraseys, N. N. (1969). Maximum intensity of ground movements caused by faulting. Proceedings, Fourth World Conference on Earthquake Engineering, Chile, 1, 154.

Ambraseys, N. N. (1970). Some characteristics of the Anatolian fault zone. Tectonophysics 9, 143.

Ambraseys, N. N. (1971). Value of historic records of earthquakes. Nature 232, Aug. 6, 375.

Bonilla, M. G. (1967). Historic surface faulting in continental United States and adjacent parts of Mexico. US Atomic Energy Commission Report TID-24124 (available from the clearing house for federal scientific and technical information, National Bureau of Standards, Springfield, Virginia, 22151).

Bonilla, M. G. (1970). Surface faulting and related effects. Chap. 3 in Earthquake Engineering (R. L. Wiegel, Editor). Prentice-Hall, Inc., Englewood Cliffs, New Jersey.

Bonilla, M. G. \& Buchanan, J. M. (1970). Interim report on worldwide historic surface faulting. US Geological Survey open file report.

Brown, R. D. \& Vedder, J. G. (1967). Surface tectonic fractures along the San Andreas Fault. US Geological Survey Prof. Paper 579, 2-23.

Brune, J. N. \& Allen, C. R. (1967). A low-stress-drop, low-magnitude earthquake with surface faulting. The Imperial, California, Earthquake of March 4, 1966. Seismological Society of America Bulletin 57, 501-514.

California Department of Water Resources (1964). Investigation of Baldwin Hills Reservoir. Report of Engineering Board of Inquiry.

Carlifornia Department of Water Resources (1968). Cedar Springs Dam specifications and bid documents, No. 68-30.

Casagrande, A., Wilson, S. D. \& Schwantes, E. D. (1972). The Baldwin Hills Reservoir failure in retrospect. Proceedings of the Specialty Conference on the Performance of Earth and Earth Supported Structures, ASCE 1, Part 1, 551.

Clark, M. M., Grantz, A. \& Rubin, M. (1972). Holocene activity of the Coyote Creek Fault as recorded in sediments of Lake Cahuilla. Geological Survey Professional Paper 787 U.S. Dept. of Interior, p. 112.

Castle, R. O. \& Youd, T. L. (1972). Baldwin Hills Reservoir failure. Proceedings, Specialty Conference on Performance of Earth and Earth-Supported Structures, ASCE 3, 91.

Cluff, L. S. \& Plafker, G. (1966). Implications derived from a study of thrust faulting associated with the March 27, 1964, Alaskan earthquake on Montague Island (abstract). Association of Engineering Geologists National Meeting, October, 1966.

Cluff, L. S. \& Slemmons, D. B. (1972). Wasatch Fault Zone-features defined by low-sun-angle photography. Utah Geological Society Publication 1, 6-1.

Cluff, L. S. \& Steinbrugge, K. V. (1966). Hayward Fault slippage in the Irvington-Niles districts of Fremont, California. Bull. Seismol. Soc. Am. 56, No. 2, 257.

Cortright, C. J. (1970). Re-evaluation and reconstruction of California dams. Jnl Power Div. ASCE, Jan., 55.

Curtis, R. P. \& Lawson, J. D. (1967). Flow over and through rockfill banks. Jnl Hydraulics Div., ASCE, September, 1.

Florensov, N. A. \& Solonenko, V. P. (1963). The Gobi-Altai earthquake. Akademiir Nauk. SSSR, 424 p.

Hadley, J. B. (1964). Landslides and related phenomena accompanying the Hebgen Lake earthquake of August 7, 1959. US Geological Survey, Paper 435, 107.

Jansen, R. B. et al. (1967). Earth movement at Baldwin Hills Reservoir. Jnl Soil Mech. Fdns Div., ASCE, 551.

Lawson, A. C. (1908). The California earthquake of April 18, 1906. Report of the state earthquake investigation commission. Carnegie Institute, Washington Pub. 87.

Leps, T. M. (1972). Analysis of failure of Baldwin Hills Reservoir. Proceedings of the specialty conference on the performance of earth and earth-supported structures, ASCE 1, Part 1, p. 507.

Leps, T. M. (1973). Flow through rockfill. Chapter on embankment dam engineering, 87. R. C. Hirschfeld \& S. J. Poulos, Editors. New York: John Wiley and Sons.

Louderback, G. D. (1950). Faults and engineering geology. Geological Society of America. Berkley, 125.

Louderback, G. D. (1937). Characteristics of active faults in the central coast ranges of California with applications to the safety of dams. Bull. Seismol. Soc. Am., Jan., 1.

Morante, E. M. \& Allen, C. R. (1973). Displacement on the Philippine Fault during the Ragay Gulf earthquake of 17 March 1973. (Abstract) Geological Society of American Abstracts with Programs 5, 744. 
Myers, W. B. \& Hamilton, W. (1964). Deformation accompanying the Lake Hebgen earthquake. US Geological Survey, Paper 435, 55.

Nason, R. D. (1972). Creep in Anatolia. Geotimes 17, No. 9, 30.

Oldham, R. D. (1899). Report on the great earthquake of 12 June 1897. Geological Survey India Mem. 29.

Olivier, H. (1967). Through and overflow rockfill dams-new design techniques. Proc. Inst. Civ. Engrs, paper 7012 .

Press, F., Ben-Menahem, A. \& Toksoz, M. N. (1961). Experimental determination of earthquake fault and rupture velocity. Jnl Geophysics Research 66, 3471-3485.

Reitz, R. (1971). Horizontal and vertical displacement of Pacoima Dam. Los Angeles County flood control district, Survey Division, November.

Richter, C. F. (1958). Elementary seismology. W. F. Freeman and Company, San Francisco and London.

Sewell, J. S. (1907). The effects of the earthquake and fire on buildings and engineering structures. Bulletin, US Geological Survey, No. 324.

Sherard, J. L. (1959). A report on the damage to Hebgen Dam in the West Yellowstone earthquake. Engineering News Record, 17 August.

Sherard, J. L. (1967). Earthquake considerations in earth dam design. Jnl Soil Mech. Fdns Engng Div., ASCE, 377.

Sherard, J. L. (1973). Embankment dam cracking. Chapter on embankment dam engineering 271., R. C. Hirschfeld \& S. J. Poulos, Editors. New York: John Wiley and Sons.

Sherard, J. L., Woodward, R. J., Gizienski, S. F. \& Clevenger, W. A. (1963). Earth and earth-rock dams. New York: John Wiley and Sons.

Sherard, J. L., Decker, R. S. \& Ryker, N. L. (1972). Piping of earth dams of dispersive clay. Proceedings, Specialty Conference on the Performance of Earth and Earth-supported Structures, ASCE 1, 589.

Slemmons, D. B. (1969). New methods of studying regional seismicity and surface faulting. Transactions, American Geophysical Union 50, 397.

Slemmons, D. B., Steinbrugge, K. V., Tocher, D., Oakeshott, G. B. \& Gianella, V. P. (1959). Wonder, Nevada, earthquake of 1903. Bull. Seismol. Soc. Am. 49, 251.

Smith, S. W. \& Wyss, M. (1968). Displacement on the San Andreas Fault subsequent to the 1966 Parkfield earthquake. Bull. Seismol. Soc. Am. 58, 1955-1973.

Stroppini, E. W., Babbitt, D. H. \& Struckmeyer, H. E. (1972). Foundation treatment for embankment dams on rock. Jnl, Soil Mech. Fdns Div., ASCE, 1073.

Steinbrugge, K. V. \& Zacher, E. G. (1960). Creep on the San Andreas Fault-fault creep and property damage. Bull. Seismol. Soc. Am. 50, 389-396.

Tarr, R. S. \& Martin, L. (1912). The earthquake at Yakutat Bay, Alaska, in September, 1899, with a preface by G. K. Gilbert. US Geological Survey Prof. Paper 69.

Talley, H. C., Jr. \& Cloud, W. K. (1962). United States earthquakes, 1960. Washington: US Coast and Geodetic Survey.

Terzaghi, K. \& Lacroix, Y. (1964). Mission Dam, an earth and rockfill dam on a highly compressible foundation. Géotechnique 14, No. 1, 14.

Thevenin, J. (1955). The effects of the September 9, 1954 earthquake on the hydraulic works in the Orleansville area. Terres et Eaux, No. 24 (in French).

Tibbetts, F. H. (1936). Earthquake proof earth dams. Engineering News-Record, July 2.

US Atomic Energy Commission (1973). Seismic and geologic siting criteria for nuclear power plants. US Federal Register 38, No. 218, 23 Nov.

USCOLD (1967). General Paper No. 7, Ninth Congress on Large Dams, Istanbul IV, 760.

USCOLD (1970). General Paper No. 7, Tenth Congress on Large Dams, Montréal IV, 807.

USCOLD (1971). Terzaghi Dam. Newsletter of the US Committee on Large Dams, January, 14.

USCOLD (1973). General Paper No. 1, Eleventh Congress on Large Dams, Madrid V, 366.

Wilkins, J. K. (1963). The stability of overtopped rockfill dams. Proceedings, Fourth Australia-New Zealand Conference on Soil Mech. and Fdn Engng, 141.

Witkind, I. J. et al. (1962). Geologic features of the earthquake at Hebgen Lake, Montana. Bull. Seismol. Soc. Am. 52, 163.

Yerkes, R. F., Youd, T. L. \& Alt, J. N. (1973). Deformation of the Van Norman Reservoir area, northern San Fernando Valley, California. Fifth World Congress on Earthquake Engineering, Rome, Paper No. 299. 